\title{
Assessing the Acute Effects of CDP-Choline on Sensory Gating and Cognitive
}

\section{Deficits in Chronic Schizophrenia}

by

Robert Aidelbaum

A thesis submitted to the Faculty of Graduate Studies and Postdoctoral Affairs in partial fulfillment of the requirements for the degree of

Master of Arts

In

Psychology

\author{
Carleton University \\ Ottawa, Canada
}

(C)2015

Robert Aidelbaum 


\begin{abstract}
Deficient sensory gating (SG) and cognition in schizophrenia are associated with functional outcome and offer therapeutic targets as they are linked to the altered function/expression of the $\alpha 7$ nicotinic acetylcholine receptors (nAChR). This study analyzed the effects of CDP-Choline, an $\alpha 7 \mathrm{nAChR}$ agonist, on SG and cognition in a sample of chronic schizophrenia patients. Using a randomized, placebo controlled, double-blind design the dose dependent (500 mg, $1000 \mathrm{mg}, 2000 \mathrm{mg}$ ) and baseline SG dependent (deficient vs. normal suppressors) effects of CDP-Choline were analyzed using the P50 index of SG and a computerized cognition test battery. CDP-Choline improved SG (500 mg) in the deficient suppressor subgroup by increasing suppression of the S2 P50 amplitude. No positive effects of CDP-Choline on cognition were observed. These findings tentatively support $\alpha 7 \mathrm{nAChR}$ dysfunction in the expression of SG deficits and support further trials with CDP-choline to asses the effects of sustained $\alpha 7$ nAChR activation.
\end{abstract}




\section{Acknowledgements}

I would like to sincerely thank a few people who each contributed tot the completion of this thesis. I would like to extend my thanks to my primary supervisor Dr. Verner Knott for his guidance, assistance, and patience. Thank you for offering me the opportunity to work with you and the experiences that came with it. I would also like to thank Dr. John Logan for his support and advice along the way. Thank you to all of the patients who took the time to complete the sometimes tedious test sessions. Thank you to Etelle Bourassa for all of her kind words, encouragement, and advice. Thank you to my friends and brothers for offering me motivation and distractions exactly when I needed them. Thank you to Shannon for always being there for me, offering kind words of encouragement, making me laugh, and offering her editing expertise. Finally, thank you to my family and most importantly my mom and dad for always being there for me and helping me achieve this. 


\section{Table of Contents}

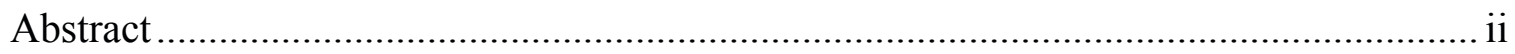

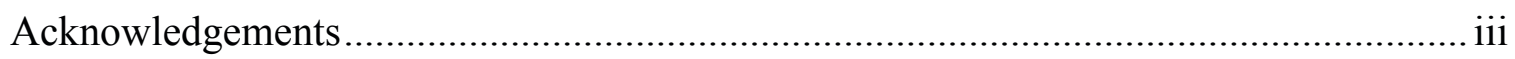

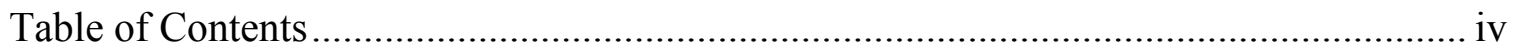

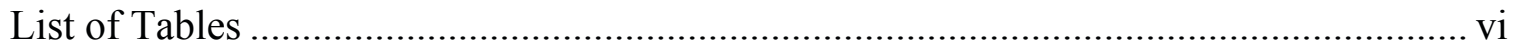

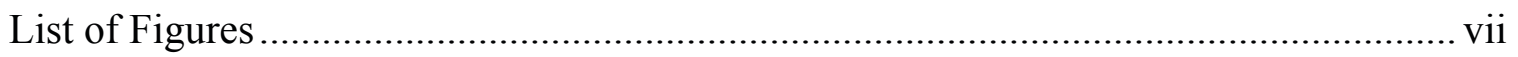

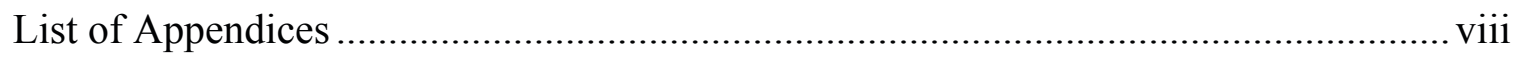

List of Abbreviations ....................................................................................... ix

Assessing the Acute Effects of CDP-Choline on Sensory Gating and Cognition in

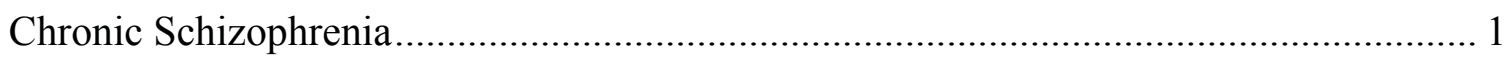

Schizophrenia: Cognitive Deficits as a Core Clinical Feature..................................... 1

Schizophrenia Endophenotypes: Sensory Gating Deficits and ERP Biomarkers.......... 3

Efficacy of Antipsychotics in Treating Sensory Gating and Cognitive Deficits .......... 10

Novel Therapeutic Targets: The Nicotinic Acetylcholine Receptor System............... 17

The Schizophrenic Brain: $\alpha 7$ nAChR Dysfunction and Sensory Gating Deficits ........ 20

Novel Cholinergic Agents: Recent drug development efforts ................................. 26

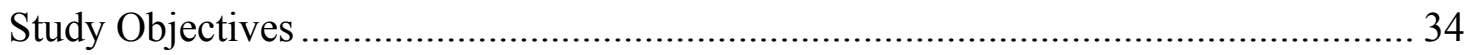

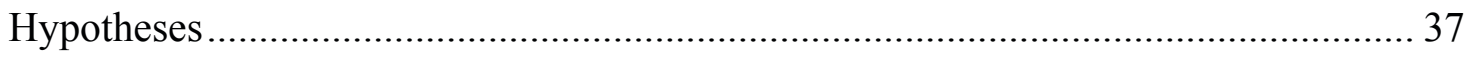

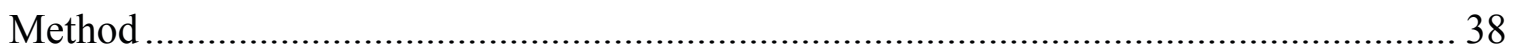

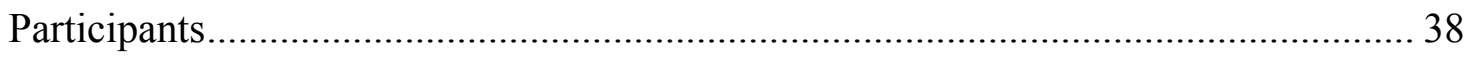

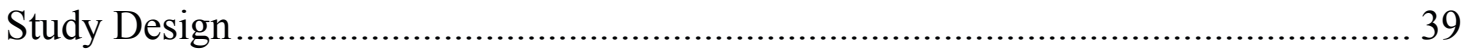

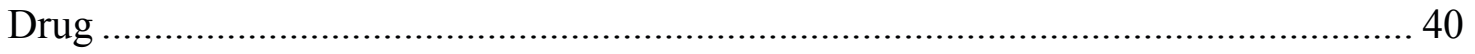

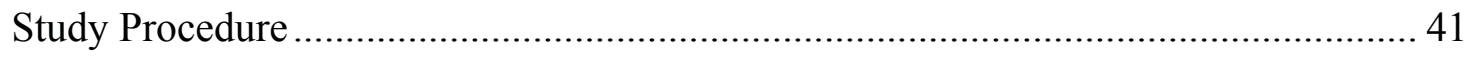

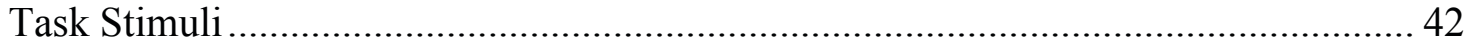

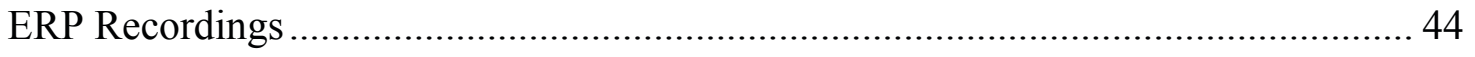

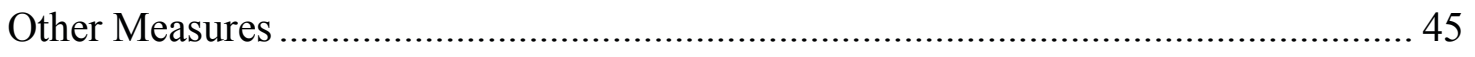

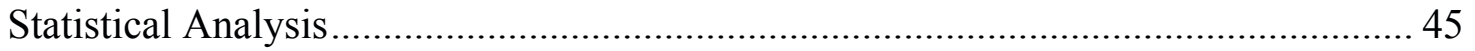

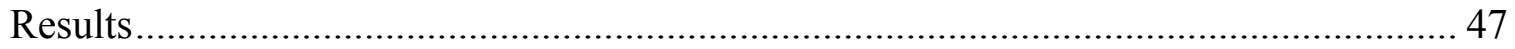




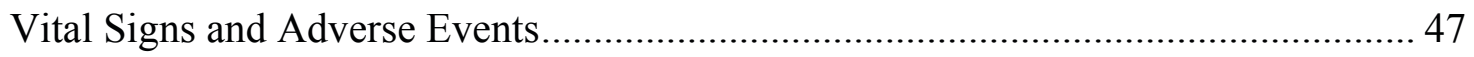

Demographic and Psychometric Measures .............................................................. 48

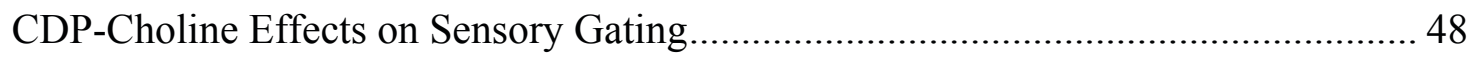

CDP-Choline Effects on Cognition ................................................................ 56

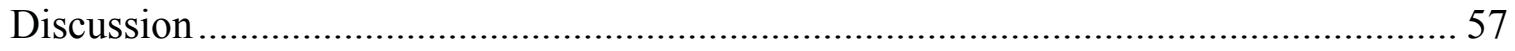

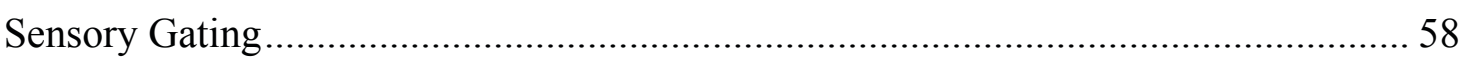

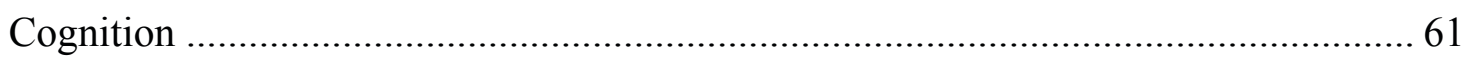

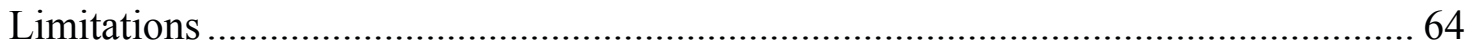

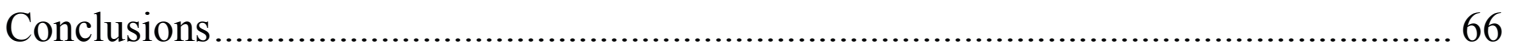

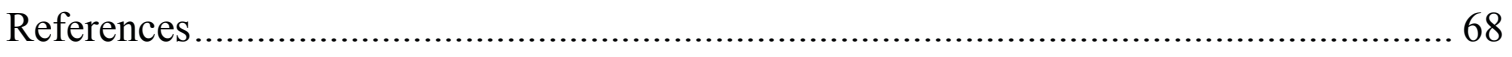

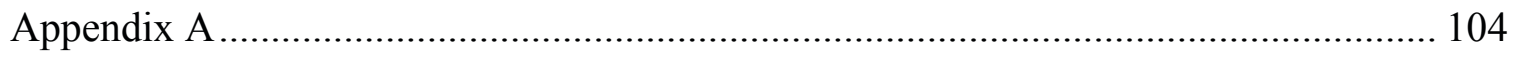

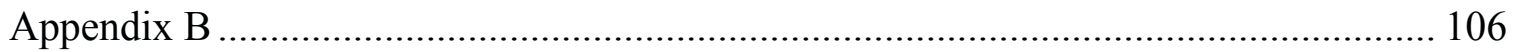

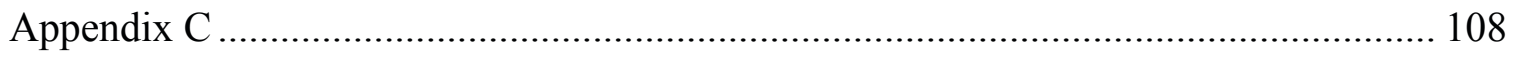

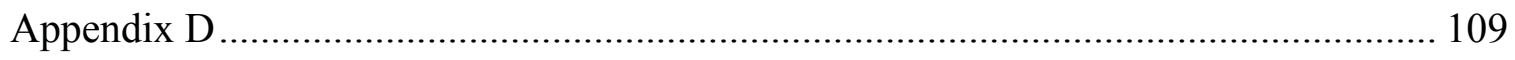

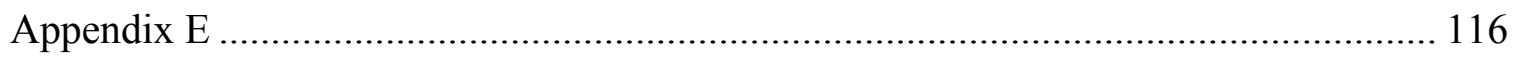

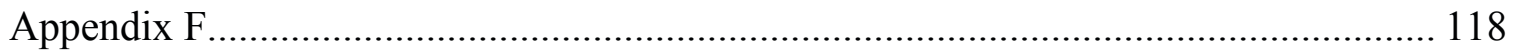




\section{List of Tables}

Table 1. Mean $( \pm S E)$ Demographic and Psychometric Scores for Whole................48

Table 2. Mean $( \pm S E)$ Suppression Measures and Stimulus Measures at................50

Table 3. Mean $( \pm S E)$ CogState Test Scores at Each CDP-Choline Dose.................57 


\section{List of Figures}

Figure 1. Normal and deficient P50 amplitudes in response to S1 and S2 ..............8

Figure 2. Grand average waveforms representing P50 responses to $\mathrm{S} 1 \ldots \ldots \ldots \ldots \ldots . . \ldots 49$

Figure 3. Mean $( \pm S E)$ P50 ratio (S2/S1) and difference (S1-S2) scores..............52

Figure 4. A) Grand average waveform representing the P50 amplitude difference.......54

Figure 5. Mean $( \pm S E)$ stimulus amplitude $(\mathrm{S} 1$ and $\mathrm{S} 2)$ scores recorded at the..........55 


\section{List of Appendices}

Appendix A. Positive and Negative Symptom Scale................................. 104

Appendix B. Structural Clinical Interview for DSM-IV-TR $\ldots \ldots \ldots \ldots \ldots \ldots \ldots \ldots \ldots \ldots \ldots$

Appendix C. Inclusion \& Exclusion Form ..................................... 108

Appendix D. Consent Form ..................................................... 109

Appendix E. Psychotic Symptoms Rating Scale............................... 116

Appendix F. Adverse Event Questionnaire ..................................... 118 


\section{List of Abbreviations}

Abbreviation

ANOVA

CDP-Choline

CSB

dP50

DSM-5

ERP

GABA

GAF

nAChRs

PANSS

PSYRATS

rP50

S1

S2

SCID-CV

SZ

\section{Explanation}

Analysis of Variance

5"-Cytidine Diphosphocholine

Cogstate Test Battery

P50 Difference Scores

Diagnostic and Statistical Manual

Event Related Potential

$\gamma$-Aminobutyric Acid

General Assessment of Function

Nicotinic Acetylcholine Receptors

Positive and Negative Symptom Scale

Psychotic Rating Scale

Ratio P50 Scores

First Stimuli in Paired Click Paradigm

Second Stimuli in Paired Click Paradigm

Structured Clinical Interview for DSM-IV

Schizophrenia 
Running Head: CHOLINE AND SENSORY GATING DEFICITS IN SCHIZOPHRENIA

\section{Assessing the Acute Effects of CDP-Choline on Sensory Gating and Cognition in Chronic Schizophrenia}

\section{Schizophrenia: Cognitive Deficits as a Core Clinical Feature}

Schizophrenia (SZ) is a chronic brain disorder affecting approximately 21 million people worldwide (WHO, 2015). It is characterized by a number of symptoms appearing heterogeneously. Primarily, SZ has come to be associated with positive symptoms and negative symptoms (Keefe \& Fenton, 2007). Positive symptoms encompass disturbances of cognitive, sensory, or motor processes that are not commonly observed in healthy individuals. This would include many of the trademark symptoms associated with the disorder, namely hallucinations, delusions, and disorganized thought and speech. Negative symptoms refer to the deficit of normal behaviours. This would include such symptoms as apathy, social withdrawal, and flat affect.

Recently, neurocognitive deficits have come to the forefront of SZ research and have been recognized as a core clinical feature of the disorder (Keefe \& Fenton, 2007). These deficits seem to affect a variety of cognitive abilities, the most consistently demonstrated being working memory, attention/vigilance, reasoning, speed of processing, verbal learning and memory, reasoning and problem solving, and social cognition (Green et al., 2004; Keefe \& Fenton, 2007; Keefe \& Harvey, 2012). On tests of neurocognitive performance, SZ patients consistently score $1-2$ standard deviations below the average of healthy controls (Keefe et al., 2013). In addition, 98\% of patients diagnosed with SZ perform below their predicted ability on cognitive tests based on the education level of their parents (Keefe, Eesley, \& Poe, 2005) while monozygotic twin studies have demonstrated that the majority of all twins diagnosed with SZ perform worse than their 
unaffected twin on cognitive tests (Goldberg, 1990). Based on the mounting evidence, it can be assumed that the majority of individuals diagnosed with SZ perform worse on tests of cognitive performance than would be expected without the diagnosis.

Despite earlier beliefs, cognitive deficits evident in SZ patients have been shown to have a weak correlation with psychotic symptoms (Bilder, Mukherjee, Rieder, \& Pandurangi, 1985) and are not a side effect from the use of antipsychotic medication (Keefe \& Harvey, 2012). This weak correlation has been demonstrated within both chronic SZ samples (Addington, Addington, \& Maticka-Tyndale, 1991) and first episode SZ samples (Mohamed, Paulsen, O’Leary, Arndt, \& Andreasen, 1999). Furthermore, a number of recent studies have analyzed these cognitive deficits and have noted that they appear before the onset of psychosis (Heydebrand, 2006; Snitz, MacDonald, \& Carter, 2005) and remain stable throughout the course of the illness (Hughes et al., 2003). Evidence also shows that cognitive deficits appear in unaffected familial relatives (Heydebrand, 2006; Snitz et al., 2005). Families of patients with SZ on average perform more than half a standard deviation below the score of healthy participants with the most robust findings being related to verbal memory, executive function (verbal fluency, cognitive flexibility, and working memory), and attention, to a slightly lesser degree (Heydebrand, 2006). The above demonstrates the stability of cognitive deficits in SZ and that they are an independent core clinical characteristic of the disorder.

Perhaps the most notable fact related to the presence of cognitive deficits in SZ is that they reliably predict real-world community functioning better than clinical symptoms (e.g., positive and negative symptoms) (Bryson \& Bell, 2003; Green, Kern, Braff, \& Mintz, 2000; Harvey et al., 1998; Keefe \& Harvey, 2012). Analyses using both 
longitudinal (Keefe \& Harvey, 2012; Malla, Norman, Manchanda, \& Townsend, 2002) and cross-sectional studies (Green et al., 2000) have demonstrated effect sizes in the medium range supporting a significant relationship between measures of the above mentioned neurocognitive processes and functional outcome. Furthermore, cognitive impairments have consistently been shown to predict employment outcome, functional capacity, medical comorbidity, relapse prevention, quality of life, and economic cost (Keefe \& Harvey, 2012). These results suggest that cognitive impairments may well be the single greatest obstacle to improving the quality of life for SZ patients thus highlighting the need for effect treatment strategies targeting these deficits.

\section{Schizophrenia Endophenotypes: Sensory Gating Deficits and ERP Biomarkers}

SZ research has recently sought to identify neurocognitive markers that represent known neurobiological pathways that can be used in the evaluation and development of novel treatment strategies. A number of valuable markers have been identified in relation to SZ. These markers occur frequently in SZ patients, as well as their unaffected relatives. They have been shown to be enduring and independent of clinical symptoms or pharmacological treatment. The identification and understanding of these trait biomarkers or "endophenotypes" allows researchers to circumvent the complicating issue of clinical heterogeneity in SZ risk-related gene discovery (Gottesman \& Gould, 2003). Currently, endophenotypes which appear across different species are being used to test SZ pathophysiology hypotheses and offer potentially valuable biomarkers in the analysis of novel drug strategies and the identification of heterogeneous SZ subgroups which will most benefit from their use (Cho et al., 2005; Duncan, 1988; Thaker, 2007). 
The growing literature suggesting that the symptomology of SZ includes cognitive impairments as a primary characteristic advocates that these deficits include reduced perceptual and attentional function. The primary explanation to account for these deficits suggests that SZ patients cannot gate out or inhibit sensory information that has been coded as redundant or irrelevant. This process of inhibition or sensory gating is a neuronal level mechanism that filters incoming stimuli and reduces neuronal responses to sensory stimuli deemed irrelevant. This system dysfunction could lead to sensory overload stemming from sub-cortical and cortical neuronal hyper function (Freedman et al., 1987; Freedman, Waldo, Bickford-Wimer, \& Nagamoto, 1991; Geyer \& Braff, 1987). Deficient neuronal suppression has been associated with the conscious experience of greater perceptual anomalies (e.g., perceptions of heightened stimulus sensitivity) and attentional disturbances (e.g., over-inclusion of sounds in the focus of attention; (Hetrick, Erickson, \& Smith, 2012). A SZ associated sensory gating deficit has been confirmed repeatedly and has been suggested to be one of, if not the, strongest and most reliable finding in the SZ literature (Bramon, Rabe-Heskethb, Shama, Murraya, \& Frangoua, 2004; Heinrichs, 2004; Hong et al., 2009). Research also observes this deficit in unaffected relatives of patients with SZ (Patterson et al., 2008). As such, this sensory gating deficit has been suggested to be a genetically associated fixed trait of the disorder with potential as a candidate endophenotype.

As stated, SZ patients exhibit abnormalities across a number of cognitive domains but most importantly demonstrate a defect related to the gating of sensory information. (Leitman, Laukka, et al., 2010; Leitman, Sehatpour, et al., 2010). Electroencephalographically (EEG) derived electrical event-related brain potentials 
(ERP) are a useful neurophysiological tool that is able to demonstrate these deficits in early, elementary sensory processes and their contribution to higher-order cognitive impairments and functional deficits. Several ERP biomarkers show differential sensitivity to deficits in specific neurochemical systems, which are leading targets for treating cognitive impairment in SZ (Buchanan, Freedman, Javitt, Abi-Dargham, \& Lieberman, 2007). In the pursuit of novel drug therapy development, ERPs have an advantage in their ability to demonstrate large effect-size changes relative to standard neuropsychological tests (Cho et al., 2005; Thaker, 2007; Turetsky et al., 2007). In comparison to functional brain imaging techniques, ERPs have a superior temporal resolution (1 millisecond vs. $1-2$ seconds). This warrants their preferential use in the investigation of cognitive deficits ranging from bottom up (low-level) to top down (higher order) processes. Scalprecorded ERP components allow researchers to non-invasively track neural processes, ranging from the earliest automatic stages of pre-attentional sensory-based operations, through to controlled attention-dependent higher level decision and response-related processing (Rissling, Makeig, Braff, \& Light, 2010). The advantage of early latency ERPs over neuropsychological tests is that they are able to index automatic processes and are less affected by top-down information processing or practice/motivational effects. In addition, animal models (i.e., rodent and primate models) demonstrate similar auditory ERPs to humans. These animal ERP components demonstrate similar responses to stimulus manipulation and drugs. This gives ERPs a huge advantage in the development of novel drug therapies (Javitt, Spencer, Thaker, Winterer, \& Hajós, 2008).

The sensory gating process is measured in humans and animals using EEG derived ERPs. The P50 ERP is used in humans, and the P20-N40 complex is used in 
animals as an index of sensory gating. The successful processing of sensory information involves the inhibition of automatic responses to information deemed redundant or irrelevant while facilitating the response to salient events. Abnormalities related to this sensory-level process are best reflected in the auditory system. Here, early latency ERP components are used to probe the integrity of sensory functions.

The P50 ERP is an early positive voltage component that appears approximately $50 \mathrm{~ms}$ after the presentation of an auditory stimulus. The P50 indexes a predominantly pre-conscious early stage operation. The paradigm most commonly used to elicit the P50 ERP is the paired click technique (Adler et al., 1990; Boutros, Zouridakis, Rustin, Peabody, \& Warner, 1993; Freedman et al., 1987). Subjects are presented pairs of identical auditory stimuli separated by an intra-pair interval of approximately $10 \mathrm{~s}$ and an inter-pair interval of approximately $500 \mathrm{~ms}$. The first auditory stimulus of the pair is commonly referred to as the conditioning stimulus or S1. This stimulus initiates an inhibitory process in the brain resulting in the amplitude of the P50 ERP in response to the second stimuli, referred to as the test stimulus or S2, being reduced.

The P50 indexed measurement of the neuronal response to S2 offers a test of the inhibitory processes activated in response to the first click (S1). Therefore, by comparing the P50 amplitude in response to S1 and S2 researchers are able to quantify the strength of the inhibition process, where a greater difference indicates more robust sensory gating. This suppression of the auditory P50 ERP is measured as either a ratio (rP50: S2-P50 / S1-P50), a difference score (dP50: S1-P50 - S2-P50), or as a gating difference waveform (GDW: subtract the S2 waveform from the S1 waveform). Studies analyzing the P50 measure of sensory gating have implemented two methods of measuring the P50 peak 
amplitude. Researchers either measure the peak amplitude relative to the preceding trough (i.e., peak to trough) or from the individual's pre-stimulus baseline (i.e., peak to baseline). Each of these methods have shown variability in their reliability in measuring P50 suppression (Fuerst, Gallinat, \& Boutros, 2007; Rentzsch, Jockers-Scherübl, Boutros, \& Gallinat, 2008; Smith, Boutros, \& Schwarzkopf, 1994). A recent study sought to clarify this reliably issue by directly comparing the reliability of difference scores and ratio scores measured either peak to trough or peak to baseline (Dalecki, 2015). The reliability of each of these measures was shown to be significant with more trials (100 trials most effective) and when the peak to baseline measurement method applied. Notably, P50 difference scores highly correlate with the S1 P50 amplitude while P50 ratio scores correlate with S2 amplitude (Fuerst et al., 2007; Lu et al., 2007). This suggests that ratio scores offer a more direct indication of P50 suppression while difference scores instead reflects more S1-related processes, including early sensory registration.

In healthy individuals, P50 suppression typically takes the form of robust suppression (i.e., 50\% - 70\% suppression) (Adler, Freedman, Ross, Olincy, \& Waldo, 1999; Light, Geyer, Clementz, Cadenhead, \& Braff, 2000). In contrast, SZ patients exhibit sensory gating suppression that is significantly reduced (see Figure 1 below). This is a phenomenon that has been repeatedly demonstrated (Boutros, Zouridakis, \& Overall, 1991). However, despite the volume of research that has identified this deficit in SZ patients, others have failed to replicate the findings. Some studies have failed to identify a failure to suppress the P50 response to S2 in samples of SZ patients (Arnfred, Chen, Glenthøj, \& Hemmingsen, 2003; de Wilde, Bour, Dingemans, Koelman, \& Linszen, 
2007; Domján, Csifcsák, Drótos, Janka, \& Szendi, 2012; Light et al., 2012) while others have failed to identify robust suppression in healthy individuals (Kathmann \& Engel, 1990). The underlying reason for a failure to observe P50 suppression deficits remains unclear though variability within the sample (e.g., gender, smoking status, medication status) and methodological differences (e.g., stimulus intensity, number of paired-click trials presented, instructions given by experimenter related to whether to focus on auditory stimuli or ignore them) between studies may offer some explanation (Patterson et al., 2008).

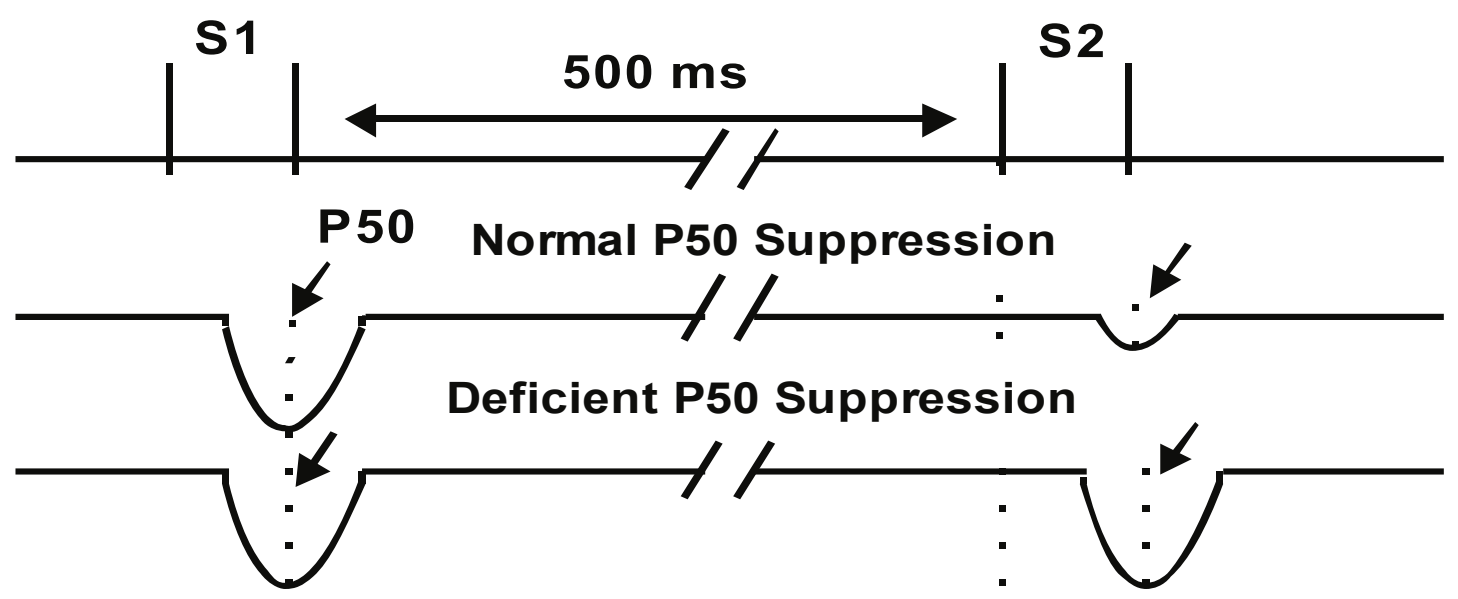

Figure 1. Normal and deficient P50 amplitudes in response to S1 and S2.

The P50 ERP component has been shown using neuroimaging techniques to be generated in the auditory cortex. The inhibitory aspect of the P50 ERP is facilitated by a number of cortical and subcortical regions. For example, the frontal cortex, auditory cortex, thalamic cortices, and the hippocampal regions have all been recognized as contributing areas (Bak, Glenthoj, Rostrup, Larsson, \& Oranje, 2011; Grunwald et al., 
2003; Korzyukov et al., 2007; Krause, Hoffmann, \& Hajós, 2003; Tregellas et al., 2007;

Waldo et al., 1994). Specifically, research has supported a prominent role associated with the hippocampal regions. Post-mortem studies have demonstrated decreased hippocampal region volume in the schizophrenic brain while further research has demonstrated decreased functioning, thus supporting hippocampal dysfunction (Freedman \& Goldowitz, 2010; Heckers, 2001).

The hippocampus consists of pyramidal neurons. These neurons respond to environmental sensory input. Their activation is regulated by $\gamma$-aminobutyric acid (GABA) -containing interneurons through excitability monitoring. In response to sensory input, depth recordings using the human brain (Goff, Williamson, Gilder, Allison, \& Fisher, 1980) and single neuron recordings (Wilson, Babb, Halgren, Wang, \& Crandall, 1984) have documented hippocampal activation in the form of a positive response occurring $50 \mathrm{~ms}$ post-stimulus presentation and a habituation of this response. Using single neuron recordings in animals, pyramidal neurons in the CA3 region of the hippocampus have been identified as the source of the P50 ERP designed to index this habituation process (Bickford-Wimer et al., 1990; Flach et al., 1996; Moxon, Gerhardt, \& Adler, 2003). These results are further bolstered by the evidence demonstrating that removal of the CA3 and CA4 hippocampal regions in rats results in the abolishment of the P20-N40 complex, the analog of the human P50 ERP (Nagamoto et al., 1990). Current theories have proposed that the final mechanism for P50 suppression involves some form of inhibition, perhaps modulated by the CA3-CA4 GABA containing interneuron, initiated by S1. 


\section{Efficacy of Antipsychotics in Treating Sensory Gating and Cognitive Deficits}

With their stability and strong predictive relationship to functional outcome, cognitive impairments have come to be viewed as a possible target for psychopharmacological treatments (Hyman \& Fenton, 2003). Unfortunately, there are currently no approved pharmacologic or behavioral treatments for SZ's cognitive deficits. Though antipsychotic drugs have demonstrated their efficacy in treating positive symptoms, currently they offer only marginal improvements for cognitive impairments and remain a controversial topic in current research.

First generation antipsychotics, also known as typical antipsychotics, are a class of high affinity D2 receptor antagonist drugs. These drugs can be classified into three groups based on their chemical structure: butyrophenomes (e.g., haloperidol), phenothiazines (e.g., chlorpromazine), and a heterogeneous third group. First generation antipsychotics have been shown to be effective in reducing positive symptoms and the risk of relapse. Approximately $30 \%$ of patients have little to no response to these drugs, while $\sim 50 \%$ demonstrate only a partial response (Fleischhacker, 1995; Kane, 1989). The side effects associated with treatment using first generation antipsychotics are extrapyramidal symptoms (i.e., dystonia, akathisia, parkinsonism), hyperprolactinemia, and tardive dyskinesia due to the long term blockade of the dopaminergic pathways (Miyamoto et al., 2015). Currently, the only patients deemed suitable for treatment with first generation antipsychotics are those who have already demonstrated a history of good response to the medication and tolerable side effects.

Second generation antipsychotic medications are a class of drugs that lack an exact definition. The most common characteristic of this class of medication is a 
prominent antagonistic effect on serotonin 5HT2A and $\mathrm{D}_{2}$ receptors (Hill, Bishop, Palumbo, \& Sweeney, 2010). Contributing to their lack of exact definition is the fact that each second generation antipsychotic also has a unique receptor binding profile. Clozapine was the first second generation antipsychotic introduced and it demonstrated an increased efficacy in treating treatment-resistant SZ as well as reduced extrapyramidal side effects. The most prominent side effects associated with treatment with second generation antipsychotics are weight gain and glucose and lipid metabolism disruption (Lieberman et al., 2005; Miyamoto, Miyake, Jarskog, Fleischhacker, \& Lieberman, 2012; Miyamoto, Duncan, Marx, \& Lieberman, 2005).

Evidence supporting the effectiveness of either generation of antipsychotic medication in treating cognitive deficits is clouded and controversial. A number of early studies had supported the therapeutic effects of second generation antipsychotics in the treatment of cognitive deficits associated with SZ (Keefe \& Harvey, 2012; Rosenheck, Doyle, Leslie, \& Fontana, 2003; Swartz et al., 2003). One meta-analysis which analyzed the effects of second generation antipsychotics on cognition suggested that risperidone and olanzapine improved cognitive performance with an effect size of $.35-.54$ depending on the cognitive measure (Harvey, Rabinowitz, Eerdekens, \& Davidson, 2005; Keefe et al., 2004, 2006; Keefe, Silva, Perkins, \& Lieberman, 1999; Kern et al., 2008). In another study which directly compared the effects of first generation antipsychotics and second generation antipsychotics clear improvements in learning and speed of processing were observed in relation to second generation antipsychotics (specifically haloperidol) (Woodward, Purdon, Meltzer, \& Zald, 2007). Further research supported the relationship between treatment with second generation antipsychotics and cognitive benefits 
associated with long-term memory (Thornton, Van Snellenberg, Sepehry, \& Honer, 2005).

Critically, it has come to light that many of these studies were designed around methodologies with substantial limitations (e.g., small sample sizes, short duration of treatment, lack of inclusion of a comparator group, and inattention to relationship between cognitive improvement and symptom change) resulting in questionable results (Keefe \& Harvey, 2012). Research has begun to support the possibility that many of the positive effects on cognition that have been observed were in fact misidentified due to experimental limitations. The results of the Clinical Antipsychotic Trials of Intervention Effectiveness (CATIE) study (Keefe et al., 2015; Swartz et al., 2003) offered a unique opportunity to clarify these disputed results. This study analyzed the differences between one first generation antipsychotic (perhenazine) and four second generation antipsychotics (olanzapine, quetiapine, risperidone, and zipradisone). With a sample of 817 patients, randomly assigned to one of each of these treatments, there were no significant differences following two months of treatment. Though each of the treatment groups did show a small improvement in cognitive performance the magnitude of the effect was consistent with the practice effects established with the test battery utilized (Keefe \& Harvey, 2012; Keefe et al., 2008).

The European Union First Episode SZ Trial (EUFEST) is another large-scale study of relevance to this discussion. Using a sample of drug naïve first episode SZ patients, this study analyzed the effects of second-generation antipsychotic medication (i.e., haloperidol, amisalpride, olanzapine, quietiapine, and ziprasidone) (Kahn et al., 2008). No differences in cognitive change were observed between the treatments though 
a small effect similar to a practice effect was observed. Another interesting observation from the study was a strong correlation between clinical symptoms and cognitive performance. This relationship suggests that as clinical symptoms improve, there is an associated cognitive performance benefit. These results have been replicated in further studies which have shown that any short term effects of second generation antipsychotics on cognition do not remain significant when analyzed in the long term (Ayesa-Arriola et al., 2013; Keefe \& Harvey, 2012; Van Putten, Marder, Wirshing, Aravagiri, \& Chabert, 1991). Overall, based on the research currently available, it is clear that the cognitive benefits associated with the use of current antipsychotic medications are minimal at best if not wholly attributable to another co-variable (i.e., practice effects, improvement of clinical symptoms). Further large-scale randomized studies using samples of patients with known medical history is required to clarify this controversial topic. Unfortunately, antipsychotic medication's lack of efficacy in the treatment of cognitive deficits extends to those observed with sensory gating. Research has consistently shown that treatment with either first or second generation antipsychotics does not normalize the disrupted inhibitory process.

One of the first studies analyzing the effects of first generation antipsychotics on sensory gating sought to observe the differences in sensory gating performance between a group of SZ patients medicated with first generation antipsychotics, a group of nonmedicated SZ patients, and a control group of healthy volunteers. The results of this study demonstrated that both SZ groups displayed significantly reduced sensory gating compared to the control group replicating the consistent deficit. In addition, no significant differences were observed between the treatment group and the non-medicated SZ group 
(Freedman, Adler, Waldo, Pachtman, \& Franks, 1983). These results have since been replicated. It was noted that patients who had been free from first generation antipsychotics for over 10 weeks were just as likely to exhibit sensory gating deficits as those currently being treated with the medication (Hong et al., 2009). Furthermore, P50 indexed sensory gating was found to be uncorrelated with medication dosage. These results have since been replicated (Louchart-De La Chapelle et al., 2005). The observation that can be taken from this collection of studies is that P50 sensory gating performance appears to be independent of treatment with first generation antipsychotic medication status. This appears to be generalizable to a variety of patients at different stages in the course of the illness.

Some studies have supported the efficacy of second generation antipsychotics in the treatment of P50 suppression deficits (Harvey \& Keefe, 2001; Light et al., 2000) while others have not (Bramon et al., 2004; Hong et al., 2009). P50 suppression in patients being treated with clozapine, olanzapine and risperidone have been shown to be $82.6 \%, 75 \%$ and $39.2 \%$ respectively (Light et al., 2000). While clozapine and olanzapine were able to normalize sensory gating performance in SZ patients, risperidone failed to normalize the deficit. Conversely, in a study conducted by Bramon et al. (2004), no significant effect of treatment with second generation antipsychotics were observed in relation to P50 indexed sensory gating when compared to treatment with first generation antipsychotics (Bramon et al., 2004; Hong et al., 2009). These results contrast those that have shown a beneficial effect and have been demonstrated in further studies. For example, in a study which sought to directly compare the effect of risperidone, 
olanzapine, and quietiapine, no significant changes to P50 suppression were observed (Harvey \& Keefe, 2001; Hong et al., 2009).

Upon further analysis, it has become evident that not all second generation antipsychotics are equally effective in the treatment of sensory gating deficits. The mechanisms underlying these differences in treatment efficacy remain unclear though it has been suggested that affinity to 5-HT3 (5 - hydroxytryptamine 3 ) receptors and/or activation of nicotinic acetylcholine receptors (nAChRs) may mediate it (Koike et al., 2005). For example, clozapine, as mentioned above, has been shown to have a beneficial effect on sensory gating (Harvey \& Keefe, 2001; Light et al., 2000). Clozapine has a high affinity to the 5-HT3 receptors not present in other second generation antipsychotics such as risperidone (Leysen, Gommeren, \& Schotte, 1996). In addition, clozapine has been shown to increase acetylcholine levels in the rat brain possibly resulting in the activation of $\alpha 7 \mathrm{nAChRs}$ shown to be instrumental in the sensory gating process (Ichikawa, 2002). Further support for this theory demonstrates that the beneficial effects on sensory gating observed following clozapine administration in DBA/2 mice, an inbred mouse strain with genetic abnormalities resulting in the reduced expression of nAChRs, is blocked by the administration of $\alpha$-bungarotoxin, an $\alpha 7$ antagonist (Simosky, Stevens, Adler, \& Freedman, 2003).

The first study demonstrating the effects of clozapine on sensory gating demonstrated that treatment with clozapine improved P50 indexed sensory gating even in patients who had been previously treated with another antipsychotic (Nagamoto et al., 1999). Following one month of treatment, 6 out of the 10 participants demonstrated a clinical response to the medication with significantly improved P50 indexed sensory 
gating. At a 15 month follow up, nine out of the ten patients demonstrated P50 indexed sensory gating in the normal range with a paralleled clinical improvement (Jacobsen et al., 2004; Nagamoto et al., 1996) Further studies comparing different antipsychotics have replicated these results (Becker et al., 2004; Harvey \& Keefe, 2001; Hong et al., 2009; Light et al., 2000; Nagamoto et al., 1999) and found that treatment with clozapine versus other first generation antipsychotics results in a significantly lower sensory gating ratio (i.e., improved sensory gating). Light et al. (2000) conducted a meta-analysis comparing the effects of multiple second generation antipsychotics and found that the improvements observed were largely associated with treatment with clozapine. Following treatment with clozapine, Light and Geyer discovered that $62 \%$ of the patients demonstrated sensory gating performance within the normal range.

Unfortunately, the beneficial effects of clozapine have come under question. Some of the limitations of these studies include the facts they relied on cross-sectional designs, sampled primarily treatment resistant SZ patients, and included patients with a variety of medication histories. Furthermore, in a follow-up study, the effect of clozapine was tested in a sample of medication naïve first episode SZ patients (Hong et al., 2009). The results of this study contradicted the previous results with no significant effects of clozapine.

Overall, the effects of clozapine and the underlying mechanism facilitating the somewhat inconsistent benefits remain unclear, though likely associated with increased activity of the nAChRs (Hong et al., 2009). Although clozapine does seem to carry some hope for alleviating sensory gating deficits, it does not appear to be a widespread solution considering, coupled with the inconsistent results, clozapine has been shown to cause 
serious side effects including agranulocytosis, a deadly condition involving a decrease in while blood cells. Clozapine currently is used primarily to treat patients who do not respond to any alternative antipsychotic medications with mandatory consistent white blood cell count monitoring.

\section{Novel Therapeutic Targets: The Nicotinic Acetylcholine Receptor System}

The United States National Institute of Mental Health working with representatives from academia, the government, and the pharmaceutical industry recently developed the Measurement and Treatment Research to Improve Cognition in Schizophrenia (MATRICS) Project. The goal is to support the development of novel pharmacological approaches to improve upon cognitive impairments. The primary goal was to identify the core cognitive impairments associated with SZ, then to develop a standard test battery to homogenize the assessment of cognition in clinical trials. From this, the project identified seven primary domain endpoints (e.g., working memory, verbal learning and memory, visual learning and memory, attention and vigilance, reasoning and problem solving, speed of processing and social cognition) as well as developed composite scores to evaluate cognition-enhancing agents (Kern et al., 2008; Nuechterlein et al., 2008). Another purpose of the MATRICS project was to identify promising molecular targets for the development of the procognitive drugs. A number of molecular targets were identified though the one most relevant to this study was the nicotinic acetylcholine receptors in the hippocampus (Buchanan et al., 2005, 2007).

NAChRs identified by the MATRICS project are integral to the proper functioning of both cognitive and sensory processes. Among these receptors, the $\alpha 7$ nAChR subtype is the most studied and holds much promise as a therapeutic target. A 
wide range of research has associated this receptor system with preclinical, neurobiological, clinical, and genetic evidence supporting their dysfunction within the schizophrenic brain and the pathophysiology of the disorder. There has been a significant movement in the SZ research field and the pharmaceutical industry to identify and develop effective $\alpha 7 \mathrm{nAChR}$-targeting therapeutics with the aim of treating cognitive impairments, specifically sensory gating deficits. A number of novel compounds, ranging from partial agonists to positive allosteric modulators, have shown some promise, advancing to clinical development but very few have progressed to full approval in the treatment of cognitive deficits.

The relationship between cigarette use and SZ offers insight into the connection between the nAChR system and the disorder. SZ patients display a much higher prevalence of smoking habits compared to the general public ( $\sim 60-86 \%$ vs. $\sim 20 \%$ ) (De Leon, Tracy, McCann, McGrory, \& Diaz, 2002; Diwan, Castine, Pomerleau, MeadorWoodruff, \& Dalack, 1998; Hughes, Hatsukami, Mitchell, \& Dahlgren, 1986; Kumari \& Postma, 2005). This difference in cigarette use has been shown to be stable across cultures and remains when variables such as socioeconomic status, marital status, alcohol use, antipsychotic medication use, and institutionalization are accounted for (Kumari \& Postma, 2005; McEvoy \& Lindgren, 1996). In addition, SZ patients also have a higher average daily consumption of cigarettes, prefer cigarettes with higher nicotine content, and extract more nicotine from each cigarette (Kumari \& Postma, 2005; Olincy, Young, \& Freedman, 1997; Strand \& Nybäck, 2005).

These phenomena have lead researchers to hypothesize on what motivates this consistent behaviour. A current hypothesis is that cigarette smoking offers a procognitive 
effect thereafter labeling this hypothesis the self-medication hypothesis (Kumari \& Postma, 2005). It has been suggested that the continued use of cigarettes and nicotine exposure can reduce the possible side effects associated with the use of antipsychotic medication, possibly enhance the therapeutic effects of antipsychotic medication, alleviate negative symptoms, and/or normalize cognitive deficits associated the improper functioning/expression of the nAChRs associated with SZ (Kumari \& Postma, 2005).

The pharmacological effects of nicotine, moderated by nAChR activation, are diverse and act upon a number of neurotransmitter systems in the brain (Gray et al., 1994). It is likely though that the increased consumption of nicotine amongst SZ patients is an attempt to activate $\alpha 7 \mathrm{nAChRs}$ which are less sensitive to nicotine than other nicotinic receptors (Kumari \& Postma, 2005). Nicotinic receptors subtypes are commonly distinguished by their unique combination of subunits. Each subtype is pharmacologically and functionally distinct with its own level of affinity and sensitivity to nicotinic agonists and antagonists (Kumari \& Postma, 2005; Patrick et al., 1993; Sargent, 1993). The $\alpha 7 \mathrm{nAChRs}$ is composed of $5 \alpha 7$ subunits (Kumari \& Postma, 2005; McGehee \& Lorna, 1995) and is most commonly found in the neocortex, thalamus, and hippocampus (Freedman, Wetmore, Stromberg, Leonard, \& Olson, 1993; Rubboli et al., 1994; Sugaya, Giacobini, \& Chiappinelli, 1990). These receptors have been identified as critical to the inhibitory response necessary for effective sensory gating. Nicotine exposure, and subsequent activation of the $\alpha 7 \mathrm{nAChRs}$, induces an increase in the release of glutamate. The release of glutamate results in the activation of the hippocampal CA3CA4 inhibitory interneurons. The culminating result of this interaction being the 
suppression of the neuronal response to the presentation of a subsequent identical stimuli (Leonard et al., 1996).

\section{The Schizophrenic Brain: $\alpha 7$ nAChR Dysfunction and Sensory Gating Deficits}

Although cholinergic circuits and signaling mediated by the high (nicotine) affinity $\alpha 4 \beta 2$ nAChR subtype are associated with information processing and sensory gating impairments in SZ (Berman, Talmage, \& Role, 2007; Hong et al., 2011; Hyde \& Crook, 2001; Radek, Kohlhaas, Rueter, \& Mohler, 2010), the most studied has been the low affinity $\alpha 7$ receptor subtype. As discussed above, the mechanism underlying the sensory gating inhibitory process has been linked to the pyramidal neurons of the CA3 region of the hippocampus. This inhibition relies on cholinergic stimulation which results in prolong bursts of activity in the interneurons. These bursts of activity result in the release of GABA, which subsequently activates the presynaptic $\mathrm{GABA}_{\mathrm{B}}$ receptors. When these receptors are activated, the release of glutamate, an excitatory neurotransmitter, is blocked. This results in the suppression of the CA3 pyramidal neurons response to the second identical stimuli. Evidence from preclinical, clinical, neurobiological, and genetic studies have supported a dysfunction associated with the $\alpha 7 \mathrm{nAChR}$ system in the pathophysiology of the gating deficit observed with SZ and supports this system as a potential target for therapeutic drugs aimed at the normalization of sensory gating (Buchanan \& Schwarcz, 2011; Hajos, 2006; Hashimoto, Koike, Shimizu, \& Iyo, 2005; Kohlhaas, Bitner, Gopalakrishnan, \& Rueter, 2012; Leiser, Bowlby, Comery, \& Dunlop, 2009; Martin, Kem, \& Freedman, 2004; Martin \& Freedman, 2007; Olincy \& Stevens, 2007; Toyohara \& Hashimoto, 2010) 
Genetic Evidence. Genetic research has supported an association between the $\alpha 7$ receptor function and sensory gating. In a genome-wide linkage analysis, P50 sensory gating deficit was genetically linked to the chromosome 15q14 locus of the CHRNA7 gene (Myles-Worsley, Ord, Blailes, Ngiralmau, \& Freedman, 2004). This gene is responsible for the expression of the $\alpha 7$ nAChR (Freedman et al., 1997). Furthermore, functional polymorphisms in the core promoter of the CHRNA7 have been genetically linked to SZ and the presence of sensory gating deficits (Houy et al., 2004; Leonard et al., 2002). This relationship has also been demonstrated in unaffected family members (Houy et al., 2004; Leonard et al., 2002). An association between this region and SZ has been replicated in a number of studies (Gejman, Sanders, Badner, Cao, \& Zhang, 2001; Liu et al., 2001; Markou, 2010; Tsuang et al., 2001). Individuals who have the less common alleles of CHRNA7 polymorphisms demonstrate significantly reduced sensory gating performance reflected in higher average P50 ratios (Freedman et al., 2003).

These results have been replicated in animal models of sensory gating dysfunction. Animal models with genetic abnormalities in the analogue of the CHRNA7 gene (acra7) also demonstrate a failure to suppress a response to a repeated auditory stimuli (Ichikawa, Dai, O’Laughlin, Fowler, \& Meltzer, 2002). In these mice strains, P20/N40 complex inhibition is significantly associated with the expression of $\alpha 7$ nAChRs in the hippocampus (Ichikawa et al., 2002). Poorer performance was found to be associated with polymorphism in the acra7 gene, analogous to the CHNRA7, which is responsible for the expression of $\alpha 7$ receptors in the hippocampus (Stitzel, Farnham, $\&$ Collins, 1996). 
Neurobiological Evidence. In line with genetic evidence, post-mortem studies analyzing the schizophrenic brain have demonstrated that although expression of the $\alpha 3$, $\alpha 4$, and $\beta 2$ nAChR subtype does not differ from healthy controls, the expression of the $\alpha 7$ subtype in the CA3 region of the hippocampus and the dentate gyrus is significantly reduced ( 50) (Freedman, Hall, Adler, \& Leonard, 1995; Leonard et al., 2000; MartinRuiz et al., 2003; Winterer et al., 2013). This indicates a specific volume deficit of this subunit in the schizophrenic brain. In addition, the regulation of these receptors has been shown to be disrupted as well (Breese et al., 2000). In the healthy brain, nicotine administration up-regulates the nicotinic receptors, increasing nicotinic receptor binding, in the hippocampus, cingulate cortex, and the thalamus (Breese et al., 1997, 2000; Court et al., 1999; Freedman et al., 1995; Guan, Zhang, Blennow, \& Nordberg, 1999; Marutle et al., 2001). SZ subjects conversely do not demonstrate the same regulatory response (Breese et al., 2000). SZ patients who are smokers demonstrate an overall reduction in the up-regulation response independent of the dosage level (Breese et al., 2000). Research has also demonstrated reduced CHRNA7 mRNA levels, the gene responsible for the expression of the $\alpha 7$ subtype receptor (De Luca, Likhodi, Van Tol, Kennedy, \& Wong, 2006; Mexal et al., 2005), in the schizophrenic brain compared to a healthy control (Freedman et al., 2003). Furthermore, SZ patients have demonstrated elevated levels of antibodies to nAChRs in both blood and cerebrospinal fluid. This high level is associated with increased receptor loss through antigenic modulation (Bradley, Dwyer, Kemp, \& Crews, 1980; Lindstrom, Seybold, Lennon, Whittingham, \& Duane, 1976; Mukherjee et al., 1994). 
Preclinical Evidence. The DBA/2 strain of inbred mice offers a useful animal model to understand the mechanism underlying sensory gating deficits. The DBA/2 inbred mice strain has been shown to demonstrate a sensory gating deficit evident in a failure to suppress its P50 response to S2 in a paradigm analogous to the auditory click paradigm used with humans (Ichikawa et al., 2002; Olincy \& Stevens, 2007). This deficit has been shown to correlate significantly with the level of $\alpha$-bungarotoxin binding (Ichikawa et al., 2002). This suggests a facilitating role of $\alpha 7$ nAChRs. Furthermore, these mice have been shown to have a reduced expression of $\alpha 7 \mathrm{nAChRs}$ in the hippocampal region (Ichikawa et al., 2002) very similar to that observed in SZ patients (Freedman et al., 1995).

The facilitating roles of $\alpha 7$ receptors in the gating deficit have been further supported in a number of pharmacological studies. For example, the administration of scopolamine (a muscarinic antagonist), mecamylamine (a high affinity NAChR antagonist), or K-bungarotoxin (a high affinity NAChR antagonist) had no effect on the P20-N40 index of inhibition. Conversely, the administration of $\alpha$-bungarotoxin, $d$ tubocurarine, or methyllycanonitine (all specific $\alpha 7$ receptor antagonists) significantly reduced the suppression of the P50 response to S2 (Ichikawa et al., 2002; LuntzLeybman, Bickford, \& Freedman, 1992).

These results have been replicated with ABT418, an $\alpha 7$ receptor agonist. The administration of this compound to sensory gating-deficient mice results in an increased P50 amplitude in response to S1 and a decreased P50 amplitude in response to S2. Furthermore, when this agonist was administered along with the $\alpha 7$ antagonist $\alpha$ bungarotoxin, the normalizing effects were blocked. Co-administration with 
mecamylamine, and $\alpha 4 \beta 2$ antagonist, did not block the effects. These results together offer a strong foundation of support for the role of $\alpha 7$ receptors in mediating this sensory gating process (Stevens \& Wear, 1997).

Studies have also shown that this deficit is normalized following administration of an $\alpha 7$ agonist. The beneficial effects of acute nicotine administration (Olincy $\&$ Stevens, 2007; Stevens \& Wear, 1997) as well as nicotine's ability in normalizing sensory gating deficits induced by amphetamine administration in rats (Stevens, Meltzer, \& Rose, 1995) have also been shown. Similar effects were observed following clozapine administration (Simosky et al., 2003). The ameliorating effects of clozapine seem to be facilitated through the selective decrease in the S2 P50 amplitude (similar to that observed with nicotine) (Simosky et al., 2003). Furthermore, adding to the evidence supporting a facilitating role of the $\alpha 7 \mathrm{nAChRs}$ system, this beneficial effect is blocked by the administration of $\alpha$-bungarotoxin, a selective $\alpha 7$ antagonist. Administration of tropisetron, a 5-HT3 receptor agonist and a partial $\alpha 7 \mathrm{NAChR}$ agonist, normalizes deficient gating in DBA/2 mice (Hashimoto, Fujita, Ishima, Hagiwara, \& Iyo, 2006; Hashimoto, Iyo, Freedman, \& Stevens, 2005; Shiina et al., 2010). This beneficial effect was blocked by the co-administration of the methyllycaconitine, the selective $\alpha 7 \mathrm{nAChR}$ antagonist (Hashimoto, Iyo, et al., 2005). Finally, DMXB-A administration has been shown to selectively decrease P50 amplitude (Olincy, Harris, Johnson, Pender, Kongs, Allensworth, \& Ellis, 2006).

Clinical Evidence. Finally, a significant amount of clinical evidence has shown that nicotine has a beneficial effect on P50-indexed sensory gating in SZ (Adler, Hoffer, Wiser, \& Freedman, 1993). Research has since shown that nicotine administration 
enhances cognition and sensory gating in both smoker and non-smoker SZ patients (Adler et al., 1993). In addition, healthy, non-smoker volunteers have shown improved cognitive performance (i.e., attention, memory, executive function) following nicotine administration (Barr et al., 2008; Jacobsen et al., 2004; Potter, Summerfelt, Gold, \& Buchanan, 2006; Smith et al., 2006). Acute exposure to nicotine has been shown to improve sensory gating in SZ patients, and their unaffected relatives (Adler, Hoffer, Griffith, Waldo, \& Freedman, 1992; Adler \& Hoffer, 1993). This effect is also evident in healthy individuals who display poor baseline sensory gating (Knott, Fisher, \& Millar, 2010a). Conversely, acute nicotine administration reduces sensory gating performance in medium and high baseline suppressors (Knott et al., 2013). Nicotine is a non-selective agonist meaning it binds with many of the NAChR subtypes including the $\alpha 7$ NAChR subtype. Importantly, if nicotine is administered along with mecamylamine, a high affinity $\alpha 4 \beta 2$ NAChR antagonist, the normalization of the sensory gating process is still evident. This supports the mediation of this beneficial effect specifically through the $\alpha 7$ nAChRs (Freedman et al., 1994).

A similar pattern of effects has been observed with other drugs that have an affinity to the $\alpha 7$ nAChRs. Administration of tropisetron has been shown to improve P50 indexed sensory gating deficits in SZ patients (Shiina et al., 2010). In addition, ondansetron, a 5-HT3 receptor antagonist (a receptor system which tonically inhibits the release of acetylcholine) has been shown to improve sensory gating deficits in a population of SZ patients being treated with first generation antipsychotics (Adler et al., 2005; Sirota et al., 2000). The effects of ondansetron were shown to be mediated through the suppression of S2 P50 amplitudes that according to the literature is the main indicator 
of sensory gating. Clozapine, a second generation antipsychotic, has been show to significantly affect P50 sensory gating ratios (Arango, Summerfelt, \& Buchanan, 2003; Becker et al., 2004) though this effect seemed to affect S1 P50 amplitude as apposed to S2 P50 amplitude. Finally, DMXB-A, a partial agonist of the $\alpha 7 \mathrm{nAChRs,} \mathrm{increased} \mathrm{P50}$ indexed S2 suppression (Olincy, Harris, Johnson, Pender, Kongs, Allensworth, Ellis, et al., 2006).

\section{Novel Cholinergic Agents: Recent drug development efforts}

Despite the beneficial sensory gating effects associated with nicotine administration (Adler et al., 1992; Adler \& Hoffer, 1993; Knott et al., 2010a; LuntzLeybman et al., 1992), it has several limitations as a therapeutic drug. Unfortunately, due to tachyphylaxis, the beneficial effects of nicotine are not long lasting. Approximately 30 minutes following cigarette use, sensory gating deficits remerge (Olincy \& Stevens, 2007). A similar length of effect is evident with transdermal nicotine patches (Griffith et al., 1998).

Nicotine quickly desensitizes the $\alpha 7$ nAChRs. Therefore, long-term sustained benefits are impossible. Nicotine is highly addictive and the health consequences of longterm sustained exposure are not currently well understood. Furthermore, without continued exposure withdrawal symptoms are experienced (Olincy \& Stevens, 2007). Although nicotine itself does not offer a useful therapeutic prospect, its actions on receptors systems support the development of NAChR targeted therapeutics. Recently, a number of $\alpha 7$ receptor targeted agonists have been developed as potential novel treatment strategies. 
DMXB-A. The selective $\alpha 7$ NAChR agonist 3-2,4-dimethoxybenzylidene anabaseine (DMXB-A) was developed as a possible adjunctive treatment for SZ related cognitive deficits. Early studies have demonstrated that administration of DMXB-A to DBA/2 mice demonstrating a sensory gating deficit produced a dose-dependent effect on sensory gating by increasing S2 P50 response suppression (Stevens, Kem, Mahnir, \& Freedman, 1998). In a sample of SZ patients, DMXB-A was administered and shown to improve P50 indexed sensory gating (Olincy, Harris, Johnson, Pender, Kongs, Allensworth, \& Ellis, 2006). DMXB-A appears to have a higher efficacy at lower doses compared to higher doses suggesting some tachyphylaxis though further research is required to specify optimal dosage.

Tropisetron. As mentioned previously, tropisetron is a high affinity partial agonist of the $\alpha 7$ NAChR and a potent $5-\mathrm{HT} 3$ receptor antagonist. Currently, it is primarily used as an antiemetic to treat nausea associated with chemotherapy and surgery. Recently though it has gained attention in SZ research as a possible treatment for sensory gating deficits. In an early study, tropisetron was administered to DBA/2 mice with auditory gating deficits and it was noted that it transiently normalized the deficit (Hashimoto, Iyo, et al., 2005). Administration of tropisetron was also observed to improve P50-indexed sensory gating ratios in SZ patients with high baseline ratios (i.e., poorer suppression) with four patients recovering to normal levels (Koike et al., 2005). Some patients with lower baseline P50 ratios (i.e., better suppression) did not show an improvement following administration (Koike et al., 2005). These results have been replicated since these studies in a sample of Japanese SZ patients (Hashimoto et al., 2006) during an 8 week trial, an 18 week treatment with coadministration of risperidone, 
and finally in a dosage study which demonstrated its effects did not vary between a $5 \mathrm{mg}$, $10 \mathrm{mg}$, and $20 \mathrm{mg}$ dosage (Shiina et al., 2010). The effects of tropisetron seem to be mediated by smoking status with non-smokers demonstrating a benefit and smokers demonstrating no effect significantly limiting its effectiveness as a large SZ patients demonstrated such a high prevalence of smoking (Koike et al., 2005). Though tropisetron offers hope for the treatment of sensory gating deficits, further research is required as it has yet to be formally approved for the treatment of SZ associated cognitive deficits.

Ondansetron. Ondansetron, an antiemetic, is a serotonin 5-HT3 receptor antagonist commonly used following surgery, chemotherapy, and radiation therapy. Ondansetron increases acetylcholine via its 5-HT3 receptor antagonism. 5-HT3 receptors tonically inhibit the release of acetylcholine (Ramírez, Cenarruzabeitia, Lasheras, \& Del Río, 1996). Some preliminary research has demonstrated that ondansetron can improve sensory gating in SZ patients. Two hours following acute administration, SZ patients demonstrated increased P50 indexed sensory gating (Adler et al., 2005). Ondansetron was administered to a sample of SZ patients medicated with first generation antipsychotics after which sensory gating was normalized (Sirota et al., 2000). Ondansetron not only facilitates the release of acetylcholine but a variety of neurotransmitters including norepinephrine and dopamine. The excessive release of these neurotransmitters have been shown to exacerbate psychotic symptoms and further disrupt sensory gating (Adler et al., 1990, 2005). Therefore, the beneficial effects of ondansetron may be dependent on the additional blockade of catecholaminergic systems to allow the stimulation of acetylcholine receptors to be therapeutic. Some of the previous findings may have only been evident due to the pattern of antipsychotic medication used in the sample. For 
example in the study conducted by Sirota et al. (2000), the majority of patients were being treated with first generation antipsychotics (known to have catecholaminergic blocking characteristics). The single participant that was not currently medicated with a first generation antipsychotic (i.e., olanzapine) did not demonstrate sensory gating normalization. Ondansetron has yet to be formally approved for the treatment of SZ associated cognitive deficits.

\section{Evaluating CDP-Choline in the Treatment of Sensory Gating and Cognitive Deficits.}

The development of $\alpha 7$ NAChR targeted therapeutics offers the opportunity to bolster both the efficacy of treating SZ associated sensory gating deficits as well as possibly improving the functional outcome of the disorder. Though progress has been made with the strategies mentioned above their lack of formal approval supports the analysis of further possible adjunctive treatment strategies. A novel candidate $\alpha 7$ NAChR agent is 5"-cytidine diphosphocholine otherwise known as CDP-Choline (citicoline) (Secades, 2011). The endogenous compound CDP-Choline is a key intermediate in the biosynthesis of phosphatidylcholine from Choline. CDP-Choline, administered either orally or intravenously has been approved in many countries (not yet Canada) as a treatment option for cerebrovascular and traumatic brain injuries (Secades, 2011). In addition, it has demonstrated tolerability as a treatment for the rehabilitation from chronic-ischemia-associated cognitive impairments (Secades, 2012), improvement of cerebrovascular disease, Alzheimer disease (Alvarez-Sabín \& Román, 2011; GarcíaCobos, Frank-García, Gutiérrez-Fernández, \& Díez-Tejedor, 2010; Secades, 2011) and late-life cognitive impairments (Conant \& Schauss, 2004; Fioravanti \& Buckley, 2006; Saver, 2008). Citicoline's efficacy in the treatment of these conditions has been attributed 
to its action of increasing phosphatidylcholine synthesis that protects and repairs damaged cell membranes.

The specific mechanism through which CDP-Choline facilitates its effects is the selective activation of the $\alpha 7$ NAChR subtype. CDP-Choline when administered at the recommended dosage increases central choline by 20\% (Babb et al., 2002; Hong, Summerfelt, McMahon, Thaker, \& Buchanan, 2004) through its hydrolization in the intestine and rapid absorption as choline and cytidine into the blood and brain (Tmax $\sim 3$ - 5 hours) (Wurtman, Regan, Ulus, \& Yu, 2000). Choline is an essential nutrient that acts as a precursor and metabolite of the neurotransmitter acetylcholine. In natural concentrations, choline acts as a full, selective $\alpha 7 \mathrm{NAChR}$ agonist compared to nicotine which activates both the low $(\alpha 7)$ and High $(\alpha 4 \beta 2)$ affinity NAChR subtypes (Alkondon \& Albuquerque, 2006; Castner et al., 2011; Papke, Bencherif, \& Lippiello, 1996; Uteshev, Meyer, \& Papke, 2002). In addition, choline also seems to allow for faster receptor re-sensitization compared to nicotine. This is evidenced by faster elimination from the synapse and quicker clearance of evoked potentials (Konradsson-geuken et al., 2009). The natural levels of choline in the brain are low. Rapid dosing of high doses of choline may result in receptor desensitization, but low and slowly delivered choline levels have been shown to produce a steady $\alpha 7$ receptor activation (Castner et al., 2011; Papke et al., 1996).

Research has demonstrated that administration of N-methyl-D-aspartate (NMDA) - receptor antagonists can elicit transient SZ-like cognitive impairment in healthy volunteers. This evidence has supported the role of NMDA receptor hypofunction in the development of cognitive deficits in SZ (Harvey \& Keefe, 1997; Kantrowitz \& Javitt, 
2010; Neill et al., 2010). In the hippocampus, NMDA receptors are diminished in the schizophrenic brain. These receptors are thought to play a primary role in activating the GABA inhibitory process, discussed earlier, mediating the P50 indexed sensory gating process (Law \& Deakin, 2001; Pilowsky et al., 2006). In an attempt to explore the NMDA mechanism, Knott conducted a study to analyze the separate and combined effects of CDP-Choline (500 mg) and the NMDA antagonist ketamine. Using NMDA antagonism as a pharmacological model of psychosis, P50 indexed sensory gating was assessed in healthy volunteers. The results of this study are still in press but preliminary findings suggest that, whereas ketamine impaired sensory gating by reducing S2 P50 response inhibition, co-administration of CDP-Choline with ketamine prevented the impairment (Knott, n.d.). This ameliorating effect afforded by the administration of CDPCholine may be due to its stimulation of the $\alpha 7$ receptors on the GABA interneurons or its ability to increase glutaminergic stimulation of the NMDA receptors on the inhibitory interneurons. The preliminary results of this study are supported by previous preclinical evidence using a rat model. In this study, the antagonistic effects of NMDA were antagonized by the co-administration of choline uptake enhancers (Shirayama, Yamamoto, Nishimura, Katayama, \& Kawahara, 2007). This resulted in reduced cognitive deficits usually observed following NMDA antagonist administration.

In animal models, doses of choline have shown procognitive activity similar to that observed in studies administering low doses of $\alpha 7$ NAChR agonist to non-human primates (Alkondon \& Albuquerque, 2006; Castner et al., 2011; Papke et al., 1996; Uteshev et al., 2002). A particular study, whose findings are relevant to this proposal, analyzed choline supplementation's effects on the in-bred DBA/2 strain of mouse 
exhibiting deficits associated with P50 sensory gating and $\alpha 7$ receptor expression. Choline supplementation was observed to increase both P50 sensory gating and $\alpha 7$ receptor expression in the hippocampus (Stevens, Adams, Mellott, Robbins, \& Kisley, 2008). In support of these findings, preclinical evidence has shown that gestational choline deficiency produces P50 sensory gating deficits in adult offspring (Stevens, Adams, Yonchek, et al., 2008). Finally, in a recent study human, infants were given choline supplements during the last two trimesters of pregnancy and during early infancy (Ross et al., 2013). Choline supplementation resulted in a lower rate (compares to placebo) of P50 indexed sensory gating deficits. In addition, the CHRNA7 genotype (the genotype responsible for $\mathrm{nAChR}$ expression and which is associated with $\mathrm{SZ}$ ) correlated with a P50 indexed sensory gating in the placebo group but not the treatment group (Ross et al., 2013).

Recent research evaluating the effects of CDP-Choline has focused on identifying its dose-dependent effects in relation to resting EEG, sensory gating, memory (as indexed by the mismatch negativity [MMN] ERP), voluntary attention as indexed by the P300a and P300b ERP components, and cognitive domains (e.g., verbal learning, processing speed, attention, working memory, and executive function). Recently, pharmaco-EEG was utilized to test the dosage at which CDP-Choline penetrates the brain (Knott, de la Salle, Smith, et al., 2015). This type of research analyzes spectral power changes in resting EEG frequencies to determine the optimal brain penetration dosage (Jobert et al., 2012; Knott, 2000). This study utilized a double blind, randomized cross over design with acute $500 \mathrm{mg}$ or $1000 \mathrm{mg}$ administration of CDP-Choline. The participant sample consisted of 24 healthy non-smoker volunteers. The results demonstrated that in response 
to $1000 \mathrm{mg}$ of CDP-Choline (vs. placebo) delta power was reduced and alpha power increased. To a lesser extent, a similar pattern was observed with the $500 \mathrm{mg}$ dosage. These reductions in slow-wave (delta) and increased fast wave (alpha) EEG activity is similar to the pharmaco-EEG profile commonly observed with acute nicotine administration (Domino, Ni, \& Thompson, 2009; Knott, Bosman, Mahoney, Ilivitsky, \& Quirt, 1999; Knott, 2001).

In the same sample discussed above, sensory gating indexed by the P50 ERP was measured in response to both doses of CDP-Choline (Knott et al., 2014). The findings support a varied effect for CDP-Choline based on baseline gating ability. Individuals participating in this study were stratified to either a low or high baseline gating ability subgroup based on their placebo P50 ratio scores. Curiously, low suppressors exhibited a reduced P50 ratio (i.e., improved gating) in response to the $1000 \mathrm{mg}$ dose of CDPCholine and to a lesser extent with the $500 \mathrm{mg}$ dose (Knott et al., 2014). CDP-Choline's effects on sensory gating were specifically mediated by the suppression of the P50 response to $\mathrm{S} 2$ with both the $1000 \mathrm{mg}$ dose and the $500 \mathrm{mg}$ dose. These findings bolster the possibility that CDP-Choline may offer promise in the treatment of sensory gating deficits but that these effects will be dependent on the individual's baseline sensory gating performance.

Finally, preliminary findings have suggested that administration of CDP-Choline can have a beneficial effect on cognition. In a sample of healthy volunteers acute effects of CDP-Choline were analyzed on a number of cognitive domains (i.e., processing speed, working memory, executive function, verbal learning, and memory) (Knott, de la Salle, Choueiry, et al., 2015). These neurocognitive processes have been shown to be generally 
deficient in SZ. The results of this study demonstrated a baseline performance and dosage dependent positive effect on processing speed, working memory, executive function, and verbal learning. Low baseline performers demonstrated a cognitive benefit associated with CDP-Choline administration. Conversely, participants demonstrating a medium or high baseline level of performance on cognitive tasks showed no benefit or in some cases (with high performers) performance impairment associated with administration. These results are line with previous findings demonstrating a distinct baseline dependent benefit associated nicotine administration. Further research has supported these findings. The Groton Maze Learning Task (Maruff et al., 2009) is used to measure executive function. Executive function has been demonstrated in the past to be sensitive to $\alpha 7$ receptor activation (Lieberman et al., 2013). As observed with the P50 indexed sensory gating, CDP-Choline's effects on performance with the Gorton Maze Learning Task was dependent on baseline performance. Low performers demonstrated an improved performance (i.e., reduced errors: the primary index of GMLT performance) in response to CDP-Choline.

\section{Study Objectives}

Altogether, the evidence supporting the role of $\alpha 7 \mathrm{nAChRs}$ in sensory gating deficits, the dysfunctional expression and regulation of these receptors in the schizophrenic brain, the preclinical and clinical evidence supporting the cognitive benefits of nicotine administration, the high prevalence of smoking amongst SZ patients, and the genetic evidence associating the $\alpha 7$ receptor gene as a risk factor for SZ, provide a solid foundation for research focusing on NAChR-targeted therapeutics for sensory and cognitive deficits associated with SZ (Buchanan \& Schwarcz, 2011; Hashimoto, Koike, 
et al., 2005; Kohlhaas et al., 2012; Leiser et al., 2009; Martin et al., 2004; Martin \& Freedman, 2007; Olincy \& Stevens, 2007; Toyohara \& Hashimoto, 2010). Evidence from studies utilizing neuroimaging techniques have supported the existence of reduced choline levels in both medicated and non-medicated SZ patients (Jessen et al., 2006; Lutkenhoff et al., 2010; Yoo et al., 2009). Lower levels of choline have also been observed in relatives of patients and at risk-individuals (Jessen et al., 2006; Lutkenhoff et al., 2010; Yoo et al., 2009). This suggests the possibility that irregular levels of choline in the brain may serve as a trait marker of SZ risk as well as a disease state marker.

CDP-choline's dose-dependent ability to activate $\alpha 7 \mathrm{nAChRs}$ offers a novel method of targeting the NAChR system in the hopes of improving sensory gating. Its low toxicity profile, safety for long-term use, and demonstrated benefit to cognitive performance support the possibility that it may be a suitable add-on treatment aimed at the alleviation of SZ associated sensory gating deficits. Though the early evidence bolsters this likelihood (Frazier et al., 1998; Knott et al., 2014; Knott, de la Salle, Choueiry, et al., 2015; Knott, de la Salle, Smith, et al., 2015; Knott, Impey, et al., 2015; Miller \& Freedman, 1995), further research is necessary given the variability in benefit demonstrated associated with the baseline gating performance of the individual. It is possible that, as observed in healthy volunteers, the benefits associated with CDPCholine in relation to sensory gating will only be observed in individuals demonstrating the most extreme S2 P50 amplitude suppression deficit.

In addition, the positive cognitive effects observed in the healthy brain associated with CDP-Choline administration and cognitive performance bolsters the possibility of seeing a mirrored effect in SZ patients. It is possible though that the beneficial effects 
may not be replicated in the diseased schizophrenic brain as varying circuits or neurotransmitter systems, possibly disrupted in the schizophrenic brain, may moderate the drug or dose effects (Barak \& Weiner, 2011). Though overall treatment effects are possible it is also the case that CDP-Choline's effects may be influenced by baseline sensory gating performance. The evaluation of both P50 indexed sensory gating and cognition afforded the present study the possibility of evaluating ratio P50 scores as a possible biomarker for the identification of individuals most likely to benefit from $\alpha 7$ nAChR activation.

Primary Objective. The P50-indexed sensory gating deficit is one of the most well researched phenomenon in SZ literature. It has been established as a translational endophenotype for SZ (Anokhin, Vedeniapin, Heath, Korzyukov, \& Boutros, 2007) and has been demonstrated to have a significant relationship with functional outcome. In addition, its pathology is closely related to the healthy function of the $\alpha 7 \mathrm{NAChR}$ system and $\alpha 7$ gene status. As such, the primary objective of this study was to examine the acute dose-dependent effects of CDP-choline administration, a selective $\alpha 7$ agonist, on P50 indexed sensory gating and whether it is moderated by baseline sensory gating ability.

Secondary Objective. Deficits related to sensory gating have consistently been linked to reduced performance on attentional tasks (Potter et al., 2006; Smith et al., 2010). In addition, CHRNA7, a gene responsible for $\alpha 7$ receptor expression, has been linked with working/episodic memory and executive function (Fernandes, Hoyle, Dempster, Schalkwyk, \& Collier, 2006). Each of these domains, (i.e., attention, working memory, executive function) have been shown to improve following administration of a NAChR agonist (Leiser et al., 2009) and specifically CDP-Choline in healthy volunteers. 
In light of this, the secondary objective of this study was to analyze the dose-dependent effects of CDP-choline on performance on seven cognitive domain tasks characteristically deficient in SZ. The evaluation of trait biomarkers for the identification of patients who will best respond to particular treatments increases the efficacy of treating the disorder. Therefore, in addition to analyzing the overall treatment effects of CDP-Choline on cognition we stratified our sample into subgroups based on their level of suppression (i.e., Normal Suppressors vs. Deficient Suppressors) in an effort to assess the use of ratio P50 scores as a biomarker for identifying SZ subgroups most likely to show treatment benefits associated with cognitive performance.

\section{Hypotheses}

Primary Hypotheses. CDP-choline's effect on $\alpha 7$ receptor activity has been shown in previous research to be dose-dependent. More sustained receptor activation has been observed with lower rather than higher choline levels. Thus we expect to see increased auditory gating (indexed by decreased P50 ratios and increased P50 difference scores) with smaller does of CDP-choline $(<2000 \mathrm{mg})$ and null or detrimental effects with the higher dose $(2000 \mathrm{mg})$. Previous research has shown that these beneficial effects are dependent on baseline sensory gating performance with deficient suppressors showing improvements and normal suppressors showing null or detrimental effects. Therefore, we hypothesize that any beneficial effects observed in response to CDPCholine will be specific to the patients exhibiting a clear sensory gating deficit.

Secondary Hypotheses. CDP-choline's effects on cognition will mirror those on sensory gating. Changes in cognitive performance will be dose and baseline sensory gating dependent with enhanced performance related to smaller doses of CDP-Choline (< 
$2000 \mathrm{mg}$ ) and null or detrimental effects associated with the higher dose (2000 mg). Also, given the association between sensory gating and attention, executive function, and working memory we hypothesize individuals demonstrating reduced sensory gating will demonstrate the greatest improvement in cognitive performance.

\section{Method}

\section{Participants}

Using $\mathrm{G}^{*}$ power (version 3.0.9, 2008) software, power analysis determined that to obtain a power of $80 \%$ a total sample of 22 was required to detect significant drug effects. This is assuming a substantial within-subject correlation of 0.5 and a modest effect size $(f=0.25)$. This sample is similar to previous pharmacogenetic studies which have shown effects with total samples as small as $\mathrm{N}=18$. As dropout rates in these repeated measures, acute dose (singe dose) studies with patients in our lab are $\sim 10 \%$, I attempted to recruit a total sample of 24 patients. This sample size is generally consistent with human EEG psychopharmacological challenge studies in healthy populations. In the end, a sample of 23 patients was recruited for this study from the SZ Outpatient Program at the Royal Ottawa Mental Health Centre. Three participants dropped out of the study before completing the 4 sessions leaving the final sample size at 20. Both males $(n=18)$ and females $(n=2)$ between the ages of $18-65$ were recruited. The mean age of the final sample was 42.85 ( $S E \pm 2.72)$. All participants reported normal hearing, normal or corrected to normal vision, and were right-handed. Smokers and non-smokers were recruited with non-smoker being defined as those reporting having smoked less than 100 cigarettes in their lifetime and no cigarette use over the past year. 
For study participation, patients were required to meet the criteria outlined in the DSM-5 for the diagnosis of SZ, be clinically stable over the past 3 months, as assessed by Dr. Alain Labelle director of the Royal Ottawa SZ Outpatient Program with the Positive and Negative Symptom Scale (PANSS; see Appendix A), and have no changes in medication dosage in the preceding 4 weeks. The Structured Clinical Interview for DSM Disorders Clinical Version (SCID-CV, see Appendix B) was used to evaluate SZ diagnosis (First, Spitzer, Gibbon, \& Browne, 1996) while the PANSS (Kay \& Fiszbein, 1987) was used to assess clinical symptoms. Patients were excluded if they meet the diagnosis requirements for a disorder other than SZ. This included a current or recent history of alcohol or substance abuse. Patients were also excluded if they demonstrated clinically significant medical illness (based on medical history), a recent head injury with loss of consciousness ( $<6$ months), a major learning disability, and/or a hearing impairment (audiometrically assessed at $100 \mathrm{~Hz}, 500 \mathrm{~Hz}$, and $1000 \mathrm{~Hz}$; all of the above were verified using an inclusion/exclusion criteria questionnaire; see Appendix C).

All participants were required to sign an informed consent form (see Appendix D) prior to participation in the study, which was approved to the Research Ethics board of Carleton University and the Research Ethics Board of the Royal Ottawa Mental Health Center. Patients received $\$ 25.00$ (CAD) for completion of the screening session and $\$ 50.00$ (CAD) for each completed treatment session, totaling \$225.00 (CAD) for completion of the whole study.

\section{Study Design}

Participants completed four test sessions and one screening session. The test sessions were organized in a randomized, double-blind, placebo-controlled, cross-over 
design. A placebo and three doses of CDP-Choline (500 mg, 1000, mg, $2000 \mathrm{mg}$ ) were administered using a Latin Square design (4 randomization orders, with 6 participants per order in each group) allowing for the identification of any potential order effects. Test sessions were separated by a minimum of 7 days to allow for washout. This accommodated the relatively long half-life of CDP-Choline ( $\sim 3.0 \mathrm{hrs})$.

The rationale for using a within-subjects design versus a between-subjects design included reduction of variance attributable to between-subject effects, increased sensitivity to detect treatment effects, and reduced sample size requirements. The possible negative consequences of this type of design included practice effects, carryover, and order effects. We controlled for these issues by alternating the versions of cognitive assessment material used (CogState Schizophrenia Battery (CSB)), adhering to an appropriate inter-condition washout period, and randomizing the order of drug administration.

\section{Drug}

CDP-Choline. CDP-Choline was administered to participants orally in three doses: $500 \mathrm{mg}(1 \times 500 \mathrm{mg}), 1000 \mathrm{mg}(2 \times 500 \mathrm{mg})$, and $2000 \mathrm{mg}$ (4 x $500 \mathrm{mg})$. In previous studies clinically effective CDP-Choline has been administered orally and by injection with doses ranging from 500 to $4000 \mathrm{mg} /$ day. Generally efficacy has not substantially improved beyond 2000 mg/day (Agut, Font, Sacristán, \& Ortiz, 1983). When it is administered orally, it is absorbed almost completely with bioavailability being $92-94 \%$ and approximately the same as when administered intravenously (Agut et al., 1983). Plasma CDP-Choline doses peak Tmax at 3 - 5 hrs (Wurtman et al., 2000). In studies with CDP-Choline administered over 12 months, it showed excellent tolerability 
and safety with few transient (never severe) adverse effects (e.g., stomach pain, diarrhea) (Conant \& Schauss, 2004; Fioravanti \& Buckley, 2006; Saver, 2008).

Placebo. Placebo (cellulose) was contained in capsules matched physically to the active drug capsules. A “double dummy" procedure was utilized with participants given 4 capsules at each session so that both participants and the experimenters remained blind (e.g., 3 placebo capsules and 1 x $500 \mathrm{mg}$ capsules will be given during the $500 \mathrm{mg}$ CDP Choline test sessions).

In order to maintain the double-blind, a research assistant from the Clinical Electrophysiology and Cognitive Research Laboratory at the Royal Ottawa Mental Health Center prepared all medications (packaging the drugs and completing the randomization). A second research assistant ran all testing sessions and dispense the medication to the patients.

\section{Study Procedure}

Screening Session. The session was conducted in the morning (beginning between 9:00 am - 11:00 am) and took $\sim 2$ hours for completion. Participants were required to abstain from drugs, medications (except those prescribed by their psychiatrist and/or physician), alcohol, caffeine, cigarettes, and food beginning at midnight of the previous day. Once patients arrived at the lab for their screening session, following procurement of informed consent, they completed an audiometric assessment, inclusion/exclusion criteria questionnaire, and the Psychotic Symptoms Rating Scales (PSYRATS; see Appendix E) (Haddock, McCarron, Tarrier, \& Faragher, 1999). Following this, EEG electrodes were applied. This session was used to expose the participants to the ERP paradigm. Recordings were conducted in a dimly lit, sound- 
attenuated chamber. Participants were seated in a comfortable chair facing a computer monitor. During this session the participant was given a practice run on the cognitive test battery to reduce novelty effects. A lap desk was placed in front of them with a computer mouse. Instructions for each test were visually displayed on the computer screen as well as read out loud by the experimenter. Participants were instructed to make their responses as quickly and as accurately as possible.

Test Sessions. Test sessions followed a similar procedure. Patients were required to abstain from drugs, medications (expect those prescribed by their psychiatrist and/or physician), alcohol, caffeine, cigarettes, and food beginning at midnight of the previous day. Once the patient arrived at the lab for the test session, they were given the randomized, double blind dose assigned to that session. Three hours were allowed for the dose to reach blood level (Tmax). During this time the patient was allowed to watch a movie and relax in the laboratory. Shortly before Tmax was reached EEG electrodes were applied. Afterwards, the test session began and P50 data was collected. During the completion of the P50 paradigm patients were instructed to view a muted movie with subtitles and to ignore the auditory stimuli presented. Afterwards, cognitive testing was conducted using the CSB.. At the end of each test session, vital signs were assessed and a physical symptoms checklist was completed to assess adverse events (see Appendix F). No participants demonstrated any adverse events in response to CDP-Choline administration.

\section{Task Stimuli}

P50 Paradigm. P50 task stimuli were presented according to previously published methodology (Buchanan et al., 2011; Knott et al., 2011, 2010a). Testing was 
completed in a closed sound-attenuated chamber. Patients sat upright in a comfortable position with their eyes open. They were instructed to remain as still as possible with a pair of headphones covering their ears. Once the patient was prepared, the paradigm began. During the completion of this paradigm patients were instructed to view a muted movie with subtitles and to ignore the auditory stimuli being presented through the headphones to the best of their abilities. The P50 paradigm consisted of 96 paired clicks inline with the necessary number of trials to insure significant reliability of P50 measures. The first click was denoted as S1 and the second was denoted as S2. Clicks were presented binaurally through headphones with intensity levels at $80 \mathrm{~dB}$, inter-click interval at $500 \mathrm{~ms}$, and inter-pair intervals at $10 \mathrm{~s}$.

CogState Schizophrenia Battery. Cognition was evaluated with computerized tests using the CSB. This battery of tests measures the 7 cognitive domains (i.e., processing speed, attention, working memory, visual learning, verbal learning, problem solving, and social cognition). The test paradigms used are the Identification Task (visual attention), the Detection Task (processing speed), the Groton Maze Learning Task (executive function), the International Shopping List Task (verbal learning \& memory), the One Back Task (attention/working memory), the Two Back Task (attention/working memory), and the Social-Emotional Cognition Task (social cognition). Use of the CSB for the measurement of cognitive domains nominated by the MATRICS project as the main targets for treatment development has been validated in a comparisons study (Lees et al., 2015). Medium to large correlations have been demonstrated between the CogState and MATRICS on measures of processing speed, attention, working memory, verbal learning, visual learning, problems solving, and social cognition (Lees et al., 2015; 
Pietrzak et al., 2009). CogState test-retest reliability was also established though an initial practice session is suggested to ameliorate any practice effects (Lees et al., 2015).

\section{ERP Recordings}

ERPs were derived with $\mathrm{Ag}^{+} / \mathrm{AgCl}$ electrodes placed at 16 scalp sites $\left(\mathrm{F}_{1}, \mathrm{~F}_{2}, \mathrm{~F}_{\mathrm{z}}\right.$, $\mathrm{C}_{1}, \mathrm{C}_{2}, \mathrm{C}_{\mathrm{z}}, \mathrm{P}_{1}, \mathrm{P}_{2}, \mathrm{P}_{\mathrm{z}}, \mathrm{O}_{1}, \mathrm{O}_{2}, \mathrm{O}_{\mathrm{z}}$, Mastoid $_{1}$, Mastoid $_{2}$ ) referenced to the nose site. Additional electro-oculograph electrodes were placed around the orbital regions to monitor horizontal and vertical eye movements. All recordings were carefully monitored to verify that electrical impedances were maintained below $5 \mathrm{~K}$ ohm. All recordings were obtained using a Brain Vision V-Amp ${ }^{\circledR}$ amplifier and analyzed offline with Brain Vision Recorder $^{\circledR}$ software (Brain Products GmbH, Munich, Germany) as described in previous established research (Boutros et al., 2004). Bandpass filter setting for amplifiers were set to $0.1-100 \mathrm{~Hz}$ and digital sampling was $500 \mathrm{~Hz}$.

Epochs were segmented (150 ms total, $50 \mathrm{~ms}$ pre-stimulus onset). From these, P50 amplitudes were identified using a semi-automatic procedure. P50 peaks were identified as the second of two positive peaks in the post-stimulus latency range of $15-$ $80 \mathrm{~ms}$ as well as proceeding an earlier positive peak in the $15-40 \mathrm{~ms}$ range. The $\mathrm{C}_{\mathrm{z}}$ scalp site was used primarily as it has been shown to be the best indicator of gating (Clementz, Blumenfeld, \& Cobb, 1997) though other central scalp sites $\left(\mathrm{C}_{3}\right.$ or $\left.\mathrm{C}_{4}\right)$ were used to verify P50 peak location. Further processing applied to the data included filtering $(10-50 \mu \mathrm{V})$, ocular correction, artifact rejection and baseline correction. Selective averaging of the epochs was conducted for the creation of grand average waveforms. S2 P50 response suppression was measured relative to S1 P50 amplitude using 2 methods: gating ratios (rP50: S2 P50/ S1 P50) and difference scores (dP50: S1 P50 - S2 P50). P50 
amplitudes, used to calculate ratio P50 scores, were measured relative to the participant's pre-stimulus baseline. Peak to baseline measurements were utilized opposed to peak to trough measurements due to its associated greater reliability (Dalecki, 2015).

\section{Other Measures}

In addition to all of the above-mentioned paradigms and questionnaires, blood pressure, heart rate, and self-reported adverse events were collected at the end of each session.

\section{Statistical Analysis}

All statistical analyses were performed using the Statistical Package for the Social Sciences software (SPSS, IBM Corporation). P50 endpoint measures were subjected to separate repeated-measures analysis of variance (ANOVA) with drug dosage (4 levels) as a within-subject factor. Planned comparisons were applied to reveal treatment effects relative to the placebo session. Additional ANOVAs were performed on measures related to the P50 ERP (i.e., S1 amplitude, S2 amplitude, S1 latency, and S2 latency). Given previous findings suggesting that CDP-Choline may exert baseline gating dependent effects and the variable nature of the symptomology of SZ, our sample was also stratified into two groups based on their baseline suppression. Using the rP50 scores (S2/S1) from the participant's placebo session, the sample was stratified into two subgroups consisting of those participants demonstrating an rP50 score within the range commonly attributed to healthy individuals $(\mathrm{n}=14)$ and those demonstrating an rP50 score indicative of deficient suppression $(n=6)$. Previous research has indicated a strong association between dP50 scores and the S1 P50 amplitude while rP50 scores show a stronger association with the S2 P50 amplitude (Chang, Arfken, Sangal, \& Boutros, 2011). As the 
primary purpose of this study is the analysis of sensory gating changes measured by S2 P50 suppression, rP50 scores opposed to dP50 scores were used to stratify the sample. In a meta analysis analyzing rP50 characteristics in normal controls and schizophrenia patients mean rP50 scores were calculated using date from 84 studies (Patterson et al., 2008). Mean p50 scores for the schizophrenia samples reported in this study ranged from $.56-1.58(M=.79, S D=.24)$ while the mean rP50 scores for normal controls ranged from $.09-.73(M=.38, S D=.15)$. In line with these mean rP50 scores for the creation of suppression subgroups normal suppression was defined as a rP50 score below .70 and deficient suppression was defined as a rP50 score above .70. This cutoff is clinically relevant as it falls within 1 SD of the mean rP50 score attributed to schizophrenia patients and therefore is indicative of a sensory gating deficit. Each subgroup's normally distributed suppression measures (i.e., rP50 \& dP50) and P50 measures (i.e., S1 amplitude, S2 amplitude, S1 latency, and S2 latency) were analyzed using a mixed design ANOVA. The between group factor was the baseline gating subgroups ( 2 levels: normal suppressors, deficient suppressors; based on rP0 placebo session scores) and the within subject factor consisted of the drug dosage (4 levels: Placebo, 500 mg, 1000 mg, 2000 $\mathrm{mg})$.

All cognition data was uploaded to the CogState server. Outcome data for each cognitive task was calculated using the CogState custom software. All experimenters maintained the blind to the dose being administered at each test session throughout this process. CogState has identified primary outcome measures that optimally detect changes in cognitive performance in clinical trials. These measures, identified as primary measures, were used for the statistical analysis. Primary measures for each task are as 
follows: Identification Task - log10 transformed average reaction speed, Detection Task - $\log 10$ transformed average reaction time, Groton Maze Learning Task - total errors, International Shopping List Task - Total correct responses, One Back Task - arcsine proportion of the correct responses, Two Back Task - arcsine proportion of the correct response, Social Emotional Cognition Task - arcsine square root of the proportion of correct responses. Acute effects of CDP-Choline on cognitive performance were also analyzed in separate repeated-measures ANOVAs with drug (4 levels) as a within-subject factor. Planned comparisons were applied to analyze any significant treatment effects relative to placebo. To explore possible baseline gating dependent effects a mixed design ANOVA was conduced with the sample stratified by rP50 scores into normal suppressors and deficient suppressors. The between group factor again was the baseline gating subgroup (2 levels: normal suppressors, deficient suppressors) and the within subject factor consisted of the drug dosage (4 levels: Placebo, $500 \mathrm{mg}, 1000 \mathrm{mg}, 2000 \mathrm{mg}$ ). Finally, to explore possible relationships between changes in P50 indexed sensory gating performance and changes in cognitive domain performance, correlation analyses were conducted. Difference scores relative to placebo for each treatment level were calculated and analyzed using the Pearson correlation coefficient. Similar mixed ANOVAs were used to analyze blood pressure, heart rate, and adverse events data.

\section{Results}

\section{Vital Signs and Adverse Events}

No main, between group, or interaction effects were observed related to blood pressure and heart rate measures. No participants demonstrated serious adverse reactions to the doses of CDP-Choline. No patients were unable to complete a test session due to 
adverse events associated with the treatments. No significant treatment or interaction effects were observed in relation to the self-reported adverse events data.

\section{Demographic and Psychometric Measures}

Table 1 contains the average age, GAF, PANSS score (positive scale, negative scale, general psychopathology scale, and total score), and PSYRATS score of the sample as a whole and divided between the suppression subgroups. No significant differences between the groups were observed in relation to the above measures. A Pearson chi square analysis demonstrated that our two suppression subgroups did not differ significantly in smoking status or treatment with either a first or second-generation antipsychotic.

Table 1. Mean $( \pm S E)$ Demographic and Psychometric Scores for Whole Sample and Stratified as Normal Suppressors and Deficient Suppressors

\begin{tabular}{clccc}
\hline & & Total & Normal & Deficient \\
& & Sample & Suppressors & Suppressors \\
\cline { 2 - 4 } Demographic & Age & $42.85(2.73)$ & $42.00(3.74)$ & $44.83(2.90)$ \\
$\&$ & GAF & $51.25(3.06)$ & $51.07(2.85)$ & $51.67(8.33)$ \\
Psychometric & Positive Scale & $12.75(.91)$ & $13.50(1.04)$ & $11.00(1.71)$ \\
Measures & Negative Scale & $13.20(.91)$ & $12.93(1.01)$ & $13.83(2.02)$ \\
& General Scale & $25.30(1.08)$ & $25.50(1.25)$ & $24.83(2.33)$ \\
& PSYRATS & $13.25(3.07)$ & $13.71(3.41)$ & $12(6.97)$ \\
\hline
\end{tabular}

Note. The Positive Scale, Negative Scale, and General Scale are all subscales of the PANSS; GAF: General Assessment of Function; PANSS: Positive and Negative Symptom Scale; PSYRATS: Psychotic Symptom Rating Scale

\section{CDP-Choline Effects on Sensory Gating}

Grand average placebo session S1 and S2 P50 ERP waveforms representing the whole sample and each subgroup (i.e., normal suppressors \& deficient suppressors) are 
shown in Figure 2. Mean $( \pm S E)$ gating indices (rP50 and dP50), and stimuli amplitude (S1 and S2) for each subgroup at each CDP-Choline dose are displayed in Table
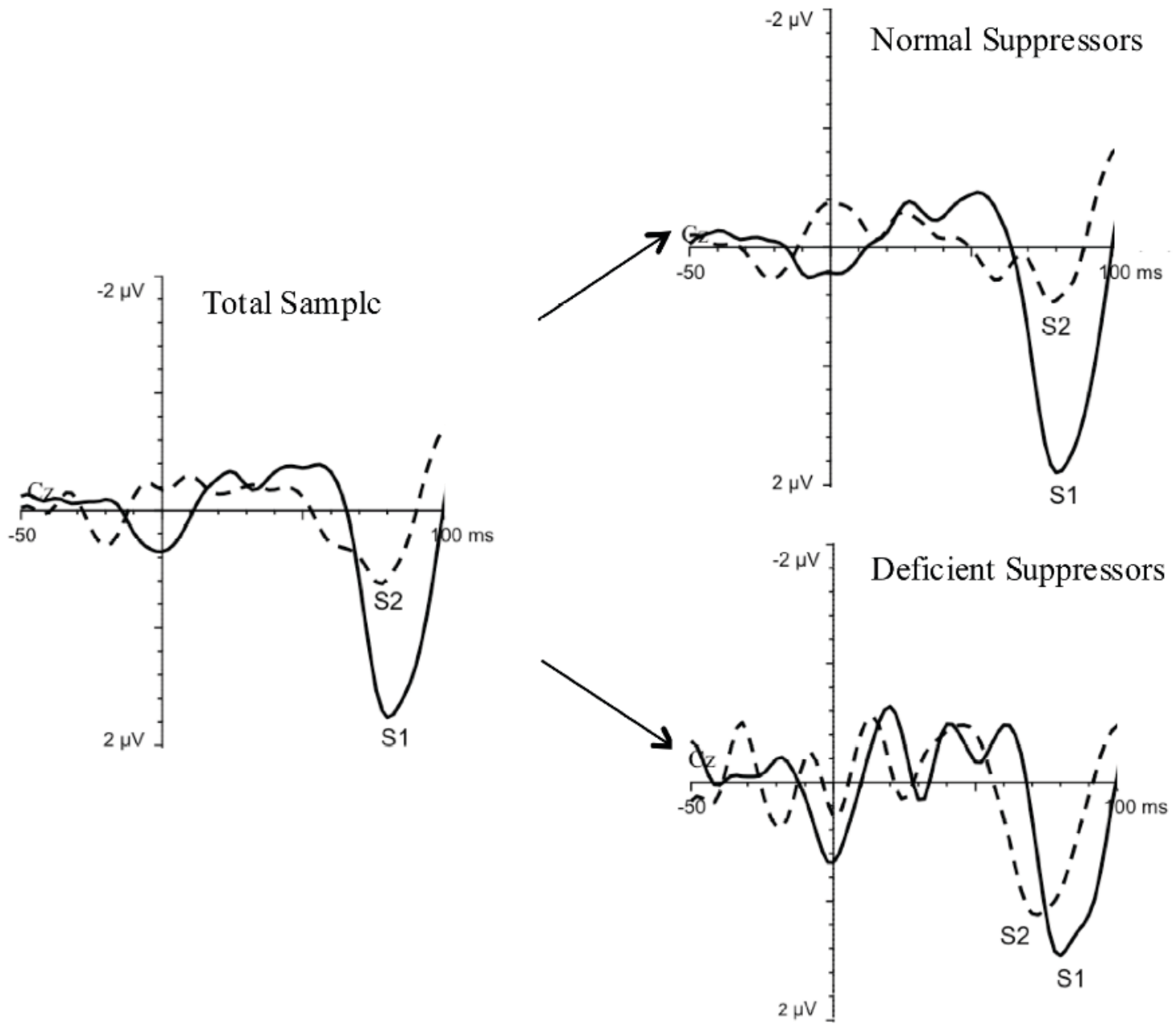

Figure 2. Grand average waveforms representing P50 response to S1 and S2 during placebo session for the total sample of participants and for each gating stratification group (i.e., normal suppressors and deficient suppressor). The mean P50 response to S2 in the deficient suppressor group failed to be significantly greater than the P50 response to $\mathrm{S} 2$ in the normal suppressor group $(p=.052)$. 
Table 2. Mean $( \pm S E)$ Suppression Measures and Stimulus Measures at each CDPCholine dose for Total Sample and Stratified as Normal Suppressors and Deficient Suppressors Based on Placebo rP50 Scores.

\begin{tabular}{lcccc}
\hline & \multicolumn{4}{c}{ Total Sample } \\
\hline rP50 & Placebo & $500 \mathrm{mg}$ & $1000 \mathrm{mg}$ & $2000 \mathrm{mg}$ \\
dP50 $(\mu \mathrm{V})$ & $.50(.06)$ & $.51(.08)$ & $.47(.12)$ & $.66(.11)$ \\
S1 Amplitude $(\mu \mathrm{V})$ & $1.36(.25)$ & $1.26(.26)$ & $1.35(.28)$ & $.89(.27)$ \\
S2 Amplitude $(\mu \mathrm{V})$ & $2.57(.33)$ & $2.47(.31)$ & $2.60(.32)$ & $2.08(.29)$ \\
& $1.22(.19)$ & $1.22(.20)$ & $1.24(.17)$ & $1.19(.16)$ \\
\hline rP50 & \multicolumn{4}{c}{ Normal Suppressors } \\
dP50 $(\mu \mathrm{V})$ & $.35(.05)$ & $.59(.08)$ & $.49(.09)$ & $.61(.16)$ \\
S1 Amplitude $(\mu \mathrm{V})$ & $1.79(.28)$ & $1.05(.27)$ & $1.50(.34)$ & $1.00(.37)$ \\
S2 Amplitude $(\mu \mathrm{V})$ & $2.76(.44)$ & $2.39(.38)$ & $2.63(.38)$ & $1.98(.40)$ \\
& $.97(.23)$ & $1.34(.25)$ & $1.13(.18)$ & $.98(.19)$ \\
\hline rP50 & \multicolumn{4}{c}{ Deficient Suppressors } \\
dP50 $(\mu \mathrm{V})$ & $.86(.06)$ & $.34(.17)$ & $.42(.38)$ & $.77(.12)$ \\
S1 Amplitude $(\mu \mathrm{V})$ & $.35(.15)$ & $1.75(.56)$ & $.99(.52)$ & $.64(.28)$ \\
S2 Amplitude $(\mu \mathrm{V})$ & $2.13(.31)$ & $2.66(.51)$ & $2.49(.64)$ & $2.30(.30)$ \\
\hline Note. rP50: ratio P50 & scores $(\mathrm{S} 2 / \mathrm{S} 1) ; \mathrm{dP} 50:$ difference P50 scores $(\mathrm{S} 1-\mathrm{S} 2)$. \\
\end{tabular}

P50 Suppression: Total Sample. Analysis of the main treatment effects for the whole sample did not yield a significant effect. Planned comparisons were still analyzed. No significant differences where observed between the drug doses whether suppression was measures by ratio P50 scores or difference P50 scores.

P50 Suppression: Stratified Sample. Significant group effects were observed, as expected with our intentional stratification method, between the normal suppressors and deficient suppressors using both rP50 scores $(F(1,18)=34.41, p<.001)$ and dP50 scores $(F(1,18)=10.34, p=.005)$ during placebo session. Figure 3 below displays the mean P50 ratio and difference scores for each suppressor group and drug dose. Suppression was shown to be significantly greater in the normal suppressor group (rP50: $M=.35, S D$ 
$=.19, \mathrm{dP} 50: M=1.79 \mu \mathrm{V}, S D=1.06)$ compared to the deficient suppressor group (rP50:

$M=.86, S D=.14, \mathrm{dP} 50: M=.35 \mu \mathrm{V}, S D=.37$ ) for both sensory gating measures.

Treatment effects in relation to rP50 scores demonstrated variation based on suppression subgroup. Deficient suppressors exhibited a significant $(p=.008)$ decrease in rP50 scores (improved sensory gating) in response to the $500 \mathrm{mg}$ dose of CDP-Choline (placebo: $M=.86, S D=.14 ; 500 \mathrm{mg}$ CDP-choline: $M=.34, S D=.41$ ). The deficient suppressor group's rP50 scores in response to the $1000 \mathrm{mg}$ dose also showed gating improvement $(M=.42, S D=.94)$ but did not reach significance $(p=.095)$.

Treatment effects when using dP50 scores demonstrated a similar baseline sensory gating dependent effect. The deficient suppressor group showed a significant increase ( $p=.021)$ in $\mathrm{dP} 50$ scores (improved sensory gating) in response to the $500 \mathrm{mg}$ dose (placebo: $M=.35 \mu \mathrm{V}, S D=.37 ; 500 \mathrm{mg}$ CDP-choline: $M=1.75 \mu \mathrm{V}, S D=1.38$ ). The normal suppressor group demonstrated a significant $(p=.007)$ reduction of dP50 scores (decreased sensory gating) in response to the $2000 \mathrm{mg}$ dose of CDP-Choline $(M=$ $1.00 \mu \mathrm{V}, S D=1.37)$. 

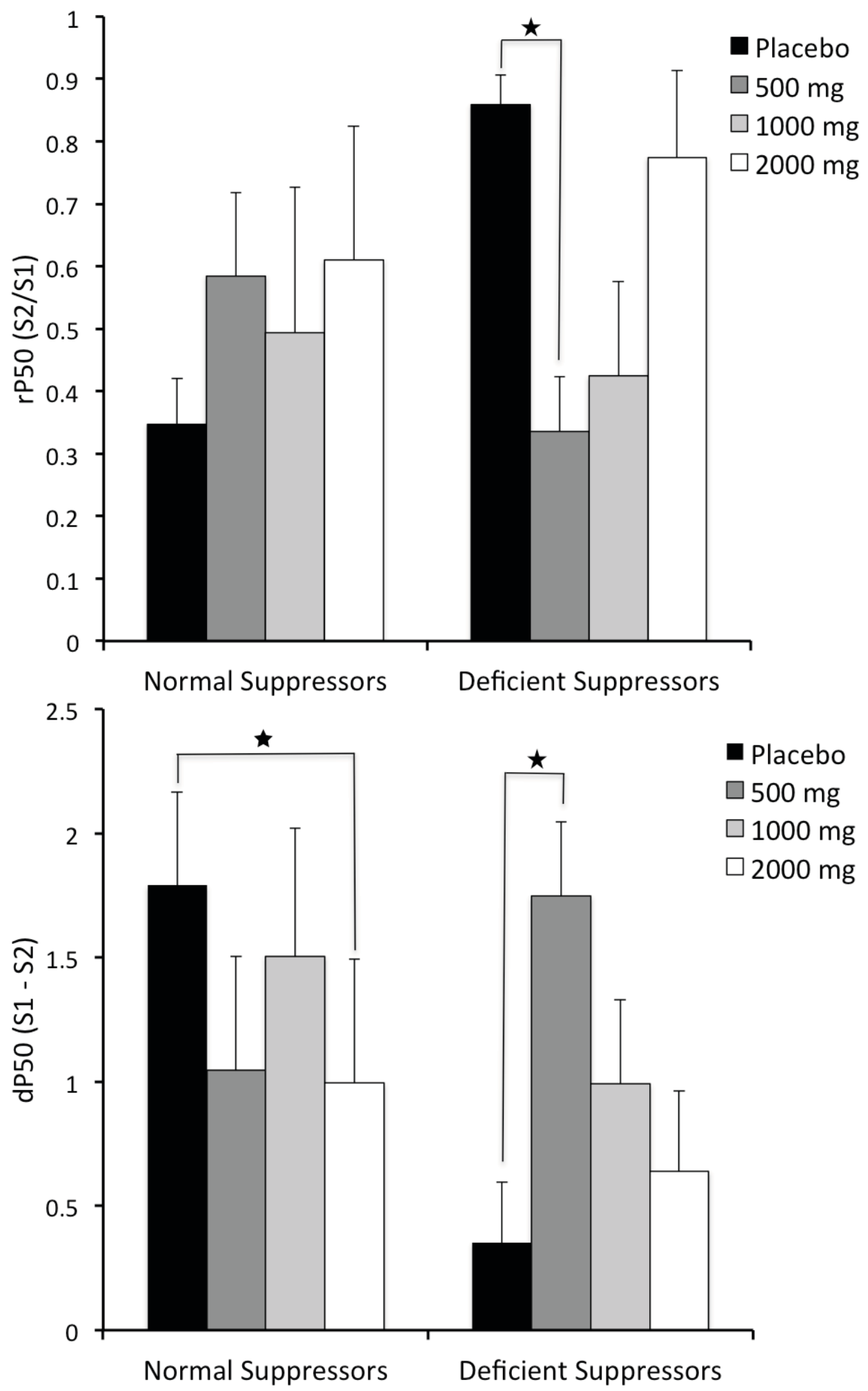

Figure 3. Mean $( \pm S E)$ P50 ratio $(\mathrm{S} 2 / \mathrm{S} 1)$ and difference $(\mathrm{S} 1-\mathrm{S} 2)$ scores recorded at the $\mathrm{C}_{\mathrm{z}}$ scalp site for both suppressor groups in response to each CDP-Choline dose. ${ }^{*} p<$ 0.05 . 
P50 Amplitude: Total Sample. Analysis of main effects for the total sample did not demonstrate a significant main treatment effect. Planned comparisons were carried out. No significant treatment effects were observed for either the S1 or the S2 P50 amplitude

P50 Amplitude: Stratified Sample. Grand average waveforms representing the significant treatment effects on stimulus P50 amplitudes within each suppression subgroup are in Figure 4. No significant differences were observed between the suppressor groups in relation to S1 P50 amplitude at the placebo session while both groups came close to demonstrating a significant difference $(F(1,18)=4.31, \mathrm{p}=.052$; Normal Suppressor group, $\mathrm{M}=.97 \mu \mathrm{V}, \mathrm{SD}=.87$; Deficient Suppressor Group, $\mathrm{M}=1.78$ $\mu \mathrm{V}, \mathrm{SD}=.58)$ from one another in relation to $\mathrm{S} 2 \mathrm{P} 50$ amplitude at the placebo session though it did not reach significance. Significant drug effects related to S1 P50 amplitude were only observed in the normal suppressor group. When compared to placebo, the 2000 $\mathrm{mg}$ dose of CDP-Choline significantly $(\mathrm{p}=.002)$ reduced S1 P50 amplitude (Placebo: $M$ $=2.76 \mu \mathrm{V}, S D=1.67,2000 \mathrm{mg}$ CDP-Choline: $M=2.39 \mu \mathrm{V}, S D=1.45$; see Figure 4). No significant effects were observed in the deficient suppressor group in relation to S1 P50 amplitude. Drug effects related to S2 P50 amplitude were observed in both suppressor groups. The deficient suppressor group demonstrated a significant $(\mathrm{p}=.016)$ reduction in S2 P50 amplitude when compared to placebo in response to the $500 \mathrm{mg}$ dose of CDP-Choline (Placebo: $M=1.78 \mu \mathrm{V}, S D=.58,500 \mathrm{mg}$ CDP-Choline: $M=.91 \mu \mathrm{V}$, $S D=.73$; see Figure 5).

P50 Latency. Statistical analysis of S1 and S2 P50 latencies did not result in any significant effects associated with stimulus, group, drug dosage, or interaction. 


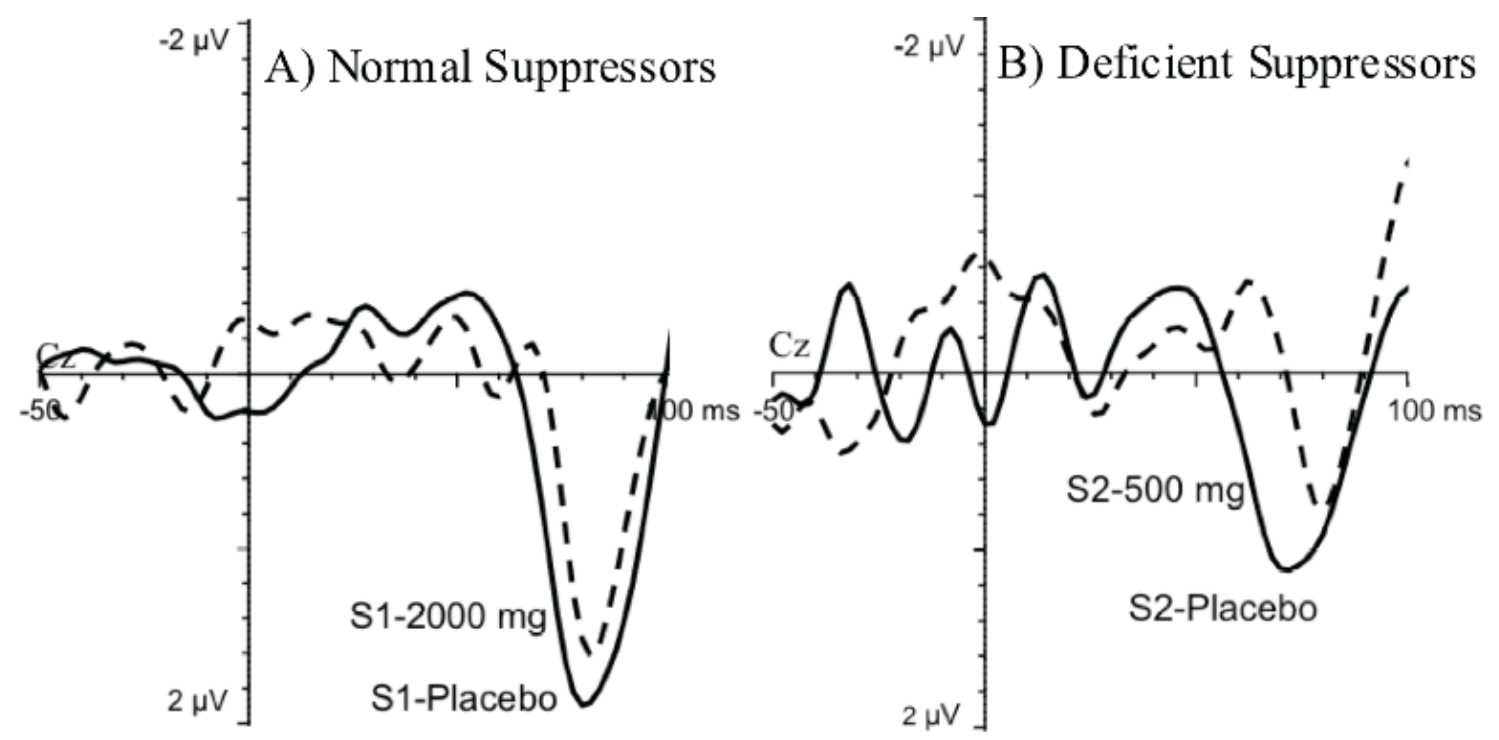

Figure 4. A) Grand average waveform representing the P50 amplitude difference in response to S1 for the normal suppressor group during their placebo and $2000 \mathrm{mg}$ CDPCholine session. The $2000 \mathrm{mg}$ dose of CDP-choline significantly reduced S1 amplitude compared to placebo $(p=.002)$. B) Grand average waveform representing the P50 amplitude difference in response to S2 for the deficient suppressor group during their placebo and $500 \mathrm{mg}$ CDP-Choline session. The $500 \mathrm{mg}$ dose of CDP-Choline significantly reduced the S2 amplitude compared to placebo $(p=.016)$. 

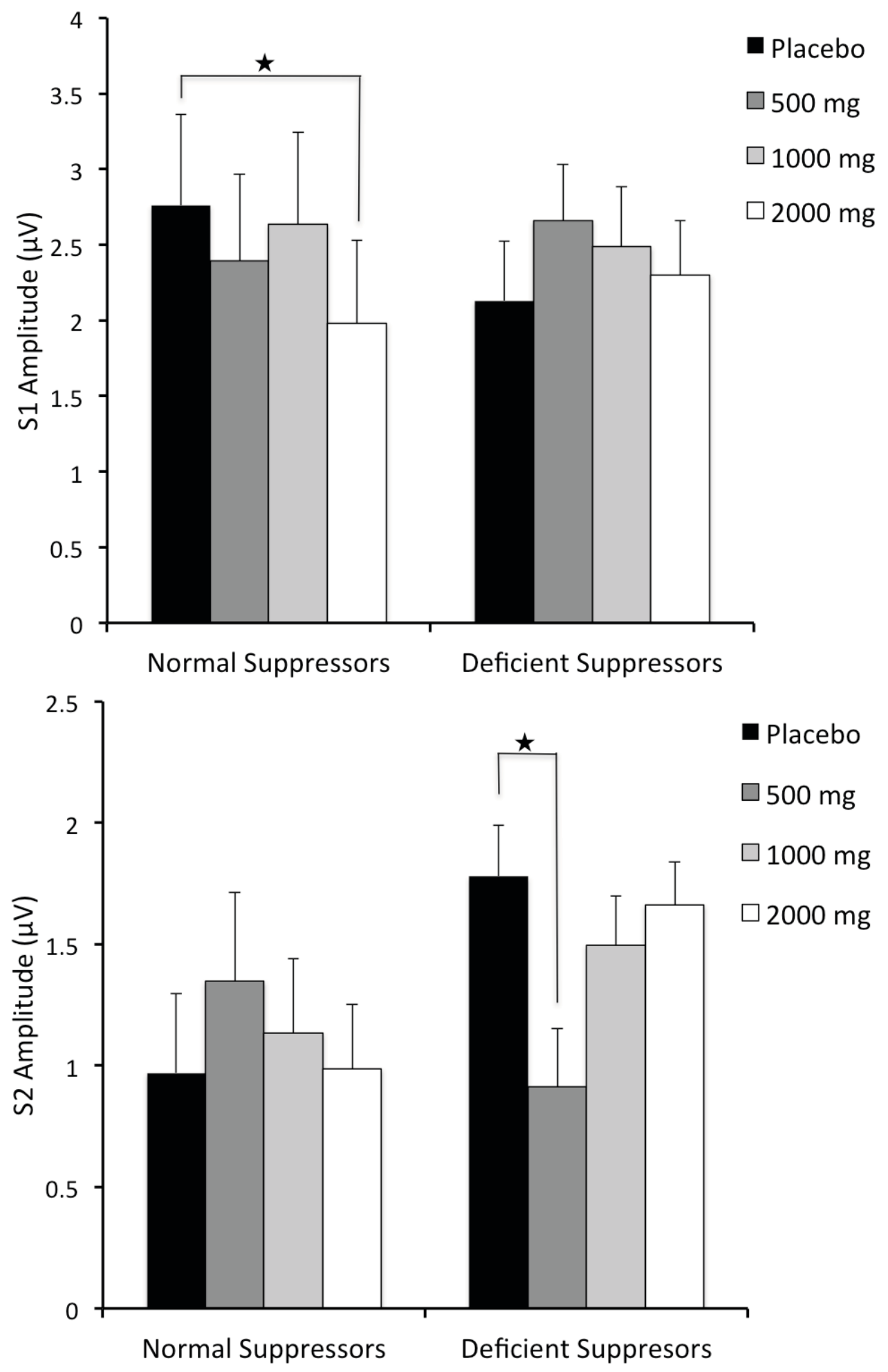

Figure 5. Mean $( \pm \mathrm{SE})$ stimulus amplitude $(\mathrm{S} 1$ and $\mathrm{S} 2)$ scores recorded at the $\mathrm{C}_{\mathrm{z}} \mathrm{scalp}$ site for both suppressor groups in response to each CDP-Choline treatment dose $* p<$ 0.05 


\section{CDP-Choline Effects on Cognition}

Mean $( \pm S E)$ scores for CogState cognitive measures for each treatment level are in Table 3.

Cognition: Total Sample. Main effect analysis for each cognitive measure did not demonstrate any significant results. Planned comparisons were carried out. No significant treatment effects for each drug dose level relative to placebo were observed in relation to any of the cognitive measures.

Cognition: Stratified Sample. Analysis of cognitive measures demonstrated a baseline dependent effect with the normal suppressor group demonstrating treatment effects. Cognitive measures were not systematically different between the suppressor groups during the placebo session. A significant $(p=.049)$ decrease in performance was observed between the $2000 \mathrm{mg}$ dose session and the placebo session in the normal suppressor group's performance on the identification task measure of attention (Placebo: $M=2.72, S D=.08 ; 2000 \mathrm{mg}$ CDP-Choline: $M=2.74, S D=.08)$. A significant effect was also observed in relation to the one back measure of working memory in the normal suppressor group. The $1000 \mathrm{mg}$ dose of CDP-Choline was shown to significantly $(\mathrm{p}=$ .043 ) decrease performance in the normal suppressor group (Placebo: $M=1.22, S D=$ .16 ; $1000 \mathrm{mg}$ CDP-Choline: $M=1.13, S D=.25)$. No other significant effects were observed. 
Table 3. Mean $( \pm S E)$ CogState Test Scores at Each CDP-Choline Dose for Total Sample and Stratified as Normal Suppressors and Deficient Suppressors Based on Placebo rP50 Scores.

\begin{tabular}{|c|c|c|c|c|}
\hline & \multicolumn{4}{|c|}{ Total Sample } \\
\hline & Placebo & $500 \mathrm{mg}$ & $1000 \mathrm{mg}$ & $2000 \mathrm{mg}$ \\
\hline Identification Task & $2.73(.02)$ & $2.73(.02)$ & $2.73(.02)$ & $2.75(.02)$ \\
\hline Detection Task & $2.55(.03)$ & $2.56(.03)$ & $2.59(.03)$ & $2.58(.03)$ \\
\hline Groton Maze & $67.24(6.95)$ & $73.94(7.69)$ & $70.94(6.72)$ & $69.88(8.78)$ \\
\hline \multicolumn{5}{|l|}{ Learning } \\
\hline Shopping List Task & $30.00(18.35)$ & $19.53(1.47)$ & $18.00(1.32)$ & $17.52(1.55)$ \\
\hline One Back Task & $1.21(.04)$ & $1.21(.05)$ & $1.15(.05)$ & $1.23(.05)$ \\
\hline Two Back Task & $1.12(.04)$ & $1.08(.05)$ & $1.07(.05)$ & $1.07(.05)$ \\
\hline \multirow[t]{2}{*}{ Social Emotion Task } & $1.00(.05)$ & $1.02(.05)$ & $1.01(.05)$ & $1.01(.05)$ \\
\hline & \multicolumn{4}{|c|}{ Normal Suppressors } \\
\hline Identification Task & $2.71(.02)$ & $2.74(.03)$ & $2.71(.02)$ & $2.75(.02)$ \\
\hline Detection Task & $2.55(.03)$ & $2.57(.03)$ & $2.61(.03)$ & $2.60(.03)$ \\
\hline Groton Maze & $70.58(9.43)$ & $77.25(10.09)$ & $72.41(8.61)$ & $71.91(11.50)$ \\
\hline \multicolumn{5}{|l|}{ Learning } \\
\hline Shopping List Task & $18.08(1.51)$ & $19.25(1.75)$ & $17.50(1.59)$ & $16.75(1.80)$ \\
\hline One Back Task & $1.21(.04)$ & $1.22(.05)$ & $1.13(.07)$ & $1.24(.05)$ \\
\hline Two Back Task & $1.12(.05)$ & $1.06(.06)$ & $1.05(.06)$ & $1.03(.06)$ \\
\hline \multirow[t]{2}{*}{ Social Emotion Task } & $.96(.06)$ & $1.01(.06)$ & $.98(.06)$ & $.98(.06)$ \\
\hline & \multicolumn{4}{|c|}{ Deficient Suppressors } \\
\hline Identification Task & $2.76(.05)$ & $2.72(.03)$ & $2.75(.03)$ & $2.74(.04)$ \\
\hline Detection Task & $2.53(.05)$ & $2.51(.04)$ & $2.53(.04)$ & $2.52(.03)$ \\
\hline Groton Maze & $59.20(6.79)$ & $66.00(10.42)$ & $67.40(11.00)$ & $65.00(12.91)$ \\
\hline \multicolumn{5}{|l|}{ Learning } \\
\hline Shopping List Task & $19.00(2.35)$ & $20.20(3.02)$ & $19.20(2.50)$ & $19.40(3.16)$ \\
\hline One Back Task & $1.18(.10)$ & $1.20(.10)$ & $1.21(.05)$ & $1.21(.10)$ \\
\hline Two Back Task & $1.10(.04)$ & $1.11(.08)$ & $1.13(.05)$ & $1.14(.10)$ \\
\hline Social Emotion Task & $1.08(.08)$ & $1.04(.08)$ & $1.05(.05)$ & $1.05(.05)$ \\
\hline
\end{tabular}

\section{Discussion}

This study, to the best of my knowledge, is the first to examine the effects of CDP-Choline, a dietary choline supplement, on P50 indexed sensory gating and cognitive performance in chronic SZ patients. The results demonstrated a baseline and dose dependent effect of CDP-Choline on sensory gating measures and cognitive function. The 
findings of this study not only offer insight about the possible treatment of sensory gating deficits commonly associated with SZ but also provide further support for the facilitating role of $\mathrm{nAChR}$ dysfunction in the expression of sensory gating deficits and the importance of individualized treatment development stemming from baseline ability for improved efficacy.

\section{Sensory Gating}

Despite the breadth for research supporting a SZ associated sensory gating deficit some studies have failed to replicate it (Arnfred et al., 2003; de Wilde et al., 2007; Domján et al., 2012; Light et al., 2012). When analyzed as a whole, our sample failed to demonstrate a mean P50 ratio score within $1 \mathrm{SD}$ (24.3) of the common clinical average ( 79\%) observed in patients with SZ (Patterson et al., 2008). When stratified though, our normal and deficient suppressor subgroups mimicked P50 ratio scores commonly associated with healthy controls (Fuerst et al., 2007) and clinical samples (Patterson et al., 2008), respectively. Significant differences were observed between the groups whether measured by rP50 or dP50. Furthermore, our deficient suppressor group demonstrated a sensory gating deficit specifically due to a reduced inhibitory response rather than an overall reduced excitability of the brain regions responsible for the sensory gating process. This reduced inhibitory response replicates the pattern of a suppression deficit commonly observed in SZ samples demonstrating a sensory gating deficit.

In line with the hypotheses, the deficient suppressor subgroup demonstrated improved sensory gating in response to the lowest $(500 \mathrm{mg})$ dose of CDP-Choline while sensory gating was reduced in the normal suppressor group in response to the highest (2000 mg) dose. These results are inline with previous studies analyzing the effects of 
selective $\alpha 7 \mathrm{nAChR}$ agonists and the broad spectrum agonist nicotine (Adler et al., 2005; Knott et al., 2013; Knott, Fisher, \& Millar, 2010b; Koike et al., 2005; Olincy \& Stevens, 2007). Furthermore, these results parallel previous acute CDP-Choline dose studies using a sample of healthy volunteers (Knott et al., 2014). Each of these studies has supported an inverted $U$ pattern of cognitive changes in response to $\mathrm{nAChR}$ stimulation (i.e., optimal effects are observed with low doses). The results of this study, the dual action of CDPCholine, mirror this inverted $U$ shape pattern of effects through its increasing and decreasing sensory gating in deficient and normal suppressors, respectively. It has been suggested before, and supported by our sample, that not all SZ patients demonstrate the same degree of sensory gating deficit with some demonstrating normal gating. These results support the selective treatment of SZ patients with $\alpha 7 \mathrm{nAChR}$ agonists as an addon treatment based on their baseline sensory gating ability with pro-sensory gating effects only associated with SZ patients exhibiting significant suppression deficits.

It is likely that the mechanism underlying CDP-Choline's normalization of the sensory gating deficit represents a selective increase of the inhibitory process necessary for successful sensory gating. Previous nAChR agonist studies have suggested that a selective decrease in S2 P50 amplitude is indicative of the selective increase of the $\alpha 7$ interneuron-mediated inhibitory process (Frazier et al., 1998; Knott et al., 2014; Miller \& Freedman, 1995). A similar selective increase in S2 P50 response suppression was demonstrated in our deficient suppressor group in response to the $500 \mathrm{mg}$ dose of CDPCholine. An overall suppression of both the S1 and S2 P50 responses would suggest that the effects of CDP-Choline are being expressed through an overall decrease in the excitability of the regions associated with the sensory gating process (Simosky, Stevens, 
Kem, \& Freedman, 2001). Instead, the selective decrease of the S2 P50 response suggests that CDP-Choline is selectively increasing the inhibitory process involved in sensory gating.

The dose dependent characterization of CDP-Choline's effects may reflect the desensitization of the $\alpha 7 \mathrm{nAChRs}$. Both the $500 \mathrm{mg}$ and $1000 \mathrm{mg}$ dose of CDP-Choline increased the suppression of the S2 P50 response in the deficient suppressor group though the $500 \mathrm{mg}$ dose was the only one to reach significance. This reduced efficacy as dosage level increases could reflect a desensitization of the $\alpha 7 \mathrm{nAChRs}$. Compared to the $\alpha 4 \beta 2$ receptor subtype, the $\alpha 7 \mathrm{nAChRs}$ demonstrate slower receptor desensitization in response to sustained activation. It has been demonstrated though that higher and more sustained agonist concentrations do result in faster receptor desensitization (Hahn, Gold, \& Buchanan, 2013) offering a possible explanation for the decreased benefit as dosage increases. Increased receptor desensitization could also explain the detrimental effects associated with the $2000 \mathrm{mg}$ dose of CDP-choline in the normal suppressor group. Brain choline levels and receptor activation/expression are functioning at optimal levels resulting in the normal suppression of the S2 P50 response. As dosage levels increased receptor desensitization increased as well resulting in no suppression benefit but instead a consistent reduction in the suppression of the S2 P50 response with the $2000 \mathrm{mg}$ dose reaching significance.

Given the documented association between the sensory gating inhibitory process and the level of availability of the $\alpha 7$ nAChRs (Ichikawa et al., 2002) the baseline dependent variability in treatment effect may well represent underlying neural differences between the groups related to $\alpha 7 \mathrm{nAChR}$ expression and sensitivity. Genetic differences 
between deficient and normal suppressors has been linked to the expression of the CHRNA7 promoter with deficient suppressors on average demonstrating a variant (Leonard et al., 2002). It should be noted though that this association has not always been replicated (Liu et al., 2013). In addition, base brain choline levels in the schizophrenic brain have been shown to be reduced (Kraguljac et al., 2012). The genes responsible for the expression of the human choline transporter and its variations have been associated with cognition (Sarter \& Parikh, 2005) and corticolimbic reactivity (Neumann et al., 2006). Variability associated with this gene expression may underpin observed differences in baseline sensory gating performance and the individual's response to $\alpha 7$ nAChR agonist treatment.

\section{Cognition}

Research in the past has shown CDP-Choline to improve cognition in healthy individuals demonstrating relatively poor cognitive performance and to reduce cognitive performance in individuals demonstrating relatively normal performance. Significant improvements have been associated with lower doses $(<2000 \mathrm{mg})(\mathrm{Knott}$, de la Salle, Choueiry, et al., 2015). In addition, studies have demonstrated an association between sensory gating performance and attention dependent cognitive tasks. As such we hypothesized a baseline sensory gating performance dependent improvement (i.e., cognitive performance improvement in our deficient suppressor group) on cognitive tasks in response to the lower doses of CDP-Choline (i.e., $500 \mathrm{mg}$ and $1000 \mathrm{mg}$ ). Notably, the results of this study do support a baseline dependent effect associated with $\alpha 7 \mathrm{nAChR}$ stimulation but do not replicate the same cognitive improvements observed in healthy volunteer relatively low cognitive performers. It is very possible that the lack of 
improvements observed is directly related to our study being underpowered due to our small sample size. It is possible that we simply did not have the power to demonstrate a beneficial effect. Despite this possibility, we will attempt to offer a discussion of alternative explanations for the results we observed. .

The results from our analysis suggest that treatment with CDP-Choline does not offer a benefit to cognitive performance in SZ patients. In a sample of healthy volunteers demonstrating relatively low cognitive performance, improvements associated with processing speed, working memory, executive function, verbal learning and memory were observed (Knott, de la Salle, Choueiry, et al., 2015). The results of our study did not replicate the same cognitive performance improvements. Instead, the only treatment effects reaching significance demonstrated a reduction in cognitive performance in the normal suppressor group in relation to the measures of attention (Identification Task) and attention/working memory (One Back Task). The heterogeneous nature of SZ's symptomology in relation to cognitive deficits has been demonstrated previously (Keri \& Janka, 2004). Not all SZ patients demonstrate the same level of cognitive deficits. A possible explanation for the lack of observed cognitive improvements could relate to the fact that our sample of SZ patients did not consistently demonstrate cognitive task performance in the range of scores commonly associated with SZ patients (Pietrzak et al., 2009). Consistently, benefits associated with CDP-Choline treatment have been evident only with poor baseline cognitive performers. It is possible that our sample represented an unconventionally high sample of cognitive performers, which prevented a CDPCholine associated benefits from being observed. With a larger SZ sample of verified low cognitive performers it is possible CDP-Choline might have a significant benefit. 
Previous studies analyzing both CDP-Choline and other $\alpha 7 \mathrm{nAChR}$ agonists have demonstrated a dose dependent effect. Studies specifically analyzing CDP-Choline demonstrated a varied dose dependent effect with certain cognitive domains showing maximal benefit in response to the $500 \mathrm{mg}$ dose and others the $1000 \mathrm{mg}$ dose (Knott, de la Salle, Choueiry, et al., 2015). Other $\alpha 7 \mathrm{nAChRs}$ agonists have shown lasting benefits in response to ultra low doses in animal models (Buchanan \& Schwarcz, 2011). It is possible that the analysis of CDP-Choline's treatment effect at an ultra low dose may reveal beneficial effects not produced at the dosage levels analyzed in this study.

The baseline dependent treatment effects observed may be moderated by the availability/expression of the $\alpha 7 \mathrm{nAChRs}$. Since the only significant effects observed were in the normal suppressor group, the increase of choline levels in the brain are possibly reducing the functioning of an already optimal $\alpha 7 \mathrm{nAChR}$ system. The increased choline concentrations may lead to faster receptor desensitization resulting in reduced performance in cognitive domains associated with $\alpha 7 \mathrm{nAChR}$ function (Hahn et al., 2013). Choline administration has also been shown to affect the dopamine and norepinephrine neurotransmitter systems (Secades, 2011). Therefor, it is also possible that the reduced cognitive performance associated with the $2000 \mathrm{mg}$ dose of CDPCholine is being facilitated by associated changes in these neurotransmitter systems and not specifically the $\alpha 7 \mathrm{nAChR}$ system.

In implementing our stratification method based on P50 ratio scores, we attempted to analyze whether or not ratio scores could be used to identify individuals who would be more likely to demonstrate cognitive benefits associated with CDP-Choline treatment. It is important to note that this stratification method failed to identify 
significant differences between the suppressor groups at placebo for any of the cognition measures. Therefore, the lack of beneficial effects observed in relation to CDP-Choline treatment could reflect our stratification method's inability to identify the low cognitive performers. Despite the previous studies which have demonstrated an association between attention and sensory gating performance (Potter et al., 2006; Smith et al., 2010) our results suggested no such association. Further analysis of the effects of CDP-Choline on cognition in a sample of SZ patients stratified based on their cognitive performance on each task could reveal alternative results with low cognitive performers demonstrating an improvement.

\section{Limitations}

This study's design contained many strengths including the use of blinded, randomized treatment administrations, the use of multiple dosage levels to identify dose dependent effects, the inclusion of both smokers and non smokers, and the use of a cross over repeated measure design. However, certain limitations were evident. Power analysis suggested that our necessary sample size equaled 22 participants. Unfortunately, due to the nature of clinical studies we struggled to reach this number of participants resulting in a final sample size somewhat less than optimal. This may have resulted in a reduction in power. Though the inclusion of both males and females allowed for increased generalizability of the study's results this may have introduced potential variance associated with the menstrual cycle. The inclusion of smokers increases the generalizability of the results but may have limited our ability to specifically attribute positive changes to treatment with CDP-Choline. Treatment benefits with a nAChR agonist could be interpreted as a reversal of nicotine withdrawal-induced cognitive 
impairment in SZ smokers. Control for treatment with medications exerting an anticholinergic effect was also not implemented. The inclusion of participants currently being treated with medications that interact with the cholinergic system may have limited the treatment effects we observed. It is possible that we would observe greater benefits in an unmedicated sample, though ethical and practical issues stand in the way of this. An alternative would be testing a younger sample of patients diagnosed with First Episode Schizophrenia (FES). This would limit the samples exposure to confounding medications and possibly increase treatment effects. Though this study incorporated multiple CDPCholine doses ranging from low to high, allowing for the analysis of dosage dependent effects, the effects of more extreme doses were not analyzed. Animal studies utilizing $\alpha 7$ nAChR agonists have demonstrated long lasting benefits at ultra low doses. It is possible similar sustained beneficial treatment effects could have been observed in response to an ultra low does (e.g., $250 \mathrm{mg}$ ) in SZ patients (Buchanan \& Schwarcz, 2011). CDP-Choline increases citicoline levels within the brain. Citicoline has been shown to exert a number of effects throughout the brain including an increase in the biosynthesis of phospholipids, an increase in brain metabolism, and the increase in levels of dopamine and norepinephrine (Secades, 2011). Since our study did not measure these changes it is possible that the beneficial effects observed were moderated or influenced by changes to these brain functions and/or neurotransmitter systems. Stratification of our sample was carried out based on P50 ratio scores recorded at the placebo session. This session's data was included in the statistical analysis and therefor may have contributed to a 'regression to the mean' effect though this possibility is lessened by the fact that the placebo session was equally distributed throughout the four sessions. In the future, a drug free and 
placebo free session may be incorporated at the beginning of testing to assess P50 ratio scores purely for stratification purposes and not to be included in the analysis.

To build upon the current findings future research should seek to analyze certain variables not incorporated into this study. The analysis of treatment benefits in relation to such patient characteristics as disease duration, disease onset, symptom severity and expression would allow for the possible identification of a further heterogeneous sample of SZ patients who are most likely to beneficially respond to an $\alpha 7 \mathrm{nAChR}$ agonists add on treatment. This study analyzed the acute effects of CDP-Choline on sensory gating and cognition. Since all sessions were spaced out by 7 days the effects of repeated dosing were without allowing for washout was not identified. This would have allowed for the analysis of receptor desensitization to observe whether or not benefits are sustained over time. This is an essential next step in the examination of CDP-Choline as a novel therapy candidate as other nAChR agonists have failed to demonstrate sustained benefits following continuous treatment (e.g., nicotine, following long-term exposure, reduces sensory gating) (Brinkmeyer et al., 2011). Finally, the possible contribution of neural plasticity could be analyzed by comparing the current effect of CDP-Choline in a chronic SZ sample to a sample of FES patients. It is possible that younger patients demonstrating greater neural plasticity may demonstrate greater and more sustained benefits associated with CDP-Choline treatment.

\section{Conclusions}

The MATRICS project has identified the $\alpha 7 \mathrm{nAChRs}$ as a possible target with great potential for the treatment of sensory and cognitive impairments in SZ. The neurophysiological findings of this study support previous neurobiological, pre-clinical, 
and clinical evidence that has suggested that $\alpha 7 \mathrm{nAChR}$ activation offers beneficial effects to sensory gating dysfunction associated with SZ (Freedman, 2014). The observation that low doses $(500 \mathrm{mg})$ of CDP-Choline improved sensory gating in the patient sample demonstrating deficient suppression of the S2 P50 response supports the use of dietary choline as a treatment strategy, the targeting of the $\alpha 7 \mathrm{nAChRs}$, and the use of rP50 as a marker to identify individuals who demonstrate the most CDP-Choline treatment benefit in relation to sensory gating performance. CDP-Choline may offer a novel treatment strategy for the alleviation of sensory gating deficits in a SZ subgroup that demonstrates deficient suppression of the S2 P50 response. The lack of beneficial effect associated with cognitive deficits observed in this study suggests that P50 suppression scores may not offer an effective means of identifying a homogenous SZ subgroup that would likely demonstrate cognitive domain improvements in response to choline administration. Despite this, further studies are necessary to identify the dose and possibly baseline cognitive performance dependent effects of CDP-Choline on varying cognitive domains. Further studies are also necessary to examine whether chronic administration of CDP-Choline will result in sustained sensory gating and cognitive improvements to verify its effectiveness as a clinically meaningful add-on treatment strategy targeting for SZ. 


\section{References}

Addington, J., Addington, D., \& Maticka-Tyndale, E. (1991). Cognitive functioning and positive and negative symptoms in schizophrenia. Schizophrenia Research, 5(2), 123-134. doi:10.1016/0920-9964(91)90039-T

Adler, Cawthra, E. M., Donovan, K. A., Harris, J. G., Nagamoto, H. T., Olincy, A., \& Waldo, M. C. (2005). Improved P50 Auditory Gating With Ondansetron in Medicated Schizophrenia Patients. American Journal of Psychiatry, 162(2), 386388. doi:10.1176/appi.ajp.162.2.386

Adler, Freedman, Ross, Olincy, \& Waldo. (1999). Elementary phenotypes in the neurobiological and genetic study of schizophrenia. Biological Psychiatry, 46(1), 818. doi:10.1016/S0006-3223(99)00085-2

Adler, Gerhardt, Franks, Baker, Nagamoto, Drebing, \& Freedman. (1990). Sensory physiology and catecholamines in schizophrenia and mania. Psychiatry Research, 31(3), 297-309. doi:10.1016/0165-1781(90)90099-Q

Adler, Hoffer, L. J., Griffith, J., Waldo, M. C., \& Freedman, R. (1992). Normalization by nicotine of deficient auditory sensory gating in the relatives of schizophrenics. Biological Psychiatry, 32(7), 607-616. doi:10.1016/0006-3223(92)90073-9

Adler, Hoffer, Wiser, \& Freedman. (1993). Normalization of auditory physiology by cigarette smoking in schizophrenic patients. American Journal of Psychiatry, $150(12), 1856-1861$.

Adler, L., \& Hoffer, L. (1993). Normalization of auditory physiology by cigarette smoking in schizophrenic patients. The American Journal of ..., (December), 18561861. 
Agut, J., Font, E., Sacristán, A., \& Ortiz, J. A. (1983). Bioavailability of methyl-14C CDP-choline by oral route. Arzneimittel-Forschung, 33(7A), 1045-1047.

Alkondon, M., \& Albuquerque, E. X. (2006). Subtype-Specific Inhibition of Nicotinic Acetylcholine Receptors by Choline : A Regulatory Pathway, 318(1), 268-275. doi:10.1124/jpet.106.103135.asterisk

Alvarez-Sabín, J., \& Román, G. C. (2011). Citicoline in vascular cognitive impairment and vascular dementia after stroke. Stroke; a Journal of Cerebral Circulation, 42(1 Suppl), S40-3. doi:10.1161/STROKEAHA.110.606509

Anokhin, A. P., Vedeniapin, A. B., Heath, A. C., Korzyukov, O., \& Boutros, N. N. (2007). Genetic and environmental influences on sensory gating of mid-latency auditory evoked responses: A twin study. Schizophrenia Research, 89(1-3), 312319. doi:10.1016/j.schres.2006.08.009

Arango, C., Summerfelt, A., \& Buchanan, R. W. (2003). Olanzapine effects on auditory sensory gating in schizophrenia. The American Journal of Psychiatry, 160(11), 2066-2068. doi:10.1176/appi.ajp.160.11.2066

Arnfred, S. M., Chen, A. C. N., Glenthøj, B. Y., \& Hemmingsen, R. P. (2003). Normal P50 gating in unmedicated schizophrenia outpatients. American Journal of Psychiatry, 160(12), 2236-2238. doi:10.1176/appi.ajp.160.12.2236

Ayesa-Arriola, R., Rodríguez-Sánchez, J. M., Pérez-Iglesias, R., Roiz-Santiáñez, R., Martínez-García, O., Sánchez-Moreno, J., ... Crespo-Facorro, B. (2013). Long-term (3-year) neurocognitive effectiveness of antipsychotic medications in first-episode non-affective psychosis: a randomized comparison of haloperidol, olanzapine, and risperidone. Psychopharmacology, 227(4), 615-25. doi:10.1007/s00213-013-2994-z 
Babb, Wald, Cohen, Villafuerte, Gruber, Yurgelun-Todd, \& Renshaw. (2002). Chronic citicoline increases phosphodiesters in the brains of healthy older subjects: An in vivo phosphorus magnetic resonance spectroscopy study. Psychopharmacology, 161(3), 248-254. doi:10.1007/s00213-002-1045-y

Bak, N., Glenthoj, B. Y., Rostrup, E., Larsson, H. B., \& Oranje, B. (2011). Source localization of sensory gating: A combined EEG and fMRI study in healthy volunteers. NeuroImage, 54(4), 2711-2718. doi:10.1016/j.neuroimage.2010.11.039

Barak, S., \& Weiner, I. (2011). Putative cognitive enhancers in preclinical models related to schizophrenia: the search for an elusive target. Pharmacology, Biochemistry, and Behavior, 99(2), 164-89. doi:10.1016/j.pbb.2011.03.011

Barr, R. S., Culhane, M. A., Jubelt, L. E., Mufti, R. S., Dyer, M. A., Weiss, A. P., ... Evins, A. E. (2008). The effects of transdermal nicotine on cognition in nonsmokers with schizophrenia and nonpsychiatric controls. Neuropsychopharmacology: Official Publication of the American College of Neuropsychopharmacology, 33(3), 480-490. doi:10.1038/sj.npp.1301423

Becker, J., Gomes, I., Ghisolfi, E. S., Schuch, A., Ramos, F. L. P., Ehlers, J. A., ... da Costa, J. C. (2004). Clozapine, but not typical antipsychotics, correct P50 suppression deficit in patients with schizophrenia. Clinical Neurophysiology: Official Journal of the International Federation of Clinical Neurophysiology, 115(2), 396-401. doi:10.1016/j.clinph.2003.09.018

Berman, J. A., Talmage, D. A., \& Role, L. W. (2007). Cholinergic circuits and signaling in the pathophysiology of schizophrenia. International Review of Neurobiology, 78(06), 193-223. doi:10.1016/S0074-7742(06)78007-2 
Bickford-Wimer, P. C., Nagamoto, H., Johnson, R., Adler, L. E., Egan, M., Rose, G. M., \& Freedman, R. (1990). Auditory sensory gating in hippocampal neurons: a model system in the rat. Biological Psychiatry, 27(151), 183-192.

Bilder, R. M., Mukherjee, S., Rieder, R. O., \& Pandurangi, A. K. (1985). Symptomatic and neuropsychological components of defect states. Schizophrenia Bulletin, 11(3), $409-419$.

Boutros, Korzyuko, Oliwa, Feingold, Campbell, McClain-Furmanski, ... Jansen. (2004). Morphological and latency abnormalities of the mid-latency auditory evoked responses in schizophrenia: A preliminary report. Schizophrenia Research, 70(2-3), 303-313. doi:10.1016/j.schres.2003.12.009

Boutros, N. N., Zouridakis, G., \& Overall, J. (1991). Replication and extension of P50 findings in schizophrenia. Clinical EEG (electroencephalography), 22(1), 40-45. doi:10.1177/155005949102200109

Boutros, Zouridakis, Rustin, Peabody, \& Warner. (1993). The P50 component of the auditory evoked potential and subtypes of schizophrenia. Psychiatry Research, 47(3), 243-254. doi:10.1016/0165-1781(93)90082-R

Bradley, R., Dwyer, D., Kemp, G., \& Crews, E. Antibodies Against Acetylcholine Receptor in Tardive Dyskinesia. , 315 The Lancet 320-321 (1980). doi:10.1016/S0140-6736(80)90824-7

Bramon, E., Rabe-Heskethb, S., Shama, P., Murraya, R. M., \& Frangoua, S. (2004). Meta-analysis of the P300 and P50 waveforms in schizophrenia. Schizophrenia Research, 70(2-3), 315-329. doi:10.1016/j.schres.2004.01.004

Breese, Lee, M. J., Adams, C. E., Sullivan, B., Logel, J., Gillen, K. M., ... Leonard, S. 
(2000). Abnormal Regulation of High Affinity Nicotinic Receptors in Subjects with Schizophrenia. Neuropsychopharmacology, 23(4), 351-364. doi:10.1016/S0893$133 \mathrm{X}(00) 00121-4$

Breese, Marks, M. J., Logel, J., Adams, C. E., Sullivan, B., Collins, a C., \& Leonard, S. (1997). Effect of smoking history on $[3 \mathrm{H}]$ nicotine binding in human postmortem brain. The Journal of Pharmacology and Experimental Therapeutics, 282(1), 7-13. Brinkmeyer, J., Mobascher, A., Musso, F., Schmitz, M., Wagner, M., Frommann, I., ... Winterer, G. (2011). P50 sensory gating and smoking in the general population. Addiction Biology, 16(3), 485-98. doi:10.1111/j.1369-1600.2010.00302.x

Bryson, G., \& Bell, M. (2003). Initial and Final Work Performance in Schizophrenia: The Journal of Nervous and Mental Disease, 191(2), 87-92.

doi:10.1097/01.NMD.0000050937.06332.3C

Buchanan, R. W., Davis, M., Goff, D., Green, M. F., Keefe, R. S. E., Leon, A. C., ... Marder, S. R. (2005). A Summary of the FDA-NIMH-MATRICS Workshop on Clinical Trial Design for Neurocognitive Drugs for Schizophrenia. Schizophrenia Bulletin, 31(1), 5-19. doi:10.1093/schbul/sbi020

Buchanan, R. W., Freedman, R., Javitt, D. C., Abi-Dargham, A., \& Lieberman, J. a. (2007). Recent advances in the development of novel pharmacological agents for the treatment of cognitive impairments in schizophrenia. Schizophrenia Bulletin, 33(5), 1120-30. doi:10.1093/schbul/sbm083

Buchanan, R. W., Keefe, R. S. E., Lieberman, J. A., Barch, D. M., Csernansky, J. G., Goff, D. C., ... Marder, S. R. (2011). A Randomized Clinical Trial of MK-0777 for the Treatment of Cognitive Impairments in People with Schizophrenia, 69(5), 442- 
449. doi:10.1016/j.biopsych.2010.09.052.A

Buchanan, R. W., \& Schwarcz, R. (2011). a7 Nicotinic Receptor Agonists as Cognitive

Treatments: Is Less (or Less Often) More? Biological Psychiatry, 69(1), 5-6. doi:10.1016/j.biopsych.2010.11.004

Castner, S. A., Smagin, G. N., Piser, T. M., Wang, Y., Smith, J. S., Christian, E. P., ... Williams, G. V. (2011). Immediate and Sustained Improvements in Working Memory After Selective Stimulation of $\alpha 7$ Nicotinic Acetylcholine Receptors. Biological Psychiatry, 69(1), 12-18. doi:10.1016/j.biopsych.2010.08.006

Chang, W. P., Arfken, C. L., Sangal, M. P., \& Boutros, N. N. (2011). Probing the relative contribution of the first and second responses to sensory gating indices: a metaanalysis. Psychophysiology, 48(7), 980-92. doi:10.1111/j.1469-8986.2010.01168.x

Cho, R. Y., Ford, J., Krystal, J., Laruelle, M., Cuthbert, B., \& Carter, C. (2005). Functional Neuroimaging and Electrophysiology Biomarkers for Clinical Trials for Cognition in Schizophrenia. Schizophrenia Bulletin, 31(4), 865-869. doi:10.1093/schbul/sbi050

Clementz, B. A., Blumenfeld, L. D., \& Cobb, S. (1997). The gamma band response may account for poor P50 suppression in schizophrenia. Neuroreport, 8(18), 3889-3893. doi:10.1097/00001756-199712220-00010

Conant, R., \& Schauss, A. G. (2004). Therapeutic Applications of Citicoline for Stroke and Cognitive Dysfunction in the Elderly: A Review of the Literature. Alternative Medicine Review, 9(1), 17-31.

Court, J., Spurden, D., Lloyd, S., McKeith, I., Ballard, C., Cairns, N., ... Perry, E. (1999). Neuronal nicotinic receptors in dementia with Lewy bodies and schizophrenia: 
alpha-bungarotoxin and nicotine binding in the thalamus. Journal of Neurochemistry, 73(4), 1590-7. doi:10.1046/j.1471-4159.1999.0731590.x

Dalecki, A. (2015). Clarifying the Functional Process Represented by Reduced P50 Suppression in Schizophrenia. PhD Dissertation, 1-161. doi:10.1017/CBO9781107415324.004

De Leon, J., Tracy, J., McCann, E., McGrory, A., \& Diaz, F. J. (2002). Schizophrenia and tobacco smoking: A replication study in another US psychiatric hospital. Schizophrenia Research, 56(1-2), 55-65. doi:10.1016/S0920-9964(01)00192-X

De Luca, V., Likhodi, O., Van Tol, H. H. M., Kennedy, J. L., \& Wong, A. H. C. (2006). Regulation of $\alpha 7$-nicotinic receptor subunit and $\alpha 7$-like gene expression in the prefrontal cortex of patients with bipolar disorder and schizophrenia. Acta Psychiatrica Scandinavica, 114(3), 211-215. doi:10.1111/j.16000447.2006.00785.x

de Wilde, O. M., Bour, L. J., Dingemans, P. M., Koelman, J. H. T. M., \& Linszen, D. H. (2007). Failure to find P50 suppression deficits in young first-episode patients with schizophrenia and clinically unaffected siblings. Schizophrenia Bulletin, 33(6), 1319-23. doi:10.1093/schbul/sbm001

Diwan, A., Castine, M., Pomerleau, C. S., Meador-Woodruff, J. H., \& Dalack, G. W. (1998). Differential prevalence of cigarette smoking in patients with schizophrenic vs mood disorders. Schizophrenia Research, 33(1-2), 113-118. doi:10.1016/S09209964(98)00045-0

Domino, E., Ni, L., \& Thompson, M. (2009). Tobacco Smoking Produces Widespread Dominant Brain Wave Alpha Frequency Increases. International Journal of ..., 
74(3), 192-198. doi:10.1016/j.ijpsycho.2009.08.011.Tobacco

Domján, N., Csifcsák, G., Drótos, G., Janka, Z., \& Szendi, I. (2012). Different patterns of auditory information processing deficits in chronic schizophrenia and bipolar disorder with psychotic features. Schizophrenia Research, 139(1-3), 253-259. doi:10.1016/j.schres.2012.06.002

Duncan, C. C. (1988). Event-related brain potentials: a window on information processing in schizophrenia. Schizophrenia Bulletin, 14(2), 199-203.

Fernandes, C., Hoyle, E., Dempster, E., Schalkwyk, L. C., \& Collier, D. A. (2006). Performance deficit of $\alpha 7$ nicotinic receptor knockout mice in a delayed matchingto-place task suggests a mild impairment of working/episodic-like memory. Genes, Brain and Behavior, 5(6), 433-440. doi:10.1111/j.1601-183X.2005.00176.x

Fioravanti, M., \& Buckley, A. E. A. (2006). Citicoline (Cognizin) in the treatment of cognitive impairment. Clinical Interventions in Aging, 1(3), 247-251. doi:10.2147/ciia.2006.1.3.247

First, M. B., Spitzer, R. L., Gibbon, M., \& Browne, E. al. B. L. A. (1996). Structured Clinical Interview for DSM-IV Axis I Disorders, Clinical Version (SCID-CV).

Flach, K. a, Adler, L. E., Gerhardt, G. a, Miller, C., Bickford, P., \& MacGregor, R. J. (1996). Sensory gating in a computer model of the CA3 neural network of the hippocampus. Biological Psychiatry, 40(12), 1230-45. doi:10.1016/00063223(95)00624-9

Fleischhacker, W. W. (1995). New Drugs for the Treatment of Schizophrenic Patients. Acta Psychiatrica Scandinavica, 91(388), $24-30$.

Frazier, C. J., Rollins, Y. D., Breese, C. R., Leonard, S., Freedman, R., \& Dunwiddie, T. 
V. (1998). Acetylcholine activates an alpha-bungarotoxin-sensitive nicotinic current in rat hippocampal interneurons, but not pyramidal cells. The Journal of Neuroscience : The Official Journal of the Society for Neuroscience, 18(4), 11871195.

Freedman. (2014). a7-Nicotinic Acetylcholine Receptor Agonists for Cognitive Enhancement in Schizophrenia. Annual Review of Medicine, 65(1), 245-261. doi:10.1146/annurev-med-092112-142937

Freedman, Adler, Bickford, Byerley, Coon, Cullum, ... Miller. (1994). Schizophrenia and nicotinic receptors. Harvard Review of Psychiatry, 2(4), 179-192. doi:10.3109/10673229409017136

Freedman, Adler, L. E., Gerhardt, G. a, Waldo, M., Baker, N., Rose, G. M., ... Franks, R. (1987). Neurobiological studies of sensory gating in schizophrenia. Schizophrenia Bulletin, 13(4), 669-678. doi:10.1093/schbul/13.4.669

Freedman, Adler, Waldo, Pachtman, \& Franks. (1983). Neurophysiological evidence for a defect in inhibitory pathways in schizophrenia: comparison of medicated and drugfree patients. Biological Psychiatry, 18(5), 537-551.

Freedman, Coon, H., Myles-Worsley, M., Orr-Urtreger, A., Olincy, A., Davis, A., ... Byerley, W. (1997). Linkage of a neurophysiological deficit in schizophrenia to a chromosome 15 locus. Proceedings of the National Academy of Sciences of the United States of America, 94(2), 587-592. doi:10.1073/pnas.94.2.587

Freedman, \& Goldowitz, D. (2010). Studies on the Hippocampal Formation: From Basic Development to: Studies on Schizophrenia. Progress in Neurobiology, 90(2), 263275. doi:10.1016/j.pneurobio.2009.10.008.Studies 
Freedman, Hall, M., Adler, L. E., \& Leonard, S. (1995). Evidence in postmortem brain tissue for decreased numbers of hippocampal nicotinic receptors in schizophrenia. Biological Psychiatry, 38(1), 22-33. doi:10.1016/0006-3223(94)00252-X

Freedman, Olincy, Ross, Waldo, Stevens, Adler, \& Leonard. (2003). The genetics of sensory gating deficits in schizophrenia. Current Psychiatry Reports, 5(2), 155-61.

Freedman, Waldo, M., Bickford-Wimer, P., \& Nagamoto, H. (1991). Elementary neuronal dysfunctions in schizophrenia. Schizophrenia Research, 4(2), 233-243. doi:10.1016/0920-9964(91)90035-P

Freedman, Wetmore, C., Stromberg, I., Leonard, S., \& Olson, L. (1993). Bungarotoxin Binding to Hippocampal Interneurons: 1mmunocytochemical Characterization and Effects on Growth Factor Expression. The Journal of Neuroscience, 13(May), 1965-1975.

Fuerst, D. R., Gallinat, J., \& Boutros, N. N. (2007). Range of sensory gating values and test-retest reliability in normal subjects. Psychophysiology, 44(4), 620-626. doi:10.1111/j.1469-8986.2007.00524.x

García-Cobos, R., Frank-García, A., Gutiérrez-Fernández, M., \& Díez-Tejedor, E. (2010). Citicoline, use in cognitive decline: vascular and degenerative. Journal of the Neurological Sciences, 299(1-2), 188-92. doi:10.1016/j.jns.2010.08.027

Gejman, P. V., Sanders, A. R., Badner, J. a., Cao, Q., \& Zhang, J. (2001). Linkage analysis of schizophrenia to chromosome 15. American Journal of Medical Genetics - Neuropsychiatric Genetics, 105(8), 789-793. doi:10.1002/ajmg.1552

Geyer, \& Braff. (1987). Startle habituation and sensorimotor gating in schizophrenia and related animal models. Schizophrenia Bulletin, 13(4), 643-668. 
doi:10.1093/schbul/13.4.643

Geyer, M. A., \& Tamminga, C. A. (2004). Measurment and Treatment Research to Improve Cognition in Schizophrenia: Neuropharmacological Aspects.

Psychopharmacology, 174, 1-2. doi:10.1007/BF02245088

Goff, W. R., Williamson, P., Gilder, J. C. Van, Allison, T., \& Fisher, T. C. (1980). Neural origins of long latency evoked potentials recorded from the depth and cortical surface of the brain in man. Progress in Clinical Neurophysiology, 7, 126-145.

Goldberg, T. E. (1990). Neuropsychological Assessment of Monozygotic Twins Discordant for Schizophrenia. Archives of General Psychiatry, 47(11), 1066. doi:10.1001/archpsyc.1990.01810230082013

Gottesman, I. I., \& Gould, T. D. (2003). The Endophenotype Concept in Psychiatry : Etymology and Strategic Intentions. American Journal of Psychiatry, 160(April), 636-645. doi:10.1176/appi.ajp.160.4.636

Gray, Mitchell, S. N., Joseph, M. H., Grigoryan, C. A., Dawe, S., \& Hodges, H. (1994). Neurochemical mechanisms mediating the behavioural and cognitive effects of nicotine. Drug Dev.Res., 31, 3-17.

Green, Kern, R. S., Braff, D. L., \& Mintz, J. (2000). Neurocognitive deficits and functional outcome in schizophrenia: are we measuring the "right stuff"? Schizophrenia Bulletin, 26(1), 119-136. doi:10.1093/oxfordjournals.schbul.a033430 Green, Nuechterlein, K. H., Gold, J. M., Barch, D. M., Cohen, J., Essock, S., .. Marder, S. R. (2004). Approaching a consensus cognitive battery for clinical trials in schizophrenia: The NIMH-MATRICS conference to select cognitive domains and test criteria. Biological Psychiatry, 56(5), 301-307. 
doi:10.1016/j.biopsych.2004.06.023

Griffith, J. M., O’Neill, J. E., Petty, F., Garver, D., Young, D., \& Freedman, R. (1998).

Nicotinic receptor desensitization and sensory gating deficits in schizophrenia.

Biological Psychiatry, 44(2), 98-106. doi:10.1016/S0006-3223(97)00362-4

Grunwald, T., Boutros, N. N., Pezer, N., von Oertzen, J., Fernandez, G., Schaller, C., \&

Elger, C. E. (2003). Neuronal substrates of sensory gating within the human brain.

Biological Psychiatry, 53(6), 511-519. doi:10.1016/S0002-3223(03)01673-2

Guan, Z. Z., Zhang, X., Blennow, K., \& Nordberg, a. (1999). Decreased protein level of nicotinic receptor alpha7 subunit in the frontal cortex from schizophrenic brain. Neuroreport, 10(8), 1779-1782. doi:10.1097/00001756-199906030-00028

Haddock, G., McCarron, J., Tarrier, N., \& Faragher, E. B. (1999). Scales to measure dimensions of hallucinations and delusions: the psychotic symptom rating scales (PSYRATS). Psychological Medicine, 29(4), 879-889.

doi:10.1017/S0033291799008661

Hahn, B., Gold, J. M., \& Buchanan, R. W. (2013). The potential of nicotinic enhancement of cognitive remediation training in schizophrenia. Neuropharmacology, 64, 185-190. doi:10.1016/j.neuropharm.2012.05.050

Hajos, M. (2006). Targeting information-processing deficit in schizophrenia: a novel approach to psychotherapeutic drug discovery. Trends in Pharmacological Sciences, 27(7), 391-398. doi:10.1016/j.tips.2006.05.005

Harvey, P. D., Howanitz, E., Parrella, M., White, L., Davidson, M., Mohs, R. C., ... Davis, K. L. (1998). Symptoms, cognitive functioning, and adaptive skills in geriatric patients with lifelong schizophrenia: a comparison across treatment sites. 
The American Journal of Psychiatry, 155(8), 1080-6.

Harvey, P. D., \& Keefe, R. S. E. (1997). Cognitive Impairment in Schizophrenia and Implications of Atypical Neuroleptic Treatment. CNS Spectrums, 2(1), 41-55. doi:10.1016/j.biopsych.2010.03.004

Harvey, P. D., \& Keefe, R. S. E. (2001). Studies of Cognitive Change in Patients With Schizophrenia Following Novel Antipsychotic Treatment. American Journal of Psychiatry, 158(10), 176-184. doi:10.1176/appi.ajp.161.10.1822

Harvey, P. D., Rabinowitz, J., Eerdekens, M., \& Davidson, M. (2005). Treatment of cognitive impairment in early psychosis: a comparison of risperidone and haloperidol in a large long-term trial. The American Journal of Psychiatry, 162(10), 1888-95. doi:10.1176/appi.ajp.162.10.1888

Hashimoto, K., Fujita, Y., Ishima, T., Hagiwara, H., \& Iyo, M. (2006). Phencyclidineinduced cognitive deficits in mice are improved by subsequent subchronic administration of tropisetron: role of alpha7 nicotinic receptors. European Journal of Pharmacology, 553(1-3), 191-5. doi:10.1016/j.ejphar.2006.09.055

Hashimoto, K., Iyo, M., Freedman, R., \& Stevens, K. E. (2005). Tropisetron improves deficient inhibitory auditory processing in DBA/2 mice: role of alpha 7 nicotinic acetylcholine receptors. Psychopharmacology, 183(1), 13-9. doi:10.1007/s00213005-0142-0

Hashimoto, K., Koike, K., Shimizu, E., \& Iyo, M. (2005). a7 Nicotinic Receptor Agonists as Potential Therapeutic Drugs for Schizophrenia. Current Medicinal Chemistry - Central Nervous System Agents, 5(3), 171-184. doi:10.2174/1568015054863828 
Heckers, S. (2001). Neuroimaging studies of the hippocampus in schizophrenia.

Hippocampus, 11(June), 520-528. doi:10.1002/hipo.1068

Heinrichs. (2004). Meta-analysis and the science of schizophrenia: Variant evidence or evidence of variants? Neuroscience and Biobehavioral Reviews, 28(4), 379-394. doi:10.1016/j.neubiorev.2004.06.003

Hetrick, W. P., Erickson, M. a., \& Smith, D. a. (2012). Phenomenological dimensions of sensory gating. Schizophrenia Bulletin, 38(1), 178-191. doi:10.1093/schbul/sbq054

Heydebrand, G. (2006). Cognitive Deficits in the Families of Patients with

Schizophrenia. Current Opinion in Psychiatry, 19, 277-281.

doi:10.1097/01.yco.0000218598.38807.b0

Hill, Bishop, J. R., Palumbo, D., \& Sweeney, J. a. (2010). Effect of second-generation antipsychotics on cognition: current issues and future challenges. Expert Review of Neurotherapeutics, 10(1), 43-57. doi:10.1586/ern.09.143.Effect

Hong, Chan, R. C. K., Zhuang, X., Jiang, T., Wan, X., Wang, J., ... Weng, B. (2009). Neuroleptic effects on P50 sensory gating in patients with first-episode nevermedicated schizophrenia. Schizophrenia Research, 108(1-3), 151-157. doi:10.1016/j.schres.2008.11.016

Hong, Summerfelt, A., McMahon, R. P., Thaker, G., \& Buchanan, R. (2004). Gamma/beta oscillation and sensory gating deфcit in schizophrenia. Clinical Neuroscience and Neuropathology, 15(19), 88-94. doi:10.1007/BF02805979

Hong, Thaker, G. K., McMahon, R. P., Summerfelt, A., RachBeisel, J., Fuller, R. L., ... Nye, A. (2011). Effects of Moderate-Dose Treatment With Varenicline on Neurobiological and Cognitive Biomarkers in Smokers and Nonsmokers With 
Schizophrenia or Schizoaffective Disorder. Archives of General Psychiatry, 68(12), 1195-1206. doi:10.1001/archgenpsychiatry.2011.83

Houy, E., Raux, G., Thibaut, F., Belmont, A., Demily, C., Allio, G., ... Campion, D. (2004). The promoter $-194 \mathrm{C}$ polymorphism of the nicotinic alpha 7 receptor gene has a protective effect against the P50 sensory gating deficit. Molecular Psychiatry, 9(3), 320-322. doi:10.1038/sj.mp.4001443

Hughes, J. R., Hatsukami, D. K., Mitchell, J. E., \& Dahlgren, L. A. (1986). Prevalence of smoking among psychiatric outpatients. American Journal of Psychiatry, 143(8), 993-997.

Hughes, Kumari, V., Soni, W., Das, M., Binneman, B., Drozd, S., ... Sharma, T. (2003). Longitudinal study of symptoms and cognitive function in chronic schizophrenia. Schizophr Res, 59(2-3), 137-146.

Hyde, T. M., \& Crook, J. M. (2001). Cholinergic systems and schizophrenia: Primary pathology or epiphenomena? Journal of Chemical Neuroanatomy, 22(1-2), 53-63. doi:10.1016/S0891-0618(01)00101-6

Hyman, S. E., \& Fenton, W. S. (2003). What Are the Right Targets for Psychopharmacology? Science, 299(5605), 350-351. doi:10.1126/science.1077141 Ichikawa, J. (2002). Atypical, but Not Typical, Antipsychotic Drugs Increase Cortical Acetylcholine Release without an Effect in the Nucleus Accumbens or Striatum. Neuropsychopharmacology, 26(3), 325-339. doi:10.1016/S0893-133X(01)00312-8

Ichikawa, J., Dai, J., O’Laughlin, I. A., Fowler, W. L., \& Meltzer, H. Y. (2002). Atypical, but not Typical, Antipsychotic Drugs Increase Cortical Acetylcholine Release without and Effect in the Nucleus Accumbens or Striatum. 
Neuropsychopharmacology, 26, 325-339. doi:10.1016/0893-133X(95)00178-G

Jacobsen, L. K., D’Souza, D. C., Mencl, W. E., Pugh, K. R., Skudlarski, P., \& Krystal, J. H. (2004). Nicotine Effects on Brain Function and Functoinal Connectivity in Schizophrenia. Biological Psychiatry, 55, 850-858. doi:0006-3223(89)90215-1 [pii]

Javitt, D. C., Spencer, K. M., Thaker, G. K., Winterer, G., \& Hajós, M. (2008).

Neurophysiological biomarkers for drug development in schizophrenia. Nature Reviews. Drug Discovery, 7(1), 68-83. doi:10.1038/nrd2463.Neurophysiological

Jessen, F., Scherk, H., Träber, F., Theyson, S., Berning, J., Tepest, R., ... Block, W. (2006). Proton magnetic resonance spectroscopy in subjects at risk for schizophrenia. Schizophrenia Research, 87(1-3), 81-8. doi:10.1016/j.schres.2006.06.011

Jobert, M., Wilson, F. J., Ruigt, G. S. F., Brunovsky, M., Prichep, L. S., \& Drinkenburg, W. H. I. M. (2012). Guidelines for the recording and evaluation of pharmaco-EEG data in man: the International Pharmaco-EEG Society (IPEG). Neuropsychobiology, 66(4), 201-20. doi:10.1159/000343478

Kahn, R. S., Fleischhacker, W. W., Boter, H., Davidson, M., Vergouwe, Y., Keet, I. P., \& Gheorge, M. D. (2008). Cognitive effects of antipsychotic drugs in first-episode schizophrenia and schizophreniform disorder: A randomized, open-label clinical trial (EUFEST). The Lancet, 371, 1085-1097. doi:10.1176/appi.ajp.2008.08060806

Kane, J. M. (1989). The current status of neuroleptic therapy. Journal of Clinical Psychiatry.

Kantrowitz, J. T., \& Javitt, D. C. (2010). N-methyl-d-aspartate (NMDA) receptor dysfunction or dysregulation: The final common pathway on the road to 
schizophrenia? Brain Research Bulletin, 83(3-4), 108-121.

doi:10.1016/j.brainresbull.2010.04.006

Kathmann, N., \& Engel, R. R. (1990). Sensory gating in normals and schizophrenics: A failure to find strong P50 suppression in normals. Biological Psychiatry, 27(11), 1216-1226. doi:http://dx.doi.org/10.1016/0006-3223(90)90419-3

Kay SR, Fiszbein A, O. L. (1987). The Positive and Negative Syndrome Scale for schizophrenia. Schizophr Bull., 13(2), 261-276. doi:10.1093/schbul/13.2.261

Keefe, Bilder, Davis, Harvey, Rosenheck, Perkins, ... Hsiao. (2015). Neurocognitive Effects of Antipsychotic Medications in Patients With Chronic Schizophrenia in the CATIE Trial. Archives of General Psychiatry, 64(June 2007), 633-647. doi:10.1001/archpsyc.64.6.633

Keefe, Buchanan, Marder, Schooler, Dugar, Zivkov, \& Stewart. (2013). Clinical trials of potential cognitive-enhancing drugs in schizophrenia: What have we learned so far? Schizophrenia Bulletin, 39(2), 417-435. doi:10.1093/schbul/sbr153

Keefe, Eesley, \& Poe. (2005). Defining a cognitive function decrement in schizophrenia. Biological Psychiatry, 57(6), 688-91. doi:10.1016/j.biopsych.2005.01.003

Keefe, \& Fenton. (2007). How Should DSM-V Criteria for Schizophrenia Include Cognitive Impairment? Schizophrenia Bulletin, 33(4), 912-920. doi:10.1093/schbul/sbm046

Keefe, \& Harvey. (2012). Cognitive Impairment in Schizophrenia. Handbook of Experimental Pharmacology, 213, 11-38. doi:10.1007/978-3-642-25758-2

Keefe, Malhotra, Meltzer, Kane, Buchanan, Murthy, ... Goldman. (2008). Efficacy and Safety of Donepezil in Patients with Schizophrenia or Schizoaffective Disorder : 
Significant Placebo / Practice Effects in a 12-Week, Randomized, Double-Blind Placebo-Controlled Trial. Neuropsychopharmacology, 33(6), 1217-1228. doi:10.1038/sj.npp.1301499

Keefe, Seidman, Christensen, Hamer, Sharma, Sitskoorn, ... Lieberman. (2004). Comparative effect of atypical and conventional antipsychotic drugs on neurocognition in first-episode psychosis: A randomized, double-blind trial of olanzapine versus low doses of haloperidol. American Journal of Psychiatry, 161(6), 985-995. doi:10.1176/appi.ajp.161.6.985

Keefe, Seidman, Christensen, Hamer, Sharma, Sitskoorn, ... Lieberman. (2006). LongTerm Neurocognitive Effects of Olanzapine or Low-Dose Haloperidol in FirstEpisode Psychosis. Biological Psychiatry, 59(2), 97-105. doi:10.1016/j.biopsych.2005.06.022

Keefe, Silva, Perkins, \& Lieberman. (1999). The effects of atypical antipsychotic drugs on neurocognitive impairment in schizophrenia: a review and meta-analysis. Schizophrenia Bulletin, 25(2), 201-222.

Keri, S., \& Janka, Z. (2004). Critical evaluation of cognitive dysfunctions as endophenotypes of schizophrenia. Acta Psychiatrica Scandinavica, 110(2), 83-91. doi:10.1111/j.1600-0047.2004.00359.x

Kern, R. S., Nuechterlein, K. H., Green, M. F., Baade, L. E., Fenton, W. S., Gold, J. M., ... Marder, S. R. (2008). The MATRICS Consensus Cognitive Battery, Part 2: CoNorming and Standardization. American Journal of Psychiatry, 165(2), 214-220. doi:10.1176/appi.ajp.2007.07010043

Knott. (n.d.). Acute effects of an alpha7 agonist on ketamine induced sensory gating 
impairments. Neuropharmacology, In Press.

Knott. (2000). Quantitative EEG methods and measures in human psychopharmacological research. Human Psychopharmacology, 15(7), 479-498. doi:10.1002/1099-1077(200010)15:7<479::AID-HUP206>3.0.CO;2-5

Knott. (2001). Electroencephalographic characterization of cigarette smoking behavior. Alcohol, 24(2), 95-97. doi:10.1016/S0741-8329(00)00140-3

Knott, Bosman, M., Mahoney, C., Ilivitsky, V., \& Quirt, K. (1999). Transdermal Nicotine: Single Dose Effects on Mood, EEG, Performance, and Event-Related Potential. Pharmacology Biochemistry and Behavior, 63(2), 253-261. doi:10.1016/S0091-3057(99)00006-4

Knott, de la Salle, S., Choueiry, J., Impey, D., Smith, D., Smith, M., ... Labelle, A. (2015). Neurocognitive effects of acute choline supplementation in low, medium and high performer healthy volunteers. Pharmacology Biochemistry and Behavior, 131, 119-129. doi:10.1016/j.pbb.2015.02.004

Knott, de la Salle, S., Smith, D., Choueiry, J., Impey, D., Smith, M., ... Labelle, A. (2015). Effects of acute CDP-choline treatment on resting state brain oscillations in healthy volunteers. Neuroscience Letters, 591, 121-5. doi:10.1016/j.neulet.2015.02.032

Knott, de la Salle, S., Smith, D., Phillipe, T., Dort, H., Choueiry, J., \& Impey, D. (2013). Baseline dependency of nicotine's sensory gating actions: similarities and differences in low, medium and high P50 suppressors. Journal of Psychopharmacology (Oxford, England), 27(9), 790-800. doi:10.1177/0269881113490449 
Knott, Fisher, \& Millar. (2010a). Differential effects of nicotine on P50 amplitude, its gating, and their neural sources in low and high suppressors. Neuroscience, 170(3), 816-26. doi:10.1016/j.neuroscience.2010.07.012

Knott, Impey, Choueiry, Smith, Salle, de la, Saghir, ... Labelle. (2015). An acute dose, randomized trial of the effects of CDP-Choline on Mismatch Negativity (MMN) in healthy volunteers stratified by deviance detection level. Neuropsychiatric Electrophysiology, 1(1), 1-23. doi:10.1186/s40810-014-0002-4

Knott, Millar, McIntosh, Shah, Fisher, Blais, ... Horn. (2011). Separate and combined effects of low dose ketamine and nicotine on behavioural and neural correlates of sustained attention. Biological Psychology, 88(1), 83-93.

doi:10.1016/j.biopsycho.2011.06.012

Knott, Smith, D., de la Salle, S., Impey, D., Choueiry, J., Beaudry, E., ... Labelle, A. (2014). CDP-choline: Effects of the procholine supplement on sensory gating and executive function in healthy volunteers stratified for low, medium and high P50 suppression. Journal of Psychopharmacology (Oxford, England), 28(12), 1095-108. doi:10.1177/0269881114553254

Knott, V. J., Fisher, D. J., \& Millar, A. M. (2010b). Differential effects of nicotine on P50 amplitude, its gating, and their neural sources in low and high suppressors. Neuroscience, 170(3), 816-826.

Kohlhaas, K. L., Bitner, R. S., Gopalakrishnan, M., \& Rueter, L. E. (2012). Effects of $\alpha 7$ nicotinic acetylcholine receptor agonists on antipsychotic efficacy in a preclinical mouse model of psychosis. Psychopharmacology, 220(4), 823-33.

doi:10.1007/s00213-011-2535-6 
Koike, K., Hashimoto, K., Takai, N., Shimizu, E., Komatsu, N., Watanabe, H., .. Iyo, M. (2005). Tropisetron improves deficits in auditory P50 suppression in schizophrenia. Schizophrenia Research, 76(1), 67-72. doi:10.1016/j.schres.2004.12.016

Konradsson-geuken, Å., Gash, C. R., Alexander, K., Pomerleau, F., Huettl, P., Gerhardt, G. A., \& Bruno, J. P. (2009). Second-By-Second Analysis of Alpha 7 Nicotinic Receptor Regulation of Glutamate Release in the Prefrontal Cortex of Awake Rate. Synapse, 63(12), 1069-1082. doi:10.1002/syn.20693.Second-By-Second

Korzyukov, O., Pflieger, M. E., Wagner, M., Bowyer, S. M., Rosburg, T., Sundaresan, K., ... Boutros, N. N. (2007). Generators of the intracranial P50 response in auditory sensory gating. NeuroImage, 35(2), 814-826.

doi:10.1016/j.neuroimage.2006.12.011

Kraguljac, N. V., Reid, M., White, D., Jones, R., den Hollander, J., Lowman, D., \& Lahti, A. C. (2012). Neurometabolites in schizophrenia and bipolar disorder - A systematic review and meta-analysis. Psychiatry Research - Neuroimaging, 203(2-3), 111-125. doi:10.1016/j.pscychresns.2012.02.003

Krause, M., Hoffmann, W. E., \& Hajós, M. (2003). Auditory sensory gating in hippocampus and reticular thalamic neurons in anesthetized rats. Biological Psychiatry, 53(3), 244-253. doi:10.1016/S0006-3223(02)01463-4

Kumari, V., \& Postma, P. (2005). Nicotine use in schizophrenia: the self medication hypotheses. Neuroscience and Biobehavioral Reviews, 29(6), 1021-34.

doi:10.1016/j.neubiorev.2005.02.006

Law, A. J., \& Deakin, J. F. (2001). Asymmetrical reductions of hippocampal NMDAR1 glutamate receptor mRNA in the psychoses. Neuroreport, 12(13), 2971-2974. 
doi:10.1097/00001756-200109170-00043

Lees, J., Applegate, E., Emsley, R., Lewis, S., Michalopoulou, P., Collier, T., ... Drake, R. J. (2015). Calibration and cross-validation of MCCB and CogState in schizophrenia. Psychopharmacology, 232(21-22), 3873-3882. doi:10.1007/s00213015-3960-8

Leiser, S. C., Bowlby, M. R., Comery, T. a, \& Dunlop, J. (2009). A cog in cognition: how the alpha 7 nicotinic acetylcholine receptor is geared towards improving cognitive deficits. Pharmacology \& Therapeutics, 122(3), 302-11. doi:10.1016/j.pharmthera.2009.03.009

Leitman, D. I., Laukka, P., Juslin, P. N., Saccente, E., Butler, P., \& Javitt, D. C. (2010). Getting the cue: sensory contributions to auditory emotion recognition impairments in schizophrenia. Schizophrenia Bulletin, 36(3), 545-56. doi:10.1093/schbul/sbn115

Leitman, D. I., Sehatpour, P., Higgins, B. a., Foxe, J. J., Silipo, G., \& Javitt, D. C. (2010). Sensory deficits and distributed hierarchical dysfunction in schizophrenia. American Journal of Psychiatry, 167(July), 818-827. doi:10.1176/appi.ajp.2010.09030338

Leonard, Breese, Adams, Benhammou, Gault, Stevens, ... Freedman. (2000). Smoking and schizophrenia: Abnormal nicotinic receptor expression. European Journal of Pharmacology, 393(1-3), 237-242. doi:10.1016/S0014-2999(00)00035-2

Leonard, S., Adams, C., Breese, C. R., Adler, L. E., Bickford, P., Byerley, W., ... Freedman, R. (1996). Nicotinic receptor function in schizophrenia. Schizophrenia Bulletin, 22(3), 431-445.

Leonard, S., Gault, J., Hopkins, J., Logel, J., Vianzon, R., Short, M., ... Freedman, R. (2002). Association of promoter variants in the alpha 7 nicotinic acetylcholine 
receptor subunit gene with an inhibitory deficit found in schizophrenia. Archives of General Psychiatry, 59(12), 1085-1096. doi:10.1001/archpsyc.59.12.1085

Leysen, J. E., Gommeren, W., \& Schotte, A. (1996). Serotonin Receptor Subtypes: possible roles and implications in antipsychotic drug action.

Lieberman, J. A., Dunbar, G., Segreti, A. C., Girgis, R. R., Seoane, F., Beaver, J. S., ... Hosford, D. A. (2013). A randomized exploratory trial of an $\alpha-7$ nicotinic receptor agonist (TC-5619) for cognitive enhancement in schizophrenia. Neuropsychopharmacology: Official Publication of the American College of Neuropsychopharmacology, 38(6), 968-75. doi:10.1038/npp.2012.259

Lieberman, J. A., Stroup, T. S., McEvoy, J. P., Swartz, M. S., Rosenheck, R. A., Perkins, D. O., ... Hsiao, J. K. (2005). Effectiveness of Antipsychotic Drugs in Patients with Chronic Schizophrenia. The New England Journal of Medicine, 353(12), 877-889. doi:10.1056/NEJMoa1404304

Light, G. A., Geyer, M. A., Clementz, B. A., Cadenhead, K. S., \& Braff, D. L. (2000). Normal P50 Suppression in Schizophrenia Patients Treated With Atypial Antipsychotic Medications. American Journal of Psychiatry, 157, 767-771.

Light, G. A., Swerdlow, N. R., Rissling, A. J., Radant, A., Sugar, C. A., Sprock, J., ... Braff, D. L. (2012). Characterization of neurophysiologic and neurocognitive biomarkers for use in genomic and clinical outcome studies of schizophrenia. PloS One, 7(7), e39434. doi:10.1371/journal.pone.0039434

Lindstrom, J. M., Seybold, M. E., Lennon, V. A., Whittingham, S., \& Duane, D. D. (1976). Antibody to acetylcholine receptor in myasthenia gravis. Prevalence, clinical correlates, and diagnostic value. Neurology, 26(11), 1054-1059. 
doi:10.1212/WNL.26.11.1054

Liu, Hong, X., Chan, R. C. K., Kong, F., Peng, Z., Wan, X., ... Cheng, L. (2013). Association study of polymorphisms in the alpha 7 nicotinic acetylcholine receptor subunit and catechol-o-methyl transferase genes with sensory gating in first-episode schizophrenia. Psychiatry Research, 209(3), 431-438.

doi:10.1016/j.psychres.2013.03.027

Liu, Hwu, H. G., Lin, M. W., Ou-Yang, W. C., Lee, S. F. C., Fann, C. S. J., ... Hsieh, S. H. (2001). Suggestive evidence for linkage of schizophrenia to markers at chromosome 15q13-14 in Taiwanese families. American Journal of Medical Genetics - Neuropsychiatric Genetics, 105(8), 658-661. doi:10.1002/ajmg.1547

Louchart-De La Chapelle, S., Levillain, D., Ménard, J. F., Van Der Elst, A., Allio, G., Haouzir, S., ... Thibaut, F. (2005). P50 inhibitory gating deficit is correlated with the negative symptomatology of schizophrenia. Psychiatry Research, 136(1), 27-34. doi:10.1016/j.psychres.2003.04.001

Lu, B. Y., Edgar, J. C., Jones, A. P., Smith, A. K., Huang, M. X., Miller, G. a., \& Cañive, J. M. (2007). Improved test-retest reliability of 50-ms paired-click auditory gating using magnetoencephalography source modeling. Psychophysiology, 44(1), 86-90. doi:10.1111/j.1469-8986.2006.00478.x

Luntz-Leybman, V., Bickford, P. C., \& Freedman, R. (1992). Cholinergic gating of response to auditory stimuli in rat hippocampus. Brain Research, 587(1), 130-136. doi:10.1016/0006-8993(92)91437-J

Lutkenhoff, E. S., van Erp, T. G., Thomas, M. A., Therman, S., Manninen, M., Huttunen, M. O., ... Cannon, T. D. (2010). Proton MRS in twin pairs discordant for 
schizophrenia. Molecular Psychiatry, 15(3), 308-318. doi:10.1038/mp.2008.87

Malla, a K., Norman, R. M. G., Manchanda, R., \& Townsend, L. (2002). Symptoms, cognition, treatment adherence and functional outcome in first-episode psychosis. Psychological Medicine, 32(6), 1109-1119. doi:10.1017/S0033291702006050

Markou, A. (2010). Disruption of Performance in the 5-Choice Serial Reaction Time Task Induced by Administration of NMDA Receptor Antagonists: Relevance to Cognitive Dysfunction in Schizophrenia. Biological Psychiatry, 68(1), 5-16. doi:10.1002/ajmg.1549

Martin, Kem, W., \& Freedman, R. (2004). Alpha-7 nicotinic receptor agonists: potential new candidates for the treatment of schizophrenia. Psychopharmacology, 174(1), 54-64. doi:10.1007/s00213-003-1750-1

Martin, L. F., \& Freedman, R. (2007). Schizophrenia and the alpha7 nicotinic acetylcholine receptor. International Review of Neurobiology, 78(06), 225-246. doi:10.1016/S0074-7742(06)78008-4

Martin-Ruiz, C. M., Haroutunian, V. H., Long, P., Young, A. H., Davis, K. L., Perry, E. K., \& Court, J. A. (2003). Dementia rating and nicotinic receptor expression in the prefrontal cortex in schizophrenia. Biological Psychiatry, 54(11), 1222-1233. doi:10.1016/S0006-3223(03)00348-2

Maruff, P., Thomas, E., Cysique, L., Brew, B., Collie, A., Snyder, P., \& Pietrzak, R. H. (2009). Validity of the CogState Brief Battery: Relationship to Standardized Tests and Sensitivity to Cognitive Impairment in Mild Traumatic Brain Injury, Schizophrenia, and AIDS Dementia Complex. Archives of Clinical Neuropsychology, 24(2), 165-178. doi:10.1093/arclin/acp010 
Marutle, A., Zhang, X., Court, J., Piggott, M., Johnson, M., Perry, R., ... Nordberg, A. (2001). Laminar distribution of nicotinic receptor subtypes in cortical regions in schizophrenia. Journal of Chemical Neuroanatomy, 22(1-2), 115-126. doi:10.1016/S0891-0618(01)00117-X

McEvoy, J. P., \& Lindgren, J. (1996). Smoking and schizophrenia. Drug Development Research, 38(3-4), 263-266. doi:10.1002/(SICI)10982299(199607/08)38:3/4<263::AID-DDR15>3.0.CO;2-\#

McGehee, D., \& Lorna, R. (1995). Physiological Diversity of Nicotinic Acetylcholine Receptors Expressed By Vertebrate Neurons. Annu. Rev. Physiol., 57, 521-546. doi:10.1146/annurev.ph.57.030195.002513

Mexal, S., Frank, M., Berger, R., Adams, C. E., Ross, R. G., Freedman, R., \& Leonard, S. (2005). Differential modulation of gene expression in the NMDA postsynaptic density of schizophrenic and control smokers. Molecular Brain Research, 139(2), 317-332. doi:10.1016/j.molbrainres.2005.06.006

Miller, C. L., \& Freedman, R. (1995). The activity of hippocampal interneurons and pyramidal cells during the response of the hippocampus to repeated auditory stimuli. Neuroscience, 69(2), 371-381. doi:10.1016/0306-4522(95)00249-I

Miyamoto, Merrill, D. B., Fredrik Jarskog, L., Wolfgang Fleishhacker, W., Marder, S. R., \& Lieberman, J. A. (2015). Antipsychotic Drugs. Psychiatry, 2088-2128. doi:10.1002/9781118753378.ch104

Miyamoto, Miyake, N., Jarskog, L. F., Fleischhacker, W. W., \& Lieberman, J. A. (2012). Pharmacological treatment of schizophrenia: a critical review of the pharmacology and clinical effects of current and future therapeutic agents. Molecular Psychiatry, 
17(12), 1206-1227. doi:10.1038/mp.2012.47

Miyamoto, S., Duncan, G. E., Marx, C. E., \& Lieberman, J. a. (2005). Treatments for schizophrenia: a critical review of pharmacology and mechanisms of action of antipsychotic drugs. Molecular Psychiatry, 10(1), 79-104.

doi:10.1038/sj.mp.4001556

Mohamed, S., Paulsen, J. S., O’Leary, D., Arndt, S., \& Andreasen, N. (1999).

Generalized cognitive deficits in schizophrenia: A study of first- episode patients. Archives of General Psychiatry, 56(8), 749-754.

Moxon, K., Gerhardt, G., \& Adler, L. E. (2003). Dopaminergic modulation of the P50 auditory-evoked potential in a computer model of the CA3 region of the hippocampus: its relationship to sensory gating in schizophrenia. Biological Cybernetics, 88(4), 265-75. doi:10.1007/s00422-002-0372-8

Mukherjee, S., Mahadik, S. P., Korenovsky, a, Laev, H., Schnur, D. B., \& Reddy, R. (1994). Serum antibodies to nicotinic acetylcholine receptors in schizophrenic patients. Schizophrenia Research, 12(2), 131-6.

Myles-Worsley, M., Ord, L., Blailes, F., Ngiralmau, H., \& Freedman, R. (2004). P50 sensory gating in adolescents from a pacific island isolate with elevated risk for schizophrenia. Biological Psychiatry, 55(7), 663-7.

doi:10.1016/j.biopsych.2003.12.006

Nagamoto, Adler, L. E., Hea, R. a., Griffith, J. M., McRae, K. a., \& Freedman, R. (1996). Gating of auditory P50 in schizophrenics: Unique effects of clozapine. Biological Psychiatry, 40(3), 181-188. doi:10.1016/0006-3223(95)00371-1

Nagamoto, Adler, L. E., McRae, K. A., Huettl, P., Cawthra, E., Gerhardt, G., ... Griffith, 
J. (1999). Auditory P50 in Schizophrenics on Clozapine: Improved Gating Parallels Clinical Improvement and Changes in Plasma 3-Methoxy-4-Hydroxyphenylglycol. Neuropsychobiology, 39(1), 10-17. doi:10.1159/000026553

Nagamoto, Stevens, Fuller, Bernal, Johnson, \& Rose. (1990). Effects of intraventricular kainic acid on sensory gating of the rat N40 evoked potential. Soc Neurosci Abst, 16, 1351.

Neill, J. C., Barnes, S., Cook, S., Grayson, B., Idris, N. F., McLean, S. L., ... Harte, M. K. (2010). Animal models of cognitive dysfunction and negative symptoms of schizophrenia: Focus on NMDA receptor antagonism. Pharmacology \& Therapeutics, 128(3), 419-432. doi:10.1016/j.pharmthera.2010.07.004

Neumann, S. A., Brown, S. M., Ferrell, R. E., Flory, J. D., Manuck, S. B., \& Hariri, A. R. (2006). Human Choline Transporter Gene Variation Is Associated with Corticolimbic Reactivity and Autonomic-Cholinergic Function. Biological Psychiatry, 60(10), 1155-1162. doi:10.1016/j.biopsych.2006.03.059

Nuechterlein, K. H., Green, M. F., Kern, R. S., Baade, L. E., Barch, D. M., Cohen, J. D., ... Marder, S. R. (2008). The MATRICS consensus cognitive battery, part 1: Test selection, reliability, and validity. American Journal of Psychiatry, 165(2), 203-213. doi:10.1176/appi.ajp.2007.07010042

Olincy, A., Harris, J. G., Johnson, L. L., Pender, V., Kongs, S., Allensworth, D., ... Freedman, R. (2006). Proof-of-concept trial of an alpha7 nicotinic agonist in schizophrenia. Archives of General Psychiatry, 63(6), 630-8. doi:10.1001/archpsyc.63.6.630

Olincy, A., \& Stevens, K. E. (2007). Treating Schizophrenia Symptoms with and Alpha 7 
Nicotinic Aonist, From Mice to Men. Biochemical Pharmacology, 74(8), 11921201. doi:10.1177/00220345850640070701

Olincy, Harris, Johnson, Pender, Kongs, Allensworth, \& Ellis. (2006). An a 7-nicotinic cholinergic agonist enhances cognitive function in schizophrenia. Archives of General Psychiatry, 2006.

Olincy, Young, \& Freedman. (1997). Increased levels of the nicotine metabolite cotinine in schizophrenic smokers compared to other. Biological Psychiatry, 42(1), 1-5. doi:10.1016/S0006-3223(96)00302-2

Papke, R. L., Bencherif, M., \& Lippiello, P. (1996). An evaluation of neuronal nicotinic acetylcholine receptor activation by quaternary nitrogen compounds indicates that choline is selective for the alpha 7 subtype. Neuroscience Letters, 213(3), 201-4. doi:10.1016/S0304-3940(96)12889-5

Patrick, J., Séquéla, P., Vernino, S., Amador, M., Luetje, C., \& Dani, J. A. (1993). Functional diversity of neuronal nicotinic acetylcholine receptors. In Cholinergic Function and Dysfunction (Vol. 98, pp. 113-120).

Patterson, J. V., Hetrick, W. P., Boutros, N. N., Jin, Y., Sandman, C., Stern, H., ... Bunney, W. E. (2008). P50 sensory gating ratios in schizophrenics and controls: A review and data analysis. Psychiatry Research, 158(2), 226-247. doi:10.1016/j.psychres.2007.02.009

Pietrzak, R. H., Olver, J., Norman, T., Piskulic, D., Maruff, P., \& Snyder, P. J. (2009). A comparison of the CogState Schizophrenia Battery and the Measurement and Treatment Research to Improve Cognition in Schizophrenia (MATRICS) Battery in assessing cognitive impairment in chronic schizophrenia. Journal of Clinical and 
Experimental Neuropsychology, 31(7), 848-859. doi:10.1080/13803390802592458

Pilowsky, L. S., Bressan, R. a, Stone, J. M., Erlandsson, K., Mulligan, R. S., Krystal, J. H., \& Ell, P. J. (2006). First in vivo evidence of an NMDA receptor deficit in medication-free schizophrenic patients. Molecular Psychiatry, 11(2), 118-119. doi:10.1038/sj.mp.4001751

Potter, D., Summerfelt, A., Gold, J., \& Buchanan, R. W. (2006). Review of clinical correlates of P50 sensory gating abnormalities in patients with schizophrenia. Schizophrenia Bulletin, 32(4), 692-700. doi:10.1093/schbul/sbj050

Radek, R. J., Kohlhaas, K. L., Rueter, L. E., \& Mohler, E. G. (2010). Treating the cognitive deficits of schizophrenia with alpha4beta2 neuronal nicotinic receptor agonists. Current Pharmaceutical Design, 16(3), 309-322. doi:10.2174/138161210790170166

Ramírez, M. J., Cenarruzabeitia, E., Lasheras, B., \& Del Río, J. (1996). Involvement of GABA systems in acetylcholine release induced by 5-HT3 receptor blockade in slices from rat entorhinal cortex. Brain Research, 712(2), 274-280. doi:10.1016/0006-8993(95)01471-3

Rentzsch, J., Jockers-Scherübl, M. C., Boutros, N. N., \& Gallinat, J. (2008). Test-retest reliability of P50, N100 and P200 auditory sensory gating in healthy subjects. International Journal of Psychophysiology : Official Journal of the International Organization of Psychophysiology, 67(2), 81-90.

doi:10.1016/j.ijpsycho.2007.10.006

Rissling, A. J., Makeig, S., Braff, D. L., \& Light, G. (2010). Neurophysiologic markers of abnormal brain activity in schizophrenia. Current Psychiatry Reports, 12(6), 572- 
578. doi:10.1007/s11920-010-0149-Z

Rosenheck, R., Doyle, J., Leslie, D., \& Fontana, A. (2003). Changing environments and alternative perspectives in evaluating the cost-effectiveness of new antipsychotic drugs. Schizophrenia Bulletin, 29(1), 81-93.

Ross, R. G., Hunter, S. K., McCarthy, L., Beuler, J., Hutchison, A. K., Wagner, B. D., ... Freedman, R. (2013). Perinatal choline effects on neonatal pathophysiology related to later schizophrenia risk. American Journal of Psychiatry, 170(3), 290 - 298. doi:10.1016/j.jsbmb.2011.07.002.Identification

Rubboli, F., Court, J. A., Sala, C., Morris, C., Perry, E., \& Clementi, F. (1994). Distribution of neuronal nicotinic receptor subunits in human brain. Neurochemistry International. doi:10.1016/0197-0186(94)90055-8

Sargent, P. B. (1993). The diversity of Neuronal Nicotinic Acetylcholine Receptors. Annual Review of Neuroscience, 16, 403-443. doi:10.1086/393500

Sarter, M., \& Parikh, V. (2005). Choline transporters, cholinergic transmission and cognition. Nature Reviews Neuroscience, 6(1), 48-56. doi:10.1038/nrn1588

Saver, J. L. (2008). Citicoline: update on a promising and widely available agent for neuroprotection and neurorepair. Reviews in Neurological Diseases, 5(4), 167-177.

Secades, J. J. (2011). Citicoline: pharmacological and clinical review, 2010 update. Rev Neurol., 52(Supp1 2), S1-S62.

Secades, J. J. (2012). Probably role of citicoline in stroke rehabilitation: review of the literature. Revista de Neurologia, 54(3), 173-9.

Shiina, A., Shirayama, Y., Niitsu, T., Hashimoto, T., Yoshida, T., Hasegawa, T., ... Hashimoto, K. (2010). A randomised, double-blind, placebo-controlled trial of 
tropisetron in patients with schizophrenia. Ann Gen Psychiatry, 9(27), 27. doi:10.1186/1744-859x-9-27

Shirayama, Y., Yamamoto, A., Nishimura, T., Katayama, S., \& Kawahara, R. (2007). Subsequent exposure to the choline uptake enhancer MKC-231 antagonizes phencyclidine-induced behavioral deficits and reduction in septal cholinergic neurons in rats. European Neuropsychopharmacology: The Journal of the European College of Neuropsychopharmacology, 17(9), 616-26.

doi:10.1016/j.euroneuro.2007.02.011

Simosky, J. K., Stevens, K. E., Adler, L. E., \& Freedman, R. (2003). Clozapine improves deficient inhibitory auditory processing in DBA/2 mice, via a nicotinic cholinergic mechanism. Psychopharmacology, 165(4), 386-96. doi:10.1007/s00213-002-1285-x

Simosky, J. K., Stevens, K. E., Kem, W. R., \& Freedman, R. (2001). Intragastric DMXBA, An Alpha 7 Nicotinic Agonist, Improves Deficient Sensory Inhibition in DBA / 2 Mice. Society of Biological Psychiatry, 3223(01).

Sirota, P., Mosheva, T., Shabtay, H., Giladi, N., Korczyn, A. D., \& Sc, M. (2000). Use of the Selective Serotonin 3 Receptor Antagonist Ondansetron in the Treatment of Neuroleptic-lnduced Tardive Dyskinesia. American Journal of Psychiatry, 157(February), 287-289. doi:10.1176/appi.ajp.157.2.287

Smith, Boutros, N. N., \& Schwarzkopf, S. B. (1994). Reliability of P50 auditory eventrelated potential indices of sensory gating. Psychophysiology, 31(5), 495-502. doi:10.1111/j.1469-8986.1994.tb01053.x

Smith, Edgar, J. C., Huang, M., Lu, B. Y., Thoma, R. J., Hanlon, F. M., .. Cañive, J. M. (2010). Cognitive abilities and 50- and 100-msec paired-click processes in 
schizophrenia. The American Journal of Psychiatry, 167(10), 1264-75.

doi:10.1176/appi.ajp.2010.09071059

Smith, Warner-Cohen, J., Matute, M., Butler, E., Kelly, E., Vaidhyanathaswamy, S., \& Khan, A. (2006). Effects of Nicotine Nasal Spray on Cognitive Function in Schizophrenia. Neuropsychopharmacology, 31(3), 637-643.

doi:10.1038/sj.npp.1300881

Snitz, B. E., MacDonald, A. W., \& Carter, C. S. (2005). Cognitive Deficits in Unaffected First-Degree Relatives of Schizophrenia Patients: A Meta-analytic Review of Putative Endophenotypes. Schizophrenia Bulletin, 32(1), 179-194. doi:10.1093/schbul/sbi048

Stevens, K. E., Adams, C. E., Mellott, T. J., Robbins, E., \& Kisley, M. A. (2008). Perinatal choline deficiency produces abnormal sensory inhibition in SpragueDawley rats. Brain Research, 1237, 84-90. doi:10.1016/j.brainres.2008.08.047

Stevens, K. E., Adams, C. E., Yonchek, J., Hickel, C., Danielson, J., \& Kisley, M. a. (2008). Permanent improvement in deficient sensory inhibition in DBA/2 mice with increased perinatal choline. Psychopharmacology, 198(3), 413-20. doi:10.1007/s00213-008-1170-3

Stevens, K. E., Kem, W. R., Mahnir, V. M., \& Freedman, R. (1998). Selective alpha 7nicotinic agonists normalize inhibition of auditory response in DBA mice. Psychopharmacology, 136(4), 320-327. doi:10.1007/s002130050573

Stevens, K. E., \& Wear, K. D. (1997). Normalizing effects of nicotine and a novel nicotinic agonist on hippocampal auditory gating in two animal models. Pharmacology Biochemistry and Behavior, 57(4), 869-874. doi:10.1016/S0091- 
3057(96)00466-2

Stevens, Meltzer, \& Rose. (1995). Nicotinic cholinergic normalization of amphetamineinduced loss of auditory gating in freely moving rats. Psychopharmacology, 119(2), 163-170. doi:10.1007/BF02246157

Stitzel, J. A., Farnham, D. A., \& Collins, A. C. (1996). Linkage of strain-specific nicotinic receptor alpha 7 subunit restriction fragment length polymorphisms with levels of alpha-bungarotoxin binding in brain. Brain Research. Molecular Brain Research, 43(1-2), 30-40.

Strand, J. E., \& Nybäck, H. (2005). Tobacco use in schizophrenia: A study of cotinine concentrations in the saliva of patients and controls. European Psychiatry, 20(1), 50-54. doi:10.1016/j.eurpsy.2004.09.005

Sugaya, K., Giacobini, E., \& Chiappinelli, V. a. (1990). Nicotinic acetylcholine receptor subtypes in human frontal cortex: changes in Alzheimer's disease. J Neurosci Res, 27(3), 349-359.

Swartz, M. S., Perkins, D. O., Stroup, T. S., McEvoy, J. P., Nieri, J. M., \& Haak, D. C. (2003). Assessing clinical and functional outcomes in the Clinical Antipsychotic Trials of Intervention Effectiveness (CATIE) schizophrenia trial. Schizophrenia Bulletin, 29(1), 33-43.

Thaker, G. K. (2007). Schizophrenia endophenotypes as treatment targets. Expert Opinion on Therapeutic Targets, 11(9), 1189-1206. doi:10.1517/14728222.11.9.1189

Thornton, A. E., Van Snellenberg, J. X., Sepehry, A. A., \& Honer, W. G. (2005). The impact of atypical antipsychotic medications on long-term memory dysfunction in 
schizophrenia spectrum disorder: a quantitative review. Journal of Psychopharmacology, 20(3), 335-346. doi:10.1177/0269881105057002

Toyohara, J., \& Hashimoto, K. (2010). a7 Nicotinic Receptor Agonists: Potential Therapeutic Drugs for Treatment of Cognitive Impairments in Schizophrenia and Alzheimer's Disease. The Open Medicinal Chemistry Journal, 4, 37-56. doi:10.2174/1874104501004010037

Tregellas, J. R., Davalos, D. B., Rojas, D. C., Waldo, M. C., Gibson, L., Wylie, K., ... Freedman, R. (2007). Increased hemodynamic response in the hippocampus, thalamus and prefrontal cortex during abnormal sensory gating in schizophrenia. Schizophrenia Research, 92(1-3), 262-72. doi:10.1016/j.schres.2006.12.033

Tsuang, D. W., Skol, a D., Faraone, S. V, Bingham, S., Young, K. a, Prabhudesai, S., ... Tsuang, M. T. (2001). Examination of genetic linkage of chromosome 15 to schizophrenia in a large Veterans Affairs Cooperative Study sample. American Journal of Medical Genetics, 105(8), 662-668. doi:10.1002/ajmg.1550

Turetsky, B. I., Calkins, M. E., Light, G. a., Olincy, A., Radant, A. D., \& Swerdlow, N. R. (2007). Neurophysiological endophenotypes of schizophrenia: The viability of selected candidate measures. Schizophrenia Bulletin, 33(1), 69-94. doi:10.1093/schbul/sb1060

Uteshev, V. V., Meyer, E. M., \& Papke, R. L. (2002). Regulation of Neuronal Function by Choline and 4OH-GTS-21 Through alpha 7 Nicotinic Receptors. Journal of Neurophysiology, 89(4), 1797-1806. doi:10.1152/jn.00943.2002

Van Putten, T., Marder, S. R., Wirshing, W. C., Aravagiri, M., \& Chabert, N. (1991). Neuroleptic plasma levels. Schizophrenia Bulletin, 17(2), 197-216. 
Waldo, M. C., Cawthra, E., Adler, L. E., Dubester, S., Staunton, M., Nagamoto, H., ... Scherzinger, a. (1994). Auditory sensory gating, hippocampal volume, and catecholamine metabolism in schizophrenics and their siblings. Schizophrenia Research, 12(2), 93-106. doi:10.1016/0920-9964(94)90067-1

Wilson, C. L., Babb, T. L., Halgren, E., Wang, M. L., \& Crandall, P. H. (1984). Habituation of human limbic neuronal response to sensory stimulation. Experimental Neurology, 84(1), 74-97. doi:10.1016/0014-4886(84)90007-4

Winterer, G., Gallinat, J., Brinkmeyer, J., Musso, F., Kornhuber, J., Thuerauf, N., ... Streffer, J. R. (2013). Allosteric alpha-7 nicotinic receptor modulation and P50 sensory gating in schizophrenia: A proof-of-mechanism study. Neuropharmacology, 64, 197-204. doi:10.1016/j.neuropharm.2012.06.040

Woodward, N. D., Purdon, S. E., Meltzer, H. Y., \& Zald, D. H. (2007). A meta-analysis of cognitive change with haloperidol in clinical trials of atypical antipsychotics: Dose effects and comparison to practice effects. Schizophrenia Research, 89(1-3), 211-224. doi:10.1016/j.schres.2006.08.021

Wurtman, R. J., Regan, M., Ulus, I., \& Yu, L. (2000). Effect of oral CDP-choline on plasma choline and uridine levels in humans. Biochemical Pharmacology, 60(7), 989-992. doi:10.1016/S0006-2952(00)00436-6

Yoo, S. Y., Yeon, S., Choi, C. H., Kang, D. H., Lee, J. M., Shin, N. Y., ... Kwon, J. S. (2009). Proton magnetic resonance spectroscopy in subjects with high genetic risk of schizophrenia: investigation of anterior cingulate, dorsolateral prefrontal cortex and thalamus. Schizophrenia Research, 111(1-3), 86-93. doi:10.1016/j.schres.2009.03.036 


\section{Appendix A}

\section{PSYCHIATRIC RATING SCALE BATTERY}

Date Rated: $\frac{}{(\mathrm{m} / \mathrm{d} / \mathrm{y})} \quad$ Time Rated: $\frac{}{(24 \mathrm{hr} \text { clock })} \quad$ Rater's Initials:

POSITIVE AND NEGATIVE SYNDROME SCALE (PANSS)

Directions: Check $(\sqrt{ })$ the term for each symptom which best describes the patient's condition over the past 72 hours and not relative to any other time.

POSITIVE SCALE

\begin{tabular}{|l|l|c|c|c|c|c|c|c|}
\hline \multicolumn{2}{|c|}{ Symptom } & \multicolumn{9}{c|}{ Description } & \multicolumn{2}{c|}{} \\
\cline { 2 - 9 } & Absent & $\begin{array}{c}\text { Very } \\
\text { Mild }\end{array}$ & Mild & Moderate & $\begin{array}{c}\text { Mod. } \\
\text { Severe }\end{array}$ & Severe & Extreme \\
\hline 1 & Delusions & $1 \square$ & $2 \square$ & $3 \square$ & $4 \square$ & $5 \square$ & $6 \square$ & $7 \square$ \\
\hline 2 & $\begin{array}{l}\text { Conceptual } \\
\text { Disorganization }\end{array}$ & $1 \square$ & $2 \square$ & $3 \square$ & $4 \square$ & $5 \square$ & $6 \square$ & $7 \square$ \\
\hline 3 & $\begin{array}{l}\text { Hallucinatory } \\
\text { Behaviour }\end{array}$ & $1 \square$ & $2 \square$ & $3 \square$ & $4 \square$ & $5 \square$ & $6 \square$ & $7 \square$ \\
\hline 4 & $\begin{array}{l}\text { Excitement } \\
5\end{array}$ & $1 \square$ & $2 \square$ & $3 \square$ & $4 \square$ & $5 \square$ & $6 \square$ & $7 \square$ \\
\hline 6 & $\begin{array}{l}\text { Grandiosity } \\
\text { Persecution }\end{array}$ & $1 \square$ & $2 \square$ & $3 \square$ & $4 \square$ & $5 \square$ & $6 \square$ & $7 \square$ \\
\hline 7 & Hostility & $1 \square$ & $2 \square$ & $3 \square$ & $4 \square$ & $5 \square$ & $6 \square$ & $7 \square$ \\
\hline
\end{tabular}

\begin{tabular}{|c|c|c|c|c|c|c|c|c|}
\hline \multicolumn{9}{|c|}{ NEGATIVE SCALE } \\
\hline & \multirow[b]{2}{*}{ Symptom } & \multicolumn{7}{|c|}{ Description } \\
\hline & & Absent & $\begin{array}{l}\text { Very } \\
\text { Mild }\end{array}$ & Mild & Moderate & $\begin{array}{l}\text { Mod. } \\
\text { Severe }\end{array}$ & Severe & Extreme \\
\hline 1 & Blunted Affect & $1 \square$ & $2 \square$ & $3 \square$ & $4 \square$ & $5 \square$ & $6 \square$ & $7 \square$ \\
\hline 2 & Emotional Withdrawal & $1 \square$ & $2 \square$ & $3 \square$ & $4 \square$ & $5 \square$ & $6 \square$ & $7 \square$ \\
\hline 3 & Poor Rapport & $1 \square$ & $2 \square$ & $3 \square$ & $4 \square$ & $5 \square$ & $6 \square$ & $7 \square$ \\
\hline 4 & $\begin{array}{l}\text { Passive/ apathetic } \\
\text { social withdrawal }\end{array}$ & $1 \square$ & $2 \square$ & $3 \square$ & $4 \square$ & $5 \square$ & $6 \square$ & $7 \square$ \\
\hline 5 & $\begin{array}{l}\text { Difficulty in abstract } \\
\text { thinking }\end{array}$ & $1 \square$ & $2 \square$ & $3 \square$ & $4 \square$ & $5 \square$ & $6 \square$ & $7 \square$ \\
\hline 6 & $\begin{array}{l}\text { Lack of spontaneity } \\
\text { and flow of } \\
\text { conversation }\end{array}$ & $1 \square$ & $2 \square$ & $3 \square$ & $4 \square$ & $5 \square$ & $6 \square$ & $7 \square$ \\
\hline 7 & Stereotyped Thinking & $1 \square$ & $2 \square$ & $3 \square$ & $4 \square$ & $5 \square$ & $6 \square$ & $7 \square$ \\
\hline
\end{tabular}


PSYCHIATRIC RATING SCALE BATTERY

POSITIVE AND NEGATIVE SYNDROME SCALE (PANSS) - Continued* GENERAL PSYCHOPATHOLOGY SCALE

\begin{tabular}{|c|c|c|c|c|c|c|c|c|}
\hline & \multirow[b]{2}{*}{ Symptom } & \multicolumn{7}{|c|}{ Description } \\
\hline & & Absent & $\begin{array}{l}\text { Very } \\
\text { Mild }\end{array}$ & Mild & Moderate & $\begin{array}{l}\text { Mod. } \\
\text { Severe }\end{array}$ & Severe & Extreme \\
\hline 1 & Somatic Concern & 1ㅁ & $2 \square$ & $3 \square$ & 4ロ & $5 \square$ & 6ロ & $7 \square$ \\
\hline 2 & Anxiety & $1 \square$ & $2 \square$ & $3 \square$ & $4 \square$ & $5 \square$ & $6 \square$ & $7 \square$ \\
\hline 3 & Guilt Feelings & $1 \square$ & $2 \square$ & $3 \square$ & $4 \square$ & $5 \square$ & $6 \square$ & $7 \square$ \\
\hline 4 & Tension & $1 \square$ & $2 \square$ & $3 \square$ & $4 \square$ & $5 \square$ & $6 \square$ & $7 \square$ \\
\hline 5 & $\begin{array}{l}\text { Mannerisms and } \\
\text { Posturing }\end{array}$ & $1 \square$ & $2 \square$ & $3 \square$ & $4 \square$ & $5 \square$ & $6 \square$ & $7 \square$ \\
\hline 6 & Depression & $1 \square$ & $2 \square$ & $3 \square$ & $4 \square$ & $5 \square$ & $6 \square$ & $7 \square$ \\
\hline 7 & Motor Retardation & $1 \square$ & $2 \square$ & $3 \square$ & $4 \square$ & $5 \square$ & $6 \square$ & $7 \square$ \\
\hline 8 & Uncooperativeness & $1 \square$ & $2 \square$ & $3 \square$ & $4 \square$ & $5 \square$ & $6 \square$ & $7 \square$ \\
\hline 9 & $\begin{array}{l}\text { Unusual Thought } \\
\text { Content }\end{array}$ & $1 \square$ & $2 \square$ & $3 \square$ & $4 \square$ & $5 \square$ & $6 \square$ & $7 \square$ \\
\hline 10 & Disorientation & $1 \square$ & $2 \square$ & $3 \square$ & $4 \square$ & $5 \square$ & $6 \square$ & $7 \square$ \\
\hline 11 & Poor Attention & $1 \square$ & $2 \square$ & $3 \square$ & $4 \square$ & $5 \square$ & $6 \square$ & $7 \square$ \\
\hline 12 & $\begin{array}{l}\text { Lack of Judgement } \\
\text { and Insight }\end{array}$ & $1 \square$ & $2 \square$ & $3 \square$ & $4 \square$ & $5 \square$ & $6 \square$ & $7 \square$ \\
\hline 13 & $\begin{array}{l}\text { Disturbance of } \\
\text { Volition }\end{array}$ & $1 \square$ & $2 \square$ & $3 \square$ & $4 \square$ & $5 \square$ & $6 \square$ & $7 \square$ \\
\hline 14 & Poor Impulse Control & $1 \square$ & $2 \square$ & $3 \square$ & $4 \square$ & $5 \square$ & $6 \square$ & $7 \square$ \\
\hline 15 & Preoccupation & $1 \square$ & $2 \square$ & $3 \square$ & $4 \square$ & $5 \square$ & $6 \square$ & $7 \square$ \\
\hline 16 & $\begin{array}{l}\text { Active Social } \\
\text { Avoidance }\end{array}$ & $1 \square$ & $2 \square$ & $3 \square$ & $4 \square$ & $5 \square$ & $6 \square$ & $7 \square$ \\
\hline
\end{tabular}

*Refer to symptom definitions in the Rating Scales Procedures Manual. 


\section{Appendix B}

Date: $\_$SCZ Choline Galantamine Study ID:

- Have you ever sought treatment or been treated for drug or alcohol abuse?

NO YES:

What is your daily (or weekly) alcohol consumption?

- Do you use street drugs? (e.g. marijuana, cocaine)

NO YES:

If YES: What kind(s)? How Often?

\section{ALCOHOL AND DRUG USE}

Alcohol use

- Has there been any time in your life when you had five or more drinks (beer, wine, or liquor) on one occasion?

NO YES

(Skip the following if NO)

If YES:

- What are your drinking habits like? (How much do you drink?)

- When in your life were you drinking the most? (How long did that period last?) Record date of heaviest use and describe pattern :

During that time...

- How often were you drinking?

- What were you drinking? How much?

- Did your drinking cause problems for you?

○ Did anyone object to your drinking?

*If alcohol dependence seems likely, then participant CAN NOT participate in this study*

\section{Drug and medicine use}

- Have you ever used street drugs?

NO YES:

- Have you ever gotten "hooked" on a prescribed medicine or taken a lot more of it than you were supposed to? NO YES:

\section{(Skip the following if $\mathrm{NO}$ )}

If YES:

Guidelines for rating level of drug and medicine use:

Street Drug:

- When were you using (DRUG) the most?

- Has there been a time when you used it at least ten times in a one-month period of time?

(1) has ever taken street drug more than 10 times in a one-month period

Prescribed Medicine: 
(2) reports becoming dependent on a prescribed drug OR using much more of it than was prescribed

- If drug group never used or used only once, or if prescribed drug used as directed

- If drug used at least twice, but less than level indicated on (1)

- If drug used at level indicated in item (1) or if possibly dependent on prescribed drug (item (2) is true) $\rightarrow$ circle " 1 "

$\rightarrow$ circle " 2 "

$\rightarrow$ circle " 3 "

Drug list:

\begin{tabular}{|c|c|c|}
\hline $\begin{array}{l}\text { Circle the name of each drug ever used } \\
\text { (or write in name if other) }\end{array}$ & $\begin{array}{l}\text { Period of heaviest use (age or date, and duration) and } \\
\text { describe pattern of use }\end{array}$ & Level of use \\
\hline $\begin{array}{l}\text { Sedatives - hypnotics - anxiolytics: } \\
\text { Quaalude, Seconal, Valium, Xanax, } \\
\text { Librium, barbiturates, Miltown, Ativan, } \\
\text { Dalmane, Halcion, Restoril, or other : }\end{array}$ & & 123 \\
\hline $\begin{array}{l}\text { Cannabis: marijuana, hashish, THC, or } \\
\text { other: }\end{array}$ & & 123 \\
\hline $\begin{array}{l}\text { Stimulants: amphetamine, "speed", } \\
\text { crystal meth, dexadrine, Ritalin, "ice", } \\
\text { or other: }\end{array}$ & & 123 \\
\hline $\begin{array}{l}\text { Opioids: heroin, morphine, opium, } \\
\text { Methadone, Darvon, codein, Percodan, } \\
\text { Demerol, Dilaudid, unspecified or other: }\end{array}$ & & 123 \\
\hline $\begin{array}{l}\text { Cocaine: intranasal, IV, freebase, crack, } \\
\text { "speedball", unspecified or other: }\end{array}$ & & 123 \\
\hline $\begin{array}{l}\text { Hallucinogens/PCP: LSD, mescaline, } \\
\text { peyote, psilocybin, STP, mushrooms, } \\
\text { PCP (“angel dust"), Extasy, MDMA, or } \\
\text { other: }\end{array}$ & & 123 \\
\hline $\begin{array}{l}\text { Other: steroids, "glue", paint, inhalants, } \\
\text { nitrous oxide ("laughing gas"), amyl or } \\
\text { butyl nitrate ("popers"), nonprescription } \\
\text { sleep or diet pills, unknown, or other: }\end{array}$ & & 123 \\
\hline
\end{tabular}




\section{Appendix C}

Patient Name

ID:

Date:

Nicotine Agonist Treatment for Sensory and Cognitive Deficits in Schizophrenia (please check off and complete before contact the Research Assistant)

Inclusion Criteria

- Male or female

- $18-60$ years old

- Meet DSM-IV/DSM-IV-TR criteria for Schizophrenia

- Clinical stability of the past 2 months [assessed with the PANSS]

- Treatment with a single antipsychotic medication (concomitant psychiatric medications allowing on an "if needed basis".

- Smoker or non-smoker

Exclusion Criteria

- Any comorbid Axis I disorder including a current or recent history of alcohol/substance abuse

- A clinically significant medical illness or organic brain disorder known to cause psychosis or cognitive impairment

- Recent head trauma $(<6 \mathrm{mos})$

- Major learning disability

- Body mass index $>38 \mathrm{~kg} / \mathrm{m}^{2}$

- Use of illicit drugs

- Abnormal hearing

Requires Physician Information

- Scale for Global Assessment of Functioning

- PANSS

Medication Information

\section{Comorbid Disorders}

Duration of Illness

Number of Previous Hospitalizations 


\section{Appendix D}

\section{University of Ottawa
Institute of Mental
Health Research \\ Mental Health Centre}

\section{INFORMATION SHEET AND INFORMED CONSENT FORM}

Title of Study: An Initial Phase 2 Trial of an Add-On Nicotinic Agonist Treatment for Sensory and Cognitive Deficits in Schizophrenia

Principal Investigator: Verner J. Knott, Ph.D., C. Psych.

Co-Investigators: Alain Labelle, M.D., Paul Albert, Ph.D., Vadim Ilivitsky, M.D., Dhrasti Shah, Ph.D (Cand.), Ashley Beaudoin, M.Sc., Robert Aidelbaum, M.Sc. (Cand.)

Participation in this study is voluntary. Please read this Information Sheet and Informed Consent Form carefully before you decide if you would like to participate. Ask the study doctor and study team as many questions as you like. We encourage you to discuss your options with family, friends or your healthcare team.

\section{Why am I being given this form?}

You are being asked to participate in this research study because you have been diagnosed with schizophrenia and we are interested in learning more about the relationship between schizophrenia and a nicotine-like natural health product.

\section{Why is this study being done?}

People with schizophrenia tend to have problems with attention and concentration. Studies found that these patients are unable to block out non-relevant and distracting information (e.g., noises). This may lead to brain overload. Abilities like concentration, memory, and learning may worsen. This ability to filter sensory information has been linked to a gene that affects the way nicotine (a main ingredient of cigarettes) acts in the brain.

Patients with schizophrenia have a high rate of cigarette smoking. $60 \%$ to $90 \%$ smoke compared with $25 \%$ of the general population. It has been suggested that these patients may use nicotine to improve their ability to block out distracting information. Brain wave activity electroencephalography (EEG) in response to sounds has proven useful in understanding this information processing problem.

This study uses EEG measures and performance tasks to find out what single doses of a new nicotinelike treatment (CDP-choline) does to concentration, learning, and memory. It is hoped that this new treatment will improve the way in which you process information, as this may help you in day-to-day activities.

In addition to the above rationale, the data collected will be used in the completion of a masters thesis. Robert Aidelbaum will be involved in the data collection and utilize the results for his masters thesis at Carleton University. 


\section{How is the study designed?}

This study compares the effects of CDP-choline with a placebo. A placebo is an inactive substance that looks exactly like CDP-choline.

Whether you get CDP-choline or the placebo will be decided randomly depending on the study session. Randomization means that you are put into a group by chance. The order that you receive each CDPcholine dose or placebo will be determined in a way that is like pulling a number out of a hat.

This study will be double-blinded. That means you will not be told if you will be taking CDP-choline or the placebo during each session. Your study team will also not know. Blinding helps to remove any bias or pre-conceived notions from affecting the outcome of the study. However, in an emergency this information can be obtained quickly. You may be told once the study is finished.

\section{What is expected of me?}

Screening Session

The first study visit will be a screening visit. The results of the tests and/or questions completed during the screening visit will help the study team determine if you are eligible to continue in this study. If you do not meet the eligibility criteria at this point, you will not be able to continue participation in the study.

In a screening session you will undergo some laboratory tests such as a heart rhythm electrocardiogram (EKG), a blood/urine test, and a carbon monoxide CO test. The EKG and blood test will be used to detect any health abnormalities that may make your participation in this study unsafe. The urine test will be used to determine drug use (benzodiazepines, cocaine metabolite, cannabinoids, oxycodone, ethanol, and opiates). The CO test will be used to determine smoking status. During the screening session, Dr. Labelle will also ask for information on:

- medical, psychiatric history, current symptoms;

- current medication;

- substance use; and

- smoking status;

- Wechsler Test of Adult Reading (WTAR).

During the screening session, a saliva sample will be taken for genetic analysis. This genetic analysis will tell the researchers if you have the CHRNA7 -1831 C/A single nucleotide polymorphism, which may cause a difference if how you react to CDP-choline. The genetic analysis will be done at an external lab (Dr. Paul Albert, Ottawa Hospital Research Institute) and will be stored using a unique study code instead of your name, OHIP number or Hospital identification number (MRN) to maintain confidentiality.

\section{Baseline Session}

Following the initial screening session, you will be asked to complete a baseline session. During the baseline session, you will be asked to complete a practice session of a computer test for memory, learning, and information processing. You will also be asked to complete several EEG tasks. You will 
not have any natural supplement or placebo during this session. The entire duration of the baseline session will take approximately 2 hours.

\section{Testing Sessions}

Following the screening and baseline sessions, you will be asked to come to the study laboratory for 4 more visits. Each laboratory session will be separated by a minimum of 7 days when you will not receive any of the treatment. During these visits, you will be given a different dose of CDP-choline, placebo, or a combination of both. The placebo, an inactive substance that looks exactly like CDPcholine, is used to mask differences in CDP-choline dosage. The different doses are described below. The order in which you will receive the doses will be randomized (like pulling a name out of a hat) and neither you nor the researchers will know what dose order you will receive.

Each testing session will last approximately 4.5 hours. At each session you will have a CO test at the beginning of the session to determine smoking status. You will also receive 1 dose of the study treatment. You must agree to avoid food, caffeine, alcohol, nicotine, and drugs beginning at midnight before each study visit.

During the study visits, you will be asked whether or not you are experiencing any side effects with your study treatment. Your blood pressure and pulse rate will also be taken at the end of each test session to make sure your levels are normal.

The entire study is expected to last approximately 2 years. Your participation in this research study will last approximately 1 month.

\section{Treatment Doses}

The nicotine-like natural supplement, CDP-choline, will be administered in separate sessions as a 500 $\mathrm{mg}, 1000 \mathrm{mg}$, and $2000 \mathrm{mg}$ dose. A placebo dose of cellulose, which contains no CDP-choline and will be used to help us see if the drug is having a true effect, will also be given in a separate session. Placebo will also be used in the $500 \mathrm{mg}$ and $1000 \mathrm{mg}$ CDP-choline sessions in order to mask dosing differences. Each of these treatment doses will be orally administered in the form of 8 capsules.

\section{Lab Assessments}

For each dose, you will be required to come to the laboratory in the morning after avoiding food, caffeine, alcohol, nicotine, and drugs beginning at midnight the night before. The session will begin with you taking the proper dose for that session. You will be allowed to relax (i.e. watch a movie, read, listen to music) for approximately 2.5 hours after you have taken the dose. You will be provided with a light, standard snack during this time. Electroencephalogram EEG and performance tasks will begin 3 hours after taking the dose (after a half hour set-up). The EEG will involve placement of sensors on your scalp, ears and around your eyes, and is used to measure changes in your brain wave activity. You will be presented sounds through headphones while you are watching a video and your brain waves are being recorded. For the performance tasks, a computer will present pictures, words or numbers on the monitor and you will be required to press a response key to some stimuli but not other stimuli. The EEG and performance tasks will be the same as you will complete in the baseline session, and will be the same across all testing sessions. Your blood pressure and heart rate will be taken at the end of each session to make sure that your levels are normal. You will also be provided with a standard lunch at the end of each test session. 


\section{What are the potential risks I may experience?}

The treatment includes three doses $(500 \mathrm{mg}, 1000 \mathrm{mg}, 2000 \mathrm{mg}$ ) of CDP-choline. Studies in healthy individuals have shown that CDP-choline administered alone is safe and has no serious side effects in doses from $250 \mathrm{mg}$ to 2000 milligrams per day.

Two research studies have shown that people with schizophrenia that take up to $2000 \mathrm{mg}$ (daily) of CDP-choline, while also taking antipsychotic medications, have experienced very little side effects, with none being classified as "serious". However, it is important to note there has not been extensive research done on the effects of CDP-choline in patients with schizophrenia.

The amount of drug related side effects that appear will vary from person to person. Some may experience less or more than others, and some may experience no side effects at all. Similar symptoms can also be experienced with placebo. Possible side effects include mild stomach pain, diarrhea, low blood pressure, higher-than-normal heart rate, or low heart rate.

The risks involved in EEG testing are very minimal. Brain wave activity (EEG) monitoring procedures are similar to those carried out in hospitals. Slight redness may occur where electrodes are placed on the scalp and skin. You may also experience boredom, restlessness and some agitation because the tests are long. The performance tasks may cause some mild distress and/or fatigue, and the abstinence from food and caffeine may cause cravings, unease, anxiety, irritability, and hunger.

Blood Sample Risks

You may experience some temporary discomfort when the blood sample is taken during the screening session. There is a small risk of bruising, infection or swelling at the site where the needle is inserted, and some people may feel faint or dizzy.

Risk of Insurability and Employability:

We will take all reasonable steps to keep your research information confidential. Should someone not involved in the research find out that you took part in this research study, or if you choose to share your results (if they are provided to you), there is a possibility that this could affect your insurance or employment.

\section{Can I expect to benefit from participating in this research study?}

You may not receive any direct benefit from your participation in this study. The short-term treatment with CDP-choline will not have long-lasting effects on learning, memory, information processing or any clinical symptoms. It may briefly increase concentration and alertness. Your participation may allow the researchers to understand the connection between CDP-choline and schizophrenia. This may benefit future patients.

\section{Will I be paid for my participation?}

You will be paid a total of $\$ 225$ ( $\$ 25$ for the baseline session, and $\$ 50$ per session) for your time and effort for this study. Missed sessions will not be compensated. The screening session will not be compensated. 
Money received as a result of your participation in this study, may be considered taxable income by Revenue Canada. This does not include money given to you for the reimbursement of study expenses. To receive payment for your participation in this study, you may need to provide the study team with your Social Insurance Number. By the end of February of the following year, the University of Ottawa Institute of Mental Health Research will issue a T4A for any amount equal to or over $\$ 500$ earned in the calendar year.

\section{Do I have to participate?}

You can choose not to participate in this study. If you choose not to participate, it will not affect your medical care. Your study doctor will discuss your options with you.

Your participation in this study is voluntary. You may decide not to be in this study, or to be in the study now, and then change your mind later without affecting the medical care, education, or other services to which you are entitled or are presently receiving at this institution.

If you experience any major side effects to the study treatment during the laboratory sessions you may stop taking part in the study. In addition, if you are unable to follow the study procedures, your participation in the study will be stopped.

Your participation in the study may be stopped for any of the following reasons:

- The study doctor feels it is in your best interest.

- A government agency such as Health Canada cancels the study.

- You need additional health treatment or medication that would interfere with the study.

- If you experience any major side effects to the study treatment.

- You do not follow the study staff's instructions.

\section{If I agree now, can I change my mind and withdraw later?}

You may withdraw from the study at any time without any impact on your current or future care at this institution.

- If you decide to stop the study you should contact the study doctor or the study team first. They will discuss the related issues or possible safety concerns for you.

- You may also choose to discontinue your participation in the study. However, a final visit(s) may need to be completed to ensure your safety and well-being.

- If you withdraw your consent, the study team will no longer collect your personal health information for research purposes, unless it is needed for review of safety.

\section{How is my personal information being protected?}

If you agree to participate in the study, you will be assigned a study-specific code for storage of your personal information. Your physician will then be contacted to complete study-specific documents (including medication information), which will be transferred to the Royal in a sealed, coded envelope to ensure confidentiality.

Only the principal investigator, co-investigators, and research assistants will have access to the study information. The information will be stored by code (and not by name) to protect your privacy. The information (saliva samples, genetic information and other measures) will be stored for 25 years. The 
coded information will be stored in a locked cabinet at the Royal Ottawa Mental Health Centre. The list of participants' names with their matching codes will be stored a secured server in a password-protected file.

The data collected in this study may be used for education and/or scientific purposes. For example, in publications, classroom materials or presentations to conferences. None of these publications, materials or presentations will identify the study's participants.

Study information may be looked at by the Royal Ottawa Hospital Research Ethics Board and Health Canada, and/or the Research Quality Associate for the purpose of quality assurance. Any publications, or presentations based on this research will not use your name or identify you. All information will be destroyed 25 years after publication, as required by the Royal Ottawa Hospital REB and Health Canada.

A description of this clinical trial will be available on http://www.ClinicalTrials.gov. This Web site will not include information that can identify you. At most, the Web site will include a summary of the results. You can search this Web site at any time.

\section{What are my responsibilities as a study participant?}

It is important to remember the following things during this study:

- Ask the study researchers if you have any questions or concerns.

- Tell the study researcher or study doctor if anything about your health has changed.

- You should not have food, caffeine, alcohol, nicotine, or drugs beginning at midnight before each test session.

- Call the study doctor if you experience any side effects, even if you are unsure whether it has anything to do with this study.

Will I be informed about any new information that might affect my decision to continue participating?

You will be told in a timely fashion of any new findings during the study that could affect your willingness to continue in the study. You may be asked to sign a new consent form.

\section{Contact Information}

If you have any specific questions about this research or if a study-related emergency occurs, you should contact Dr. Knott, who can be reached 24-hours a day by telephone at 613-894-1240.

If you have any questions about the ethical conduct of this study, please contact Dr. Blier, REB Chair of the Royal Ottawa at 613-722-6521 ext 6944 during business hours for more information. 
Title of Study: An Initial Phase 2 Trial of an Add-On Nicotinic Agonist Treatment for Sensory and Cognitive Deficits in Schizophrenia

Consent to Participate in Research

- I understand that I am being asked to participate in a research study about the effects of single doses of CDP-choline on brain activity in schizophrenia patients.

- This study was explained to me by

- I have read, or have had it read to me, each page of this Participant Informed Consent Form.

- All of my questions have been answered to my satisfaction.

- If I decide later that I would like to withdraw my participation and/or consent from the study, I can do so at any time.

- I voluntarily agree to participate in this study.

- I will be given a copy of this signed Participant Informed Consent Form.

It is important that your personal doctor be aware you are in a research study, as you may be taking a treatment that could affect your health. With your permission, we will notify him/her that you are taking part in this study.

I consent to my personal doctor being notified that I am taking part in this study.

$\square$ YES $\square$ NO Participant's Initials

Participant's Printed Name

Participant's Signature

Date

Investigator or Delegate Statement

I have carefully explained the study to the study participant. To the best of my knowledge, the participant understands the nature, demands, risks and benefits involved in taking part in this study.

$\overline{\text { Investigator/Delegate's Printed Name }}$

Investigator/Delegate's Signature Date

Assistance Declaration

Was the participant assisted during the consent process? $\square$ Yes $\square$ No

The consent form was read to the participant/substitute decision-maker, and the person signing below attests that the study was accurately explained to, and apparently understood by, and consent was freely given by the participant/substitute decision-maker.

The person signing below acted as a translator for the participant/substitute decision-maker during the consent process. He/she attests that they have accurately translated the information for the participant/substitute decision-maker, and believe that the participant/substitute decision-maker has understood the information translated.

$\overline{\text { Name of Person Assisting (Print) }} \quad \overline{\text { Signature }} \overline{\text { Date }}$ 


\section{Appendix E}

\section{PSYRATS - SZ CDP-Choline Study}

Please rate the degree of your hallucinations.

ID:

Date:

A. Auditory Hallucinations

1. Frequency

Voices not present or present less than once a week 0

Voices occur at least once a week

Voices occur at least once a day

Voices occur at least once an hour

Voices occur continuously or almost continuously 4

2. Duration

Voices not present

Voices last for several minutes fleeting voices

Voices last for at least one hour 3

Voices last for hours at a time

3. Location

No voices present

Voices sound like they are inside head only

Voices outside the head, but close to ears or head 2 Voices inside head may also be present

Voices sound like they are inside or close to ears 3 and outside head away from ears

Voices sound like they are outside the head only 4

4. Loudness

Voices not present

Quieter than own voice, whispers

About the same loudness as own voice 2

Louder than own voice

Extremely loud, shouting

5. Beliefs re: origin of voices

Voices not present

Believes voices to be solely internally generated and related to self

Holds $<50 \%$ conviction that voices originate from 2 external causes

Holds $>50 \%$ (but $<100 \%$ ) conviction that voices 3 originate from external causes

Believes voices are solely due to external causes 
6. Amount of negative content of voices

No unpleasant content

Occasional unpleasant content $(<10 \%)$

Minority of voice content is unpleasant or Negative $(<50 \%)$

Majority of voice content is unpleasant or Negative $(>50 \%)$

All of the voice content is unpleasant or negative

\section{0}

2

2

3

7. Degree of negative control

Not unpleasant or negative

0

11. Controllability of voices

Subject believes they can have control over the voices and can always bring on or dismiss the voices at will.

Subject believes they can have some control over 1 the voices on the majority of occasions

Subject believes they can have some control over 2 the voices approximately half the time

Subject believes they can have some control over 3 the voices, but only occasionally. The majority of the time the subject experiences voices that are uncontrollable.

Subject has no control over when the voices occur 4 and cannot dismiss or bring them on at all. 


\title{
Appendix F
}

\author{
CCC STUDY
}

Date:

ID:

Session: Time:

\section{Checklist of Drug-Related Symptoms}

Please rate how you have felt since taking the drug dose by circling one of the following five options, as they relate to the severity of possible drug-related symptoms you may or may not have experienced.

1 - No symptoms at all

2 - Mild symptoms (i.e. light headed, jitters)

3 - Moderate symptoms (i.e. light headed, drowsy, slight headache, mild nausea)

4 - Moderately severe symptoms (i.e. dizzy, headache, nausea)

5 - Severe symptoms (i.e. disoriented, dull or pounding headache, nausea, vomiting)

To be filled out by researcher:

1. Which drug do you think you received today? (Drug or placebo?)

2. Why do you feel you received this (drug or placebo)? What feature helped you determine this? 